\title{
Randomized Trial Evaluating Ranibizumab Plus Prompt or Deferred Laser or Triamcinolone Plus Prompt Laser for Diabetic Macular Edema
}

\section{Citation}

Elman, Michael J., Lloyd Paul Aiello, Roy W. Beck, Neil M. Bressler, Susan B. Bressler, Allison R. Edwards, Frederick L. Ferris, et al. 2010. Randomized Trial Evaluating Ranibizumab Plus Prompt or Deferred Laser or Triamcinolone Plus Prompt Laser for Diabetic Macular Edema. Ophthalmology 117, no. 6: 1064-1077.e35. doi:10.1016/j.ophtha.2010.02.031.

\section{Published Version}

doi:10.1016/j.ophtha.2010.02.031

\section{Permanent link}

http://nrs.harvard.edu/urn-3:HUL.InstRepos:35669316

\section{Terms of Use}

This article was downloaded from Harvard University's DASH repository, and is made available under the terms and conditions applicable to Other Posted Material, as set forth at http:// nrs.harvard.edu/urn-3:HUL.InstRepos:dash.current.terms-of-use\#LAA

\section{Share Your Story}

The Harvard community has made this article openly available.

Please share how this access benefits you. Submit a story.

Accessibility 


\title{
Randomized Trial Evaluating Ranibizumab Plus Prompt or Deferred Laser or Triamcinolone Plus Prompt Laser for Diabetic \\ Macular Edema
}

\author{
The Diabetic Retinopathy Clinical Research Network ${ }^{*}$, Michael J. Elman, MD, Lloyd Paul \\ Aiello, MD, PhD, Roy W. Beck, MD, PhD, Neil M. Bressler, MD, Susan B. Bressler, MD, Allison \\ R. Edwards, MS, Frederick L. Ferris III, MD, Scott M. Friedman, MD, Adam R. Glassman, \\ MS, Kellee M. Miller, MPH, Ingrid U. Scott, MD, MPH, Cynthia R. Stockdale, MSPH, and Jennifer \\ K. Sun, MD, MPH
}

\begin{abstract}
Objective-Evaluate intravitreal $0.5 \mathrm{mg}$ ranibizumab or $4 \mathrm{mg}$ triamcinolone combined with focal/ grid laser compared with focal/grid laser alone for treatment of diabetic macular edema (DME).

Design-Multicenter, randomized clinical trial.

Participants-A total of 854 study eyes of 691 participants with visual acuity (approximate Snellen equivalent) of 20/32 to 20/320 and DME involving the fovea.

Methods-Eyes were randomized to sham injection + prompt laser ( $\mathrm{n}=293), 0.5 \mathrm{mg}$ ranibizumab + prompt laser ( $\mathrm{n}=187), 0.5 \mathrm{mg}$ ranibizumab + deferred ( $\geq 24$ weeks) laser $(\mathrm{n}=188)$, or $4 \mathrm{mg}$ triamcinolone + prompt laser $(\mathrm{n}=186)$. Retreatment followed an algorithm facilitated by a web-based, real-time data-entry system.
\end{abstract}

Main Outcome Measures-Best-corrected visual acuity and safety at 1 year.

Results-The 1-year mean change ( \pm standard deviation) in the visual acuity letter score from baseline was significantly greater in the ranibizumab + prompt laser group $(+9 \pm 11, P<0.001)$ and ranibizumab + deferred laser group $(+9 \pm 12, P<0.001)$ but not in the triamcinolone + prompt laser group $(+4 \pm 13, P=0.31)$ compared with the sham + prompt laser group $(+3 \pm 13)$. Reduction in mean central subfield thickness in the triamcinolone + prompt laser group was similar to both ranibizumab groups and greater than in the sham + prompt laser group. In the subset of pseudophakic eyes at baseline $(n=273)$, visual acuity improvement in the triamcinolone + prompt laser group appeared comparable to that in the ranibizumab groups. No systemic events attributable to study treatment were apparent. Three eyes $(0.8 \%)$ had injection-related endophthalmitis in the ranibizumab groups, whereas elevated intraocular pressure and cataract surgery were more frequent in the triamcinolone + prompt laser group. Two-year visual acuity outcomes were similar to 1-year outcomes.

(C) 2010 by the American Academy of Ophthalmology.

Correspondence: Protocol I Correspondence, Jaeb Center for Health Research, 15310 Amberly Drive, Suite 350, Tampa, FL 33647. drcrstat4@jaeb.org.

The members of the DRCR Network who participated in this protocol are listed in Appendix 5.

Financial Disclosure(s): Proprietary or commercial disclosure may be found after the references.

The lead author(s) have made the following disclosure(s): Scott M. Friedman: Sirion Therapeutics (S), MacuSight (S), Pfizer (S),

Vitreoretinal Technologies (S), Allergan (S), EMMES Corporation (S). Ingrid U. Scott: Genentech (C). Lloyd P. Aiello: Genentech (C). Susan B. Bressler: Glaxo- SmithKline (C). Frederick L. Ferris III; Bausch \& Lomb (P).

This article contains online-only material. The following should appear online-only: Tables 1, 2, 3, 4, 6, 7, 9, 10, 12, 13, 14, 16, 18, and 19; Figures 1, 2, 5, 7, and 8; Appendices 1, 2, 3A-D, 4, and 5. 
Conclusions-Intravitreal ranibizumab with prompt or deferred laser is more effective through at least 1 year compared with prompt laser alone for the treatment of DME involving the central macula. Ranibizumab as applied in this study, although uncommonly associated with endophthalmitis, should be considered for patients with DME and characteristics similar to those in this clinical trial. In pseudophakic eyes, intravitreal triamcinolone + prompt laser seems more effective than laser alone but frequently increases the risk of intraocular pressure elevation.

\section{Introduction}

Macular edema is a frequent manifestation of diabetic retinopathy and an important cause of impaired vision in individuals with diabetes. $1^{-3}$ Focal/grid photocoagulation, the current standard care for diabetic macular edema (DME), has been the mainstay of treatment since its benefit was demonstrated in the Early Treatment Diabetic Retinopathy Study (ETDRS) in 1985. ${ }^{4}$ In a randomized, multicenter clinical trial, the Diabetic Retinopathy Clinical Research Network (DRCR.net) showed that focal/grid photocoagulation in eyes with center-involved DME and visual acuity $\leq 20 / 40$ produces gradual visual acuity improvement of $\geq 2$ lines in approximately one third of eyes after 2 years of follow-up, although approximately $20 \%$ of laser-treated eyes worsen by $\geq 2$ lines. ${ }^{5}$ Thus, other treatment modalities, including antivascular endothelial growth factor (VEGF) therapy and steroids, alone or in combination with laser, are under investigation.

The rationale for anti-VEGF therapy for DME is based on the observation that VEGF levels are increased in the retina and vitreous of eyes with diabetic retinopathy.6 Vascular endothelial growth factor has been demonstrated to increase vessel permeability in vivo possibly by increasing the phosphorylation of tight junction proteins.7 Therefore, therapy that inhibits VEGF may represent a useful therapeutic modality that targets the underlying pathogenesis of DME. Pegaptanib (Macugen, Eyetech Pharmaceuticals, Palm Beach Gardens, FL) was the first anti-VEGF drug reported to have a favorable effect on macular edema, ${ }^{8}$ although more recently, the anti-VEGF drugs ranibizumab (Lucentis, Genentech, South San Francisco, CA) and bevacizumab (Avastin, Genentech), among others, also have been evaluated for DME.

Prior studies, which were small with short-term follow-up, have reported promising results. 9 Intravitreal triamcinolone also was evaluated previously as treatment for DME in a randomized trial conducted by the DRCR.net. ${ }^{5}$ Although the data suggest that triamcinolone treatment was superior to the expected untreated course in the ETDRS, it was not superior to focal/grid photocoagulation. ${ }^{5}$

The combination of intravitreal treatment (either triamcinolone or an anti-VEGF drug) with focal/grid photocoagulation, theoretically, could be more effective than either treatment alone. The intravitreal treatment might rapidly reduce macular edema and lead to more rapid visual acuity improvement, whereas slower benefit accrues over time as a result of laser treatment. In addition, combined treatment could enhance the effect of focal/grid photocoagulation because the retina would be less edematous if laser treatment was administered some time after the intravitreal treatment reduced macular edema. Also, laser treatment theoretically could reduce the number of repeat intravitreal injections required to optimize the outcome of DME treatment. In a study of 86 eyes randomized to $4 \mathrm{mg}$ intravitreal triamcinolone alone or followed by macular laser photocoagulation, Kang et al ${ }^{10}$ reported that after 6 months visual acuity was better and more eyes had resolution of central edema with the combined treatment when compared with intravitreal triamcinolone without macular laser. Other studies have shown greater mean visual acuity improvements at 6 months using ranibizumab + laser, or ranibizumab alone, when compared with laser alone.9

To determine whether anti-VEGF therapy alone or in combination with focal/grid laser, or intravitreal triamcinolone combined with focal/grid laser, might result in improved outcomes 
compared with the standard treatment for DME of laser alone, the DRCR.net designed a clinical trial to evaluate 3 treatment modalities for DME in comparison with focal/grid photocoagulation: ranibizumab combined with prompt (within 1 week) focal/grid photocoagulation, intravitreal triamcinolone combined with prompt (within 1 week) focal/grid photocoagulation, and intravitreal ranibizumab with focal/grid photocoagulation deferred for at least 24 weeks. The study design also provided an opportunity to determine which regimen resulted in fewer treatments if safety and efficacy were comparable.

\section{Materials and Methods}

This phase 3 randomized, multicenter clinical trial was conducted by the DRCR.net at 52 clinical sites in the United States. The study adhered to the tenets of the Declaration of Helsinki. The protocol and informed consent forms were compliant with the Health Insurance Portability and Accountability Act and approved by multiple institutional review boards. Each study participant gave written informed consent before participation in the study. Study oversight was provided by an independent data and safety monitoring committee. The study was conducted under an Investigational New Drug Application from the Food and Drug Administration. The study is listed on www.clinicaltrials.gov under identifier NCT00445003 (website registration date 03-06-2007), and the protocol is available on the DRCR.net website (www.drcr.net, date accessed January 1, 2010). Key aspects of the protocol pertinent to this article are summarized next.

\section{Study Population}

Eligible patients were at least 18 years old with type 1 or 2 diabetes. The major eligibility criteria for a study eye included the following: (1) best-corrected Electronic-Early Treatment Diabetic Retinopathy Study (E-ETDRS Visual Acuity Test11) visual acuity letter score 78 to 24 (20/32-20/320), (2) definite retinal thickening due to DME on clinical examination involving the center of the macula assessed to be the main cause of visual loss, and (3) retinal thickness measured on time domain optical coherence tomography (OCT) $\geq 250 \mu \mathrm{m}$ in the central subfield. Principal exclusion criteria included the following: (1) treatment for DME within the prior 4 months, (2) panretinal photocoagulation within the prior 4 months or anticipated need for panretinal photocoagulation within the next 6 months, (3) major ocular surgery within the prior 4 months, (4) history of open-angle glaucoma or steroid-induced intraocular pressure (IOP) elevation that required IOP-lowering treatment, and (5) IOP $\geq 25$ $\mathrm{mmHg}$. Patients were excluded if their systolic blood pressure was $>180 \mathrm{mmHg}$ or diastolic blood pressure was $>110 \mathrm{mmHg}$, or if a myocardial infarction, other cardiac event requiring hospitalization, cerebrovascular accident, transient ischemic attack, or treatment for acute congestive heart failure occurred within 4 months before randomization. A patient could have 2 study eyes in the trial only if both were eligible at the time of study entry.

\section{Synopsis of Study Design}

After eligibility was determined and informed consent was obtained, study participants with 1 study eye were assigned randomly on the DRCR.net study website (using a permuted blocks design stratified by study eye visual acuity) with equal probability to 1 of 4 treatment groups: (1) sham injection plus prompt (within 3-10 days after injection) focal/grid photocoagulation (sham + prompt laser group), (2) $0.5 \mathrm{mg}$ intravitreal ranibizumab plus prompt (within 3-10 days after injection) focal/grid photocoagulation (ranibizumab + prompt laser group), (3) 0.5 $\mathrm{mg}$ intravitreal ranibizumab with deferred ( $\geq 24$ weeks) focal/grid photocoagulation (ranibizumab + deferred laser group), and (4) $4 \mathrm{mg}$ intravitreal triamcinolone plus prompt (within 3-10 days after injection) focal/grid photocoagulation (triamcinolone + prompt laser group). For study participants with 2 study eyes, the right eye was assigned randomly with equal probability to 1 of the 4 groups as indicated above. If the right eye was assigned to a 
treatment group other than the sham + prompt laser group, then the left eye was assigned to the sham + prompt laser group. If the right eye was assigned to the sham + prompt laser group, then the left eye was assigned randomly to 1 of the other 3 groups. Thus, there were more eyes in the sham + prompt laser group than in the other 3 groups.

Follow-up was planned for 3 years, with the primary outcome at 1 year. During the first year, follow-up visits occurred every 4 weeks ( \pm 1 week). Study participants in the 3 groups receiving laser were masked to treatment assignment through the primary outcome visit, whereas the ranibizumab + deferred laser group was not masked. After the first year, visits occurred every 4 to 16 weeks depending on the treatment group, disease course, and treatment administered. After a study participant completed the primary outcome visual acuity examination at 1 year, the study participant was made aware of his or her treatment group assignment and sham injections were discontinued. Visual acuity examiners and OCT technicians were masked to treatment group assignment before and at the 1-year primary outcome visit.

\section{Examination Procedures}

At baseline and each follow-up visit, best-corrected visual acuity letter score was measured at $3 \mathrm{~m}$ by a certified examiner using an E-ETDRS Visual Acuity Test.11 The OCT images were obtained at baseline and each follow-up visit by a certified operator using the Zeiss Stratus OCT (OCT3) machine (Carl Zeiss Meditec, Inc., Dublin, CA). Scans were $6 \mathrm{~mm}$ in length and included the 6-radial line fast macular scan pattern for quantitative measures and the cross-hair pattern (6-12 o'clock and 9-3 o'clock) for qualitative assessment of retinal morphology. All baseline OCT scans, annual follow-up scans with a standard deviation of the center point $\geq 10.0 \%$, and scans from any visits in which the investigator suspected erroneous measurements because of the algorithm placement of the lines created by the OCT software that delineate the inner and outer aspects of the retina were sent to the Fundus Photograph Reading Center (University of Wisconsin, Madison) for grading. If the automated thickness measurements were judged by the Reading Center to be inaccurate on any submitted image, center point thickness was measured manually, and this value was used to impute a value for the central subfield based on a correlation of the 2 measures of 0.98 as published previously ${ }^{12}$ (20\% of 854 baseline scans were imputed and 1 scan was unable to be manually graded at baseline, and $2 \%$ of 10849 follow-up scans were imputed and $22[<1 \%]$ were unable to be manually graded during follow-up through 1 year). Manual grading of the baseline scans resulted in an imputed baseline central subfield value $<250 \mu \mathrm{m}$ for 60 eyes (7\%), which does not necessarily mean that the true thickness measurement is $<250$ if measureable. Of note, $22(37 \%)$ of the 60 scans with an imputed central subfield thickness $<250 \mu \mathrm{m}$ were from 1 clinical site and represented $85 \%$ of the 26 baseline scans from that site. All intent-to-treat results presented were similar when evaluated with exclusion of eyes from that clinical site (data not shown) and when evaluated with exclusion of eyes from any clinical site with a baseline central subfield thickness $<250 \mu \mathrm{m}$. Baseline OCT images also were assessed by the Reading Center for cystoid abnormalities and subretinal fluid.

Additional testing at baseline and each follow-up visit included slit-lamp examination, measurement of IOP, and fundus examination after pupil dilation. Standard ETDRS 7-field color stereoscopic fundus photographs were obtained at baseline and 12 months by a certified photographer and graded at the reading center for level of diabetic retinopathy. ${ }^{13}$ Hemoglobin A1c was measured at baseline. Any untoward medical occurrence, regardless of whether the event was considered treatment related, was considered as an adverse event and recorded. Treatment of adverse events and proliferative diabetic retinopathy was at the discretion of the investigator. 


\section{Treatment Protocol}

Overview-The treatment protocol (summarized in Appendix 1, available at http://aaojournal.org) included a baseline treatment followed by intravitreal study drug or sham injection retreatments every 4 weeks through the 12 -week study visit. From the 16-week study visit and thereafter, a retreatment algorithm for study drug injections and sham injections (Appendices 2 and 3, available at http://aaojournal.org) was designed to require retreatments unless a study visit was deemed a 'success' (defined below and in Table 1, available at http://aaojournal.org) at which point retreatment was at investigator discretion. From the 24week study visit and thereafter retreatment was at investigator discretion if the study visit was deemed 'no improvement' (defined in Table 1, available at http://aaojournal.org). If retreatment with a study drug or sham injection was not given, 'alternative treatment' (defined in Table 1, available at http://aaojournal.org) was permitted only if a study eye met criteria for 'failure' or 'futility' (defined in Table 1, available at http://aaojournal.org). When retreatment with a study drug or sham injection was indicated, eyes assigned to one of the ranibizumab groups could receive ranibizumab as often as every 4 weeks; eyes assigned to intravitreal triamcinolone could receive triamcinolone as often as every 16 weeks with sham injections as often as every 4 weeks in between triamcinolone injections; eyes assigned to sham + prompt laser could receive sham injections as often as every 4 weeks. A retreatment algorithm for focal/grid laser (Appendix 4, available at http://aaojournal.org) was designed to require retreatment if there was 'edema involving the center of the macula' or 'edema threatening the center of the macula' (defined in Table 1, available at http://aaojournal.org) and if 'complete laser' had not been given (defined in Table 1, available at http://aaojournal.org), provided that it had been at least 13 weeks since the last focal/grid laser application.

Retreatment Algorithm System-Compliance with the details of the treatment protocol, which depended mainly on visual acuity and OCT measurements over time, was facilitated by a web-based, real-time data-entry system. At each follow-up visit, the system provided realtime feedback to the treating physician regarding whether treatment was required or at investigator discretion. If treatment was to be given, the system also provided feedback as to whether the treatment should be an intravitreal study drug or sham injection, whether focal/ grid photocoagulation should be applied, and what the next follow-up interval should be.

\section{Statistical Methods}

Data are reported that were collected by the clinical sites from March 2007 to February 8, 2010. This includes at least 1-year follow-up for the entire study population and up to 2-year followup for participants enrolled early in the trial. Mean change in visual acuity from baseline to 1 year adjusted for baseline visual acuity was the primary outcome measure. The primary analysis consisted of 3 pairwise comparisons of the mean change in the sham + prompt laser group compared with each of the other 3 groups.

Sample size was estimated to be 842 eyes ( 701 study participants assuming $20 \%$ of study participants would have 2 study eyes) on the basis of an expected population difference in the letter score of 6.0 and standard deviation of the visual acuity letter score of 18, a correlation between baseline and 1-year scores of 0.48, a type 1 error rate of 0.016 (adjusted for multiple comparisons and alpha spending for interim data reviews), and a power of approximately $90 \%$.

The primary analysis included all randomized eyes and followed the intent-to-treat principle. Data were included in the 1-year analysis when an examination was performed between 308 and 420 days from randomization. When more than 1 visit occurred in this window, data from the visit closest to the 1-year target date were used. For eyes without 1-year data, the lastobservation-carried forward method was used to impute data for the primary analysis. Similar results (data not shown) were produced when analyses (1) used Rubin's method ${ }^{14}$ to impute 
for missing data; (2) included only eyes with a completed 1-year examination and used the last visual acuity before additional treatment for those who received a treatment other than the randomly assigned treatment before the 1-year examination (per-protocol analysis); (3) included adjustment for the following potential confounders in addition to baseline visual acuity: age, gender, race/ethnicity, baseline hemoglobin A1c, baseline OCT central subfield thickness, and prior panretinal scatter photocoagulation and prior DME treatment at baseline; (4) were performed with outlying values truncated to 3 standard deviations from the mean; and (5) used van der Waerden's normal score transformation on the visual acuity scores. For analyses other than the primary analysis, only data from completed visits were used with no imputation for missing data. For some results, medians and interquartile ranges have been reported instead of, or in addition to, means and standard deviations to describe the distribution of the data. Analyses of the number of study treatments received before the 1- and 2-year visits included only the eyes of participants completing the 1- and 2-year visits.

Three pairwise comparisons were made for all analyses, except the ranibizumab groups were pooled for analysis of progression of diabetic retinopathy and all safety analyses. For all continuous outcomes, treatment group comparisons were made using analysis of covariance models with generalized estimating equations to account for correlated data from study participants with 2 study eyes. For binary outcomes, proportions similarly were compared between treatment groups using logistic regression models with generalized estimating equations. All analyses included adjustment for baseline visual acuity. In addition, models in which the central subfield thickness was the outcome included baseline central subfield thickness as a covariate, and models with retinal volume as the outcome included both baseline central subfield thickness and retinal volume as covariates. Similar analyses were performed on 2-year results. All $P$ values are 2-sided. SAS version 9.1 (SAS Inc, Cary, NC) was used for all analyses.

\section{Results}

Between March of 2007 and December of 2008, 691 study participants (mean age 63 \pm 10 years; $44 \%$ women) were enrolled, 163 (24\%) with 2 study eyes. The mean baseline visual acuity letter score in study eyes was $63 \pm 12(\sim 20 / 63 \pm 2.4$ lines), and the mean OCT central subfield retinal thickness was $405 \pm 134 \mu \mathrm{m}$. The 854 study eyes were assigned to either sham + prompt laser $(n=293)$, ranibizumab + prompt laser $(n=187)$, ranibizumab + deferred laser $(n=188)$, or triamcinolone + prompt laser $(n=186)$. The baseline characteristics of the 4 groups were similar (Table 2, available at http://aaojournal.org).

\section{Follow-Up}

The follow-up status for all study participants (eyes) is shown in Figure 1 (available at http://aaojournal.org). Thirteen study participants (2\%) died before the 1-year primary outcome visit and 15 participants died subsequently of causes apparently unrelated to study treatment. For the remaining study participants, the 1-year primary outcome visit was completed for $94 \%$ to $96 \%$ of eyes in the 4 treatment groups. Those who completed the 1-year primary outcome visit completed $94 \%$ of the non-annual visits before 1 year. Baseline visual acuity was similar in the 55 study eyes of the 44 study participants who did not complete the 1-year primary outcome visit compared with the 799 eyes of the 647 study participants who completed the 1year primary outcome visit (data not shown). The 2-year visit was completed for 484 eyes (57\%), with 267 (31\%) still pending, as of February 8, 2010.

\section{Treatments}

Sham Injections and Intravitreal Study Drug Injections-For each study participant, there were 13 possible sham or study drug injections during the first year of follow-up. The 
median (25th, 75th percentile) number of sham injections before the 1-year primary outcome visit was $11(8,13)$ in the sham + prompt laser group (of note, this excludes 56 eyes among 163 participants with 2 study eyes that were unmasked at baseline because the study participant's other eye was in the ranibizumab + deferred laser group, precluding sham injections for the study eye assigned to sham + prompt laser). The median number of study drug injections before the 1 -year primary outcome visit was $8(6,10)$ ranibizumab injections (of 13 maximally possible injections) in the ranibizumab + prompt laser group, $9(6,11)$ ranibizumab injections (of 13 maximally possible injections) in the ranibizumab + deferred laser group, and $5(3,7)$ sham injections (of 9 maximally possible sham injections) and 3 (2, 4) triamcinolone injections (of 4 maximally possible triamcinolone injections) for a total of 13 maximally possible sham plus triamcinolone injections in the triamcinolone + prompt laser group (Fig 2, available at http://aaojournal.org).

Retreatments Relative to 'Success' and 'Failure' Criteria-At the 16-week study visit, $47(25 \%)$ of the 187 eyes in the ranibizumab + prompt laser group and $41(22 \%)$ of the 188 eyes in the ranibizumab + deferred laser group met 'success' criteria (visual acuity letter score $\geq 84[\sim \geq 20 / 20]$ or OCT central subfield $<250 \mu \mathrm{m})$ and did not receive an injection. A total of 17 eyes $(9 \%)$ in the ranibizumab + prompt laser group and 15 eyes $(8 \%)$ in the ranibizumab + deferred laser group met 'success' criteria at 16 weeks and did not receive an additional injection before the 1-year primary outcome visit. At the 1-year primary outcome visit, $89(32 \%)$ of the eyes in the sham + prompt laser group, $109(64 \%)$ of the eyes in the ranibizumab + prompt laser group, $92(52 \%)$ of the eyes in the ranibizumab + deferred laser group, and $98(56 \%)$ of the eyes in the triamcinolone + prompt laser group met the 'success' criteria, including $23(8 \%), 23(13 \%), 23(13 \%)$, and $19(11 \%)$, respectively, with a visual acuity letter score $\geq 84(\sim \geq 20 / 20)$. 'Failure' criteria were met in $10(4 \%), 3(2 \%), 1(1 \%)$, and $3(2 \%)$ of the eyes in these 4 groups, respectively, during the first year of follow-up. Sham or study drug injections were not required for eyes meeting 'success' or 'failure' criteria.

Retreatments through Year 2-For the 218 study participants (58\%) with 2 years of follow-up in the ranibizumab groups, there was a maximum of 25 possible ranibizumab injections. The median (25th, 75th percentile) number of ranibizumab injections between the 1-year visit, inclusive, and before the 2-year visit were $2(0,4)$ and $3(1,7)$ in the ranibizumab + prompt laser group and the ranibizumab + deferred laser group, respectively, for a total of $11(7,14)$ and $13(8,17)$ injections from baseline to the 2 -year visit. Only $32 \%$ of participants in the ranibizumab + prompt laser group and $21 \%$ of participants in the ranibizumab + deferred laser group had no ranibizumab injections between the 1- and 2-year visits. The 103 study participants (55\%) with 2 years of follow-up in the triamcinolone + prompt laser group received $1(0,2)$ triamcinolone injection between the 1-year visit, inclusive, and before the 2-year visit for a total of $4(3,5)$ from baseline to the 2 -year visit of a total of 8 maximum possible injections.

Focal/Grid Laser Treatments-The distribution of laser treatments before the 1- and 2year visits are shown in Table 3 (available at http://aaojournal.org). The median (25th, 75th percentile) number of focal/grid photocoagulation treatments before the 1-year primary outcome visit was $3(2,3)$ in the sham + prompt laser group, $2(1,3)$ in the ranibizumab + prompt laser group, and $2(1,3)$ in the triamcinolone + prompt laser group. In the ranibizumab + prompt laser group, after baseline and before the 1-year primary outcome visit, 53 (31\%) study eyes received no additional focal/grid laser treatments, 54 (32\%) received only 1 additional focal/grid laser treatment, 46 (27\%) received only 2 additional focal/grid laser treatments, and $18(11 \%)$ received 3 additional focal/grid laser treatments. Focal/grid laser treatment was not permitted in the ranibizumab + deferred laser group until the 24-week study visit; from the 24-week study visit and before the 1-year primary outcome visit, 128 (72\%) of these study eyes received no focal/grid laser treatment, 35 (20\%) received only 1 focal/grid 
laser treatment, and $15(8 \%)$ received 2 focal/grid laser treatments. Forty-seven percent of the sham + prompt laser group, $57 \%$ of the ranibizumab + prompt laser group, $72 \%$ of the ranibizumab + deferred laser group, and $46 \%$ of the triamcinolone + prompt laser group received no focal/grid laser treatments between the 1- and 2-year visits.

Alternative Treatments-Some eyes in the study were switched from the randomly assigned treatment to an alternative treatment during the first 2 years of follow-up because "failure" or "futility" criteria were met or the treating investigator determined deviating from the protocol would be in the best interest of the study participant as a patient. In the sham + prompt laser group, this occurred in 14 eyes during the first year and in 29 eyes during the second year. Of these eyes, 5 and 20, respectively, met the "failure" or "futility" criteria before receiving alternative treatment. In the ranibizumab + prompt laser group, 1 eye that met "failure" criteria received alternative treatment during the first year and 1 eye that met "failure" criteria received alternative treatment during the second year. There were no eyes in the ranibizumab + deferred laser group that received alternative treatment during the first or second year of follow-up. In the triamcinolone + prompt laser group, 1 and 3 eyes received alternative treatment during the first and second years, respectively. One of the 3 eyes in the second year of follow-up did not meet "failure" or "futility" criteria (Table 4, available at http://aaojournal.org, lists the alternative treatments received).

Injection Treatment Compliance-Before the 1-year primary outcome visit, when a sham injection was required per protocol at each visit, the sham + prompt laser group was given $96 \%$ (1288) of the required sham injections. Required study drug injection rates in the 3 active treatment groups were 95\% (462 injections), 97\% (525 injections), and 97\% (673 injections) in the ranibizumab + prompt laser group, ranibizumab + deferred laser group, and triamcinolone + prompt laser group, respectively.

Success with Masking of Sham Injections-At the 1-year primary outcome visit, study participants were asked to guess their treatment group assignment. Among the 430 study participants with 1 study eye who completed the masking questionnaire and had received only the randomized treatment, the correct assignment was stated by $10 \%$ of the sham + prompt laser group, $88 \%$ of the ranibizumab + prompt laser group, $90 \%$ of the ranibizumab + deferred laser group, and $44 \%$ of the triamcinolone + prompt laser group. Among the 117 study participants with 2 study eyes who completed the unmasking questionnaire and had received only the randomized treatment, the correct assignment was stated for both eyes by $28 \%$ in ranibizumab + prompt laser group, $23 \%$ of the ranibizumab + deferred laser group, and $3 \%$ of the triamcinolone + prompt laser group.

\section{Effect of Treatment on Visual Acuity}

As shown in Table 5, for the 1-year primary outcome, the mean change \pm standard deviation in the visual acuity letter score from baseline was significantly greater in the ranibizumab + prompt laser group $(+9 \pm 11, P<0.001)$ and ranibizumab + deferred laser group $(+9 \pm 12$, $P<0.001)$ but not in the triamcinolone + prompt laser group $(+4 \pm 13, P=0.31)$ compared with the sham + prompt laser group $(+3 \pm 13)$. The results (Table 5$)$ reflected both a greater proportion of eyes with a substantial improvement of $\geq 10$ letters (50\% and $47 \%$ ) and $\geq 15$ letters (30\% and $28 \%$ ) and a lower proportion of eyes with a substantial worsening of $\geq 10$ letters ( $4 \%$ and $3 \%$ ) and $\geq 15$ letters ( $2 \%$ and $2 \%$ ) in the 2 ranibizumab groups compared with the sham + prompt laser group ( $28 \%$ and $15 \%$ for $\geq 10$ and $\geq 15$ letter gain, respectively, and $13 \%$ and $8 \%$ for $\geq 10$ and $\geq 15$ letter loss, respectively). Outcomes at 2 years (Table 6 , available at http://aaojournal.org) generally mirrored the 1 -year primary outcome results. The distribution of the visual acuity letter score at the 1- and 2-year visits is shown in Table 7 (available at http://aaojournal.org). 
Most of the overall improvement in mean visual acuity (Fig 3) and proportion with $\geq 10$ letter improvement from baseline (Fig 4A) within the ranibizumab-treated groups occurred by the 8 -week study visit, with continued improvement through the 1-year primary outcome visit and stabilization thereafter. In contrast, the triamcinolone + prompt laser group showed a more complex picture with improvement in the change in mean visual acuity through the 24-week visit, with decline thereafter (Fig 3), whereas the proportion with $\geq 10$ letter improvement gradually increased through 24 weeks, then decreased to 68 weeks and gradually increased again (Fig 4A). The sham + prompt laser group showed gradual improvement in these outcomes during the first year with stabilization thereafter. Few eyes deteriorated by $\geq 10$ letters from baseline in the ranibizumab groups, whereas the proportion with this outcome in the triamcinolone + prompt laser group and sham + prompt laser group gradually increased throughout at least the first year (Fig 4B).

By limiting the analysis to the 273 eyes that were pseudophakic at baseline, results appeared similar to the overall results for the sham + prompt laser and the 2 ranibizumab groups at 1 and 2 years. However, for the 62 pseudophakic eyes at baseline in the triamcinolone + prompt laser group, visual acuity results were substantially better than for phakic eyes such that the degree of improvement appeared comparable to that of the pseudophakic eyes in the ranibizumab groups and superior to that of the pseudophakic eyes in the sham + prompt laser group at 1 year (Table 8) and 2 years (Fig 5, available at http://aaojournal.org).

There was no obvious clinically important difference in results at the 1-year primary outcome visit for any other of the following subgroups: prior treatment for DME, baseline visual acuity, baseline OCT-measured central subfield thickening, baseline level of diabetic retinopathy determined by grading of fundus photographs, or description of edema by the treating ophthalmologist as predominantly focal or predominantly diffuse (Table 8). One-year primary outcome results were similar to the overall results when limited to study participants with 2 study eyes (Table 9, available at http://aaojournal.org) and when excluding eyes from any clinical site with a baseline central subfield thickness $<250 \mu \mathrm{m}$ (Table 10, available at http://aaojournal.org).

\section{Effect of Treatment on Retinal Thickening}

At the 1-year primary outcome visit, OCT results (Table 11; Fig 6; Figs 7 and 8, available at http://aaojournal.org) in the sham + prompt laser and the ranibizumab groups generally paralleled the overall visual acuity results, favoring the ranibizumab groups. In the triamcinolone + prompt laser group the reduction in mean central subfield thickness was greater than in the sham + prompt laser group and comparable with the ranibizumab groups. The pattern of OCT results were similar regardless of whether baseline central subfield thickness was $<400$ $\mu \mathrm{m}$ or $\geq 400 \mu \mathrm{m}$ (Table 11).

The change in OCT from the 1- to 2-year visit (Table 12, available at http://aaojournal.org; Fig 6; Figs 7 and 8, available at http://aaojournal.org) when contrasted with the change in visual acuity from the 1- to 2-year visit (Fig 3) differed among the treatments. For the ranibizumab groups, the OCT results remained relatively stable from the 1- to 2-year visit and paralleled the visual acuity results over this time. In the sham + prompt laser group, the OCT results from the 1- to 2-year visit did not parallel the visual acuity results because the mean change in visual acuity from baseline did not continue to increase from the 1- to 2-year visit, even though the mean central subfield thickness continued to decrease during this time. Unlike the ranibizumab groups and sham + prompt laser group, in the triamcinolone + prompt laser group, the mean central subfield thickness increased from the 1- to 2-year visit and paralleled the slight decline in mean visual acuity from the 1- to 2-year visit. The OCT retinal volume measurements (Table 13 , available at http://aaojournal.org) at the 1-year primary outcome visit were similar to OCT central subfield thickness measurements (Table 11). 


\section{Effect of Treatment on Level of Diabetic Retinopathy}

Eyes assigned to the ranibizumab-treated groups or the triamcinolone + prompt laser group were less likely to show progression of diabetic retinopathy from baseline to the 1-year primary outcome visit as graded on fundus photographs compared with the sham + prompt laser group (Table 14, available at http://aaojournal.org). Similarly, eyes assigned to the ranibizumab groups or the triamcinolone + prompt laser group appeared less likely to have a vitreous hemorrhage or receive panretinal photocoagulation than the sham + prompt laser group (3\% $[P=0.002]$ and $3 \%[P=0.02]$, respectively, vs. $8 \%$ ) during the first year of follow-up.

\section{Safety}

Ocular Adverse Events-Major ocular adverse events through 1 and 2 years are summarized in Tables 15 and 16 (available at http://aaojournal.org), respectively. There were 3 injection-related cases of infectious endophthalmitis ( 1 after a study injection at baseline, 1 after an injection at 4 weeks, and 1 after an injection at 56 weeks) following the 3973 ranibizumab injections $(0.08 \%$; $95 \%$ confidence interval [CI] $0.02 \%$ to $0.22 \%)$ among 375 study participants $(0.8 \% ; 95 \% \mathrm{CI}, 0.2 \%$ to $2 \%)$. In these 3 cases, the maximum visual acuity letter score after the infectious endophthalmitis was unknown in the first case because of lack of follow-up after the 1-week study visit, $73(\sim 20 / 40)$ in the second case, and $58(\sim 20 / 80)$ in the third case. In addition, there was 1 case of inflammatory pseudoendophthalmitis after the 685 triamcinolone injections among 186 study participants $(0.5 \%$; $95 \%$ CI, $0.01 \%$ to $3 \%)$. There was 1 case of progression of traction retinal detachment that occurred in the ranibizumab + deferred laser group noted at an unscheduled visit 1 week before the 32-week study visit and after the eighth ranibizumab injection and 1 focal/grid photocoagulation. This one case had extramacular traction retinal detachment and prior panretinal photocoagulation at baseline that were considered stable before randomization and was among the 111 eyes in the ranibizumab groups with prior panretinal photocoagulation, evidence of proliferative diabetic retinopathy, or both, at baseline. Vitrectomy was uncommon among all 4 treatment groups, and there were 5 retinal vein occlusions ( 1 in the sham + prompt laser group, 1 in each of the ranibizumab groups, and 3 in the triamcinolone + prompt laser group).

The occurrence of IOP elevation $>10 \mathrm{mmHg}$ from baseline, IOP $>30 \mathrm{mmHg}$, or initiation of IOP-lowering medications not in use at study entry at 1 or more visits during 2 years of followup was more frequent in eyes in the triamcinolone + prompt laser group than in the ranibizumab groups or the sham + prompt laser group (93 [50\%] vs. 34 [9\%] or 32 [11\%], respectively; $P<0.001$ for both comparisons). Glaucoma surgery was performed in 4 eyes ( 1 eye in the sham + prompt laser group, 1 eye in the ranibizumab + prompt laser group, and 2 eyes in the triamcinolone + prompt laser group). Among the subgroup of 62 pseudophakic eyes at baseline in the triamcinolone + prompt laser group, $30(48 \%)$ had $\geq 1$ of the ocular hypertension events described above, compared with $10(10 \%)$ and $15(14 \%)$ among the 101 and 110 pseudophakic eyes at baseline in the sham + prompt laser and ranibizumab groups, respectively. The cumulative percentage of eyes in the triamcinolone + prompt laser group that underwent cataract surgery over the 2 years of follow-up was substantially greater compared with the sham + prompt laser group or the ranibizumab groups (59\% vs. $14 \%$ and $14 \%$, respectively; $P<0.001$ for both comparisons) (Fig 9).

Systemic Adverse Events-There were no systemic adverse events with a difference in frequency among the 4 groups that could not be attributed to chance. In particular, there was no indication of an increase in the rate of cardiovascular or cerebrovascular events in the ranibizumab groups compared with the other groups (Table 17). The mean number of systemic adverse events reported per participant through 2 years with 1 study eye was $3 \pm 3$ in the sham group, $3 \pm 3$ in the 2 ranibizumab groups combined, and $3 \pm 4$ in the triamcinolone group. All 
systemic adverse events and study eye ocular adverse events reported by the site are shown in Tables 18 and 19 (available at http://aaojournal.org).

\section{Discussion}

In this randomized clinical trial, intravitreal ranibizumab, either with prompt or deferred ( $\geq 24$ weeks) focal/grid laser, resulted in superior visual acuity and OCT outcomes compared with focal/grid laser treatment without ranibizumab at both 1 and 2 years of follow-up. Approximately half of the eyes treated with ranibizumab had substantial visual acuity improvement ( $\geq 10$ letter gain from baseline), whereas approximately $30 \%$ gained $\geq 15$ letters, equivalent to 3 lines on the eye chart, a reduction of the visual angle by half; substantial loss $(\geq 10$ letter loss from baseline) was uncommon. Among eyes treated with intravitreal ranibizumab, results were similar whether focal/grid laser was given starting with the first ranibizumab injection or it was deferred for at least 6 months. Overall, intravitreal triamcinolone combined with focal/grid laser did not result in superior visual acuity outcomes compared with laser without triamcinolone, although it did result in a greater reduction in retinal thickening at 1 year but not 2 years compared with laser alone. However, in an analysis limited to pseudophakic eyes, the triamcinolone + prompt laser group's outcome for visual acuity was of similar magnitude to that of the 2 ranibizumab groups, suggesting that cataract formation, cataract surgery, or both, may have affected visual acuity outcomes adversely among phakic eyes in the triamcinolone + prompt laser group.

If ranibizumab is to be given as it was applied in this study, the 1- and 2-year data indicate a need to follow eyes continuously undergoing this treatment because the results indicate that additional ranibizumab or focal/grid laser, or both, are needed in most eyes through at least 2 years, even if 'success' criteria are met early in the course of treatment. According to the DRCR.net retreatment algorithm used in this study, eyes assigned to ranibizumab that met 'success' criteria at the 16-week study visit were not required to have continued injections unless visual acuity worsened or macular edema returned. Approximately two thirds of these early successes received additional ranibizumab at $\geq 1$ visit after the 16 -week visit. Furthermore, not all eyes avoided the need for focal/grid laser when following the protocol assigned to the ranibizumab + deferred laser group. Specifically, for eyes assigned to ranibizumab + deferred laser, approximately one third required focal/grid laser at least once between the 24-week and the 1-year study visits when the retreatment algorithm was followed.

These results are based on rigorous adherence to a detailed retreatment protocol facilitated by a web-based, real-time data-entry system that provided feedback to the treating physician regarding the treatment (intravitreal/sham injection or focal/grid photocoagulation) and subsequent follow-up interval to be prescribed at each follow-up visit. The retreatment algorithm followed in the study may appear detailed, but the underlying rationale is to continue anti-VEGF and focal/grid laser treatment, as needed, until stabilization or lack of further improvement is noted.

The details of the retreatment algorithm represent an attempt to have a rigorous protocol within a clinical trial that can address the many possible courses of the disease (variable improvements and deteriorations in visual acuity and retinal thickness). In addition, the retreatment algorithm attempts to minimize situations when retreatment might be recommended by the algorithm and yet not judged to be desired by the investigator, as might occur if monthly retreatments for 1 or 2 years were required. Once retreatment is withheld at a particular visit in lieu of monthly treatments for 1 or 2 years, the algorithm is designed to try to identify when the investigator might believe there is a need to reinitiate intravitreal anti-VEGF treatment, focal/grid laser treatment, or both, thereby avoiding substantial vision loss and a regimen that requires monthly treatments regardless of the clinical course. The relatively stable visual acuity outcomes 
between the 1- and 2-year visits in the ranibizumab groups suggest that this detailed retreatment algorithm accomplished these goals, although it is unknown whether treatment given every 4 weeks would have led to better outcomes. The impact of different retreatment approaches or use of other anti-VEGF drugs (e.g., bevacizumab) in clinical practice compared with this DRCR.net-specific protocol on visual acuity outcomes cannot be determined from this study.

We found no evidence that ranibizumab or triamcinolone is associated with an increased risk of systemic side effects or overall mortality, including cerebrovascular accidents and cardiovascular events. However, in view of the low number of observed events, a small increased risk cannot be ruled out. With respect to ocular adverse events, there was 1 case of progressive traction retinal detachment among the 375 eyes $(0.3 \%)$ assigned to ranibizumab; this case had extramacular traction detachment before randomization, did not develop until 3 weeks after the 8 monthly consecutive intravitreal ranibizumab injections (when the concentration of the antibody in the vitreous should be low), and was among the 111 ranibizumab-treated eyes with prior panretinal photocoagulation, evidence of proliferative diabetic retinopathy, or both, at baseline. This complication has been suggested to be associated with intravitreal anti-VEGF injections in case series, ${ }^{15}, 16$ although if ranibizumab truly is causative, the event seems to be uncommon, and the only case identified in this study did not have progressive detachment with vision loss until 8 monthly ranibizumab injections had been given. In fact, eyes in the ranibizumab groups were less likely to show progression of diabetic retinopathy, development of vitreous hemorrhage, or need for panretinal photocoagulation. More information regarding the possibility of this cause-and-effect relationship may be forthcoming in another DRCR.net protocol evaluating ranibizumab in the setting of proliferative diabetic retinopathy with DME. ${ }^{17}$

There were 3 cases of injection-related endophthalmitis, including 1 in which no antiseptic was applied to the injection site, which represented 1 of only 8 injections in which povidone iodine was not applied to the injection site. Fluorescein angiograms were not required in this study, so this study cannot determine whether there were cases of development or progression of macular capillary nonperfusion with anti-VEGF injections, as has been suggested in a case series. ${ }^{18}$ However, there were few eyes assigned to ranibizumab with a loss of $\geq 10$ letters, suggesting that if this complication does occur in this setting, it is relatively uncommon and does not outweigh the benefits of treatment. As has been reported in prior studies, ${ }^{19-21}$ intravitreal triamcinolone was associated in this study with an increased risk of elevated IOP and cataract.

Subgroup analysis among pseudophakic eyes at baseline suggested that DRCR.net treatment using intravitreal triamcinolone combined with prompt focal/grid laser results in superior visual acuity outcomes compared with laser alone, although, as noted above, there is an elevated risk of increased IOP. These results are in contrast with a similar group of eyes treated with the same intravitreal triamcinolone formulation but without prompt focal/grid laser, ${ }^{5}$ in which outcomes for pseudophakic eyes at baseline were not superior using intravitreal triamcinolone compared with focal/grid laser. Although these differences in outcome could be due to differences in the characteristics of eyes between these 2 studies, it is logical to assume that the combination of 2 monotherapies (focal/grid laser and intravitreal triamcinolone) for DME in pseudophakic eyes, each of which seems to be superior to no treatment, ${ }^{5}$ is superior to focal/ grid laser alone for pseudophakic eyes.

Some of the strengths of this study include its size, which provided relatively narrow CIs in the results presented, and good adherence to a strict protocol across multiple community- and institutional-based clinical sites throughout the United States. In addition, the data suggest that most study participants assigned to sham injection were successfully masked, because most believed they received actual injections. The data among study participants with 2 study eyes 
were similar to the overall results, suggesting there was little or no contralateral effect of ranibizumab on the fellow eye assigned to laser and no intravitreal injection, and providing a cohort in which all genetic, systemic, and environmental effects on DME should be well controlled. Although the 2-year data support the findings at 1 year, the 3-year data should help determine whether improvements noted to date are sustained and how often intravitreal ranibizumab or focal/grid laser is needed over time, whether starting with ranibizumab with prompt laser or ranibizumab with deferred laser. Some weaknesses of the study include the apparent complexity of the retreatment algorithm. Study participants assigned to the ranibizumab + deferred laser group or with 2 study eyes could not be masked if 1 eye was assigned to the ranibizumab + deferred laser group because prompt laser was not performed in that eye, thus unmasking the ranibizumab + deferred laser group to the treatment assignment. It also should be noted that neither intravitreal triamcinolone nor ranibizumab is currently approved for DME by the Food and Drug Administration; use of intravitreal ranibizumab or intravitreal triamcinolone for DME would be an off-label indication at this time.

The observed benefits of intravitreal anti-VEGF treatment for DME in this study are consistent with shorter-term improvements in visual acuity outcomes and resolution of DME on OCT noted with bevacizumab ${ }^{22}$ and ranibizumab. ${ }^{9}$ However, to our knowledge, no previous publications evaluating anti-VEGF drugs for DME have compared this treatment with concurrent controls receiving focal/grid laser with follow-up through at least 1 year. Other studies are under way that are comparing intravitreal ranibizumab alone, or in combination with laser, with laser alone over 1 year ${ }^{23}$ and comparing intravitreal ranibizumab alone with sham. ${ }^{24,25}$ Results from these and other studies should complement knowledge regarding the safety and efficacy of ranibizumab and other anti-VEGF drugs, alone, or in combination with laser, for the treatment of DME. The aggregate information from these studies also would be necessary to assess cost-effectiveness.

In conclusion, focal/grid laser has been the mainstay of treatment for DME during the past 25 years. On the basis of the data from this DRCR.net protocol, intravitreal ranibizumab with deferred ( $\geq 24$ weeks) or prompt focal/grid laser is superior to focal/grid laser alone for the treatment of DME involving the center of the macula through at least 1 year of follow-up, with significantly more eyes gaining substantial vision and significantly fewer eyes losing substantial vision. Intravitreal ranibizumab as applied in this study, although uncommonly associated with endophthalmitis and theoretically associated with an increased risk of traction retinal detachments in eyes with proliferative diabetic retinopathy, should be considered for patients with DME and characteristics similar to those of the cohort in this clinical trial. In pseudophakic eyes, intravitreal triamcinolone with prompt focal/grid laser may be equally effective as ranibizumab at improving visual acuity and reducing retinal thickening but is associated with an increased risk of elevated IOP. Further follow-up is needed to determine even longer-term safety and efficacy of ranibizumab in the treatment of DME.

\section{Appendix 1}

\section{Diabetic Retinopathy Clinical Research Network Laser-Ranibizumab- Triamcinlone Study Treatment}

\section{Baseline treatment}

Injections of 0.5 -mg ranibizumab and 4-mg preservative free triamcinolone (Trivaris, Allergan, Inc., Irvine, CA) were administrated with a standardized intravitreal injection technique which included a povidone iodine prep of the conjunctiva. Antibiotics in the pre-, peri-, and postinjection period were optional. The sham injection procedure consisted of placing the hub of a syringe against the conjunctival surface following the povidone-iodine prep. Focal/grid 
photocoagulation was administered using a technique modified from the original Early Treatment Diabetic Retinopathy Study (ETDRS) protocol as described previously and used in prior Diabetic Retinopathy Clinical Research Network (DRCR.net) protocols. ${ }^{26}$ The initial intravitreal (or sham) injection was given on the day of randomization. The 3 groups assigned to prompt laser received focal/grid photocoagulation 1 week (with a treatment window of 3 to 10 days) after the baseline intravitreal (or sham) injection.

\section{Follow-up intravitreal study drug or sham retreatments through the 48-week study visit}

The protocol required retreatment with intravitreal or sham injections (depending upon the randomized assignment at baseline) and focal/grid laser following guidelines outlined below, unless precluded by adverse events. The guidelines used to make retreatment decisions had different parameters for intravitreal or sham injections depending on which study visit was occurring. Prior to the 16-week study visit, treatment with sham or study drug was given every 4 weeks regardless of the visual acuity or optical coherence tomography (OCT) central subfield thickness. At the 16 and 20 week study visits, sham or study drug was required monthly unless 'success' criteria (defined as visual acuity letter score $\geq 84$ (20/20) or OCT central subfield thickness <250; Table 1, available at http://aaojournal.org) was met, in which case sham or study drug injection was at investigator discretion. At each visit from 24 to 48 weeks, eyes were categorized as meeting either 'success' as defined above, 'improvement', 'no improvement', or 'failure' (defined below and Table 1, available at http://aaojournal.org). 'Improvement' required a sham or study drug injection and was defined as an eye that did not meet criteria for success but in which either visual acuity had improved by $\geq 5$ letters or OCT central subfield thickness had improved by $\geq 10 \%$ since the last non-sham injection or since baseline for the sham+prompt laser group. If an eye was categorized as 'no improvement' because it met neither the criteria for 'success' or 'improvement', but had not yet met the criteria for 'failure' a sham or study drug injection could be given at investigator discretion. 'Failure' was defined as a visual acuity letter score 10 or more letters worse than the baseline score, OCT central subfield thickness $\geq 250$ um, diabetic macular edema (DME) judged to be the cause of visual acuity loss and duration of at least 13 weeks since 'complete laser' (defined in Table 1, available at http://aaojournal.org) had been given with no improvement since the last laser treatment. Eyes that met 'failure' criteria could be treated at investigator discretion with a sham or randomized study drug injection or with an 'alternative' treatment regimen (defined in Table 1, available at http://aaojournal.org) other than that assigned at baseline, such as intravitreal bevacizumab or triamcinolone. Appendix 2 (available at http://aaojournal.org) provides a detailed flow chart of study drug or sham retreatments through the 48-week study visit.

\section{Intravitreal study drug retreatments after the 48-week study visit}

At and after the 1 year study visit (Appendix 3, available at http://aaojournal.org), sham injections were discontinued and follow-up study visits occurred at every 4 months instead of monthly for eyes in the sham+prompt laser group and the triamcinolone+prompt laser group. Eyes in the two ranibizumab groups that met failure criteria also had study visits every 4 months. For eyes assigned to receive injections, the same retreatment criteria were followed as at the 24 to 48 week visit with two additional considerations. First, the treatment regimen could be at investigator discretion, including treatments other than the randomly assigned treatment, not only for eyes that met 'failure' criteria but also for eyes that met 'futility' criteria (defined below and Table 1, available at http://aaojournal.org). 'Futility' criteria were defined similarly to failure criteria except that visual acuity was not required to be worse than baseline if it had been at least 29 weeks since 'complete laser' and all other criteria for 'failure' were met. Second, for eyes assigned to ranibizumab in which the injection was deferred at the current and previous two visits either due to 'success' or 'no improvement', as defined above, then the follow-up could be extended. 'Extended follow-up' (defined in Table 1, available at 
http://aaojournal.org) visits occurred at intervals that were twice the time since the previous visit, up to a maximum of 16 weeks between study visits.

\section{Follow-up focal/grid laser treatment}

Application of focal/grid laser treatment at and after the 16-week study visit (Appendix 4, available at http://aaojournal.org) for each group except the ranibizumab+deferred laser group occurred 3 to 10 days following each intravitreal (or sham) injection unless one of the following was present at the time of the injection: (1) laser was given in the previous 13 weeks; (2) the investigator considered that 'complete laser' (direct treatment to all microaneurysms within areas of edema and grid treatment to all other areas of macular edema) had already been applied; or (3) OCT central subfield thickness was $<250$ microns and there was 'no edema threatening the center of the macula', defined as no edema within 500 microns of the center of the macula, no edema associated with lipid within 500 microns of the center of the macula, and no edema $\geq 1$ disc area within 1 disc area of the center of the macula (defined in Table 1, available at http://aaojournal.org). For the ranibizumab+deferred laser group, at the 24-week and any later visit, if there was 'no improvement' as defined above from the last two study injections and the investigator believed that macular edema was present for which focal/grid laser was indicated, the eye was to receive focal/grid laser until the edema resolved or 'complete laser' was given using the same criteria defined for eyes assigned to 'prompt' focal-grid photocoagulation. 


\section{Appendix 2}

DRCR.net Retreatment Algorithm Flow Chart for Intravitreal Injection Treatment at 16 to 48 Weeks

(Following 4 Intravitreal or Sham Injections Every 4 Weeks Through Week 12)

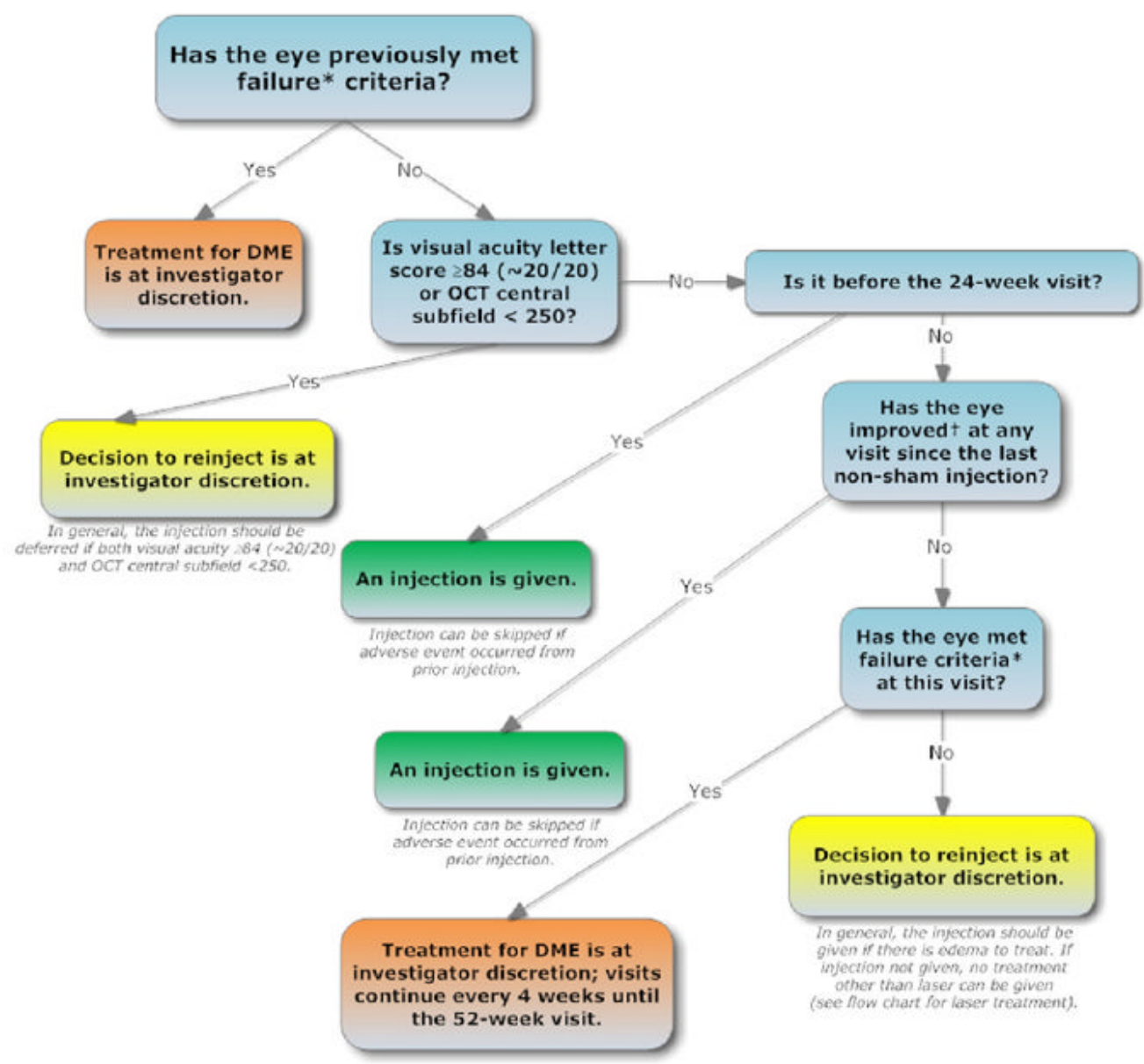

Definition of abbreviations used: DRCR.net = Diabetic Retinopathy Clinical Research Network; OCT = Optical Coherence Tomograp DME = Diabetic Macular Edema

* Failure is defined as: Visual acuity 10 or more letters worse than baseline, OCT central subfield $\geq 250$ microns, DME present on clinical exam that is the cause of the visual loss, complete laser given AND $\geq 13$ weeks since last laser treatment with no improvement since the last laser treatment.

+ Improvement defined as: OCT central subfield thickness decreased by $\geq 10 \%$ or visual acuity letter score improved by $\geq 5$. 


\section{Appendix 3}

DRCR.net Retreatment Algorithm Flow Chart for Treatment at and after $\mathbf{5 2}$ Week Follow-Up Visit

\section{SHAM + PROMPT LASER GROUP (A)}

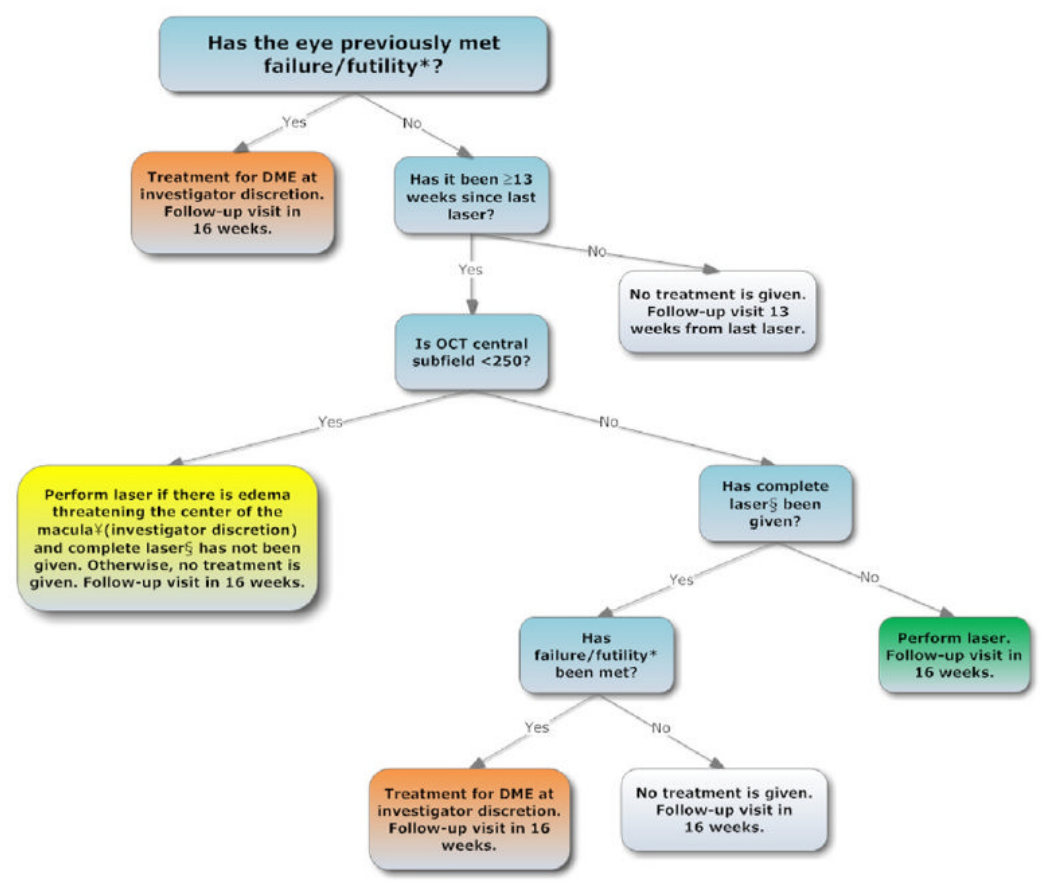

Definition of abbreviations used: $D R C R$.net $=$ Diabetic Retinopathy Clinical Research Network; OCT $=$ Optical Coherence Tomography; DME = Diabetic Macular Edema * Failure/futility defined as: Visual acuity letter score $<84(\sim 20 / 20)$, OCT central subfieid 2250 microns, DME present on clinical exam that is the cause of the visual loss, complete laser given anb either 1) 213 weeks since last laser treatment with no improvement since the last laser treatment

Improvement defined as: OCT central subfield thickness decreased by $110 \%$ or visual acuity fetter score improved by 25.

§ Complete laser: Direct treatment to all microaneurysms within areas of macular edema and grid treatment to all other areas of macular edema.

₹ Edema threatening the center of the macula: Edema on clinical exam within 500 microns of the foveal center or edema
associated with ilipid within 500 microns of the foveal center of 1 disc area of edema within 1 disc area of the foveal center. 


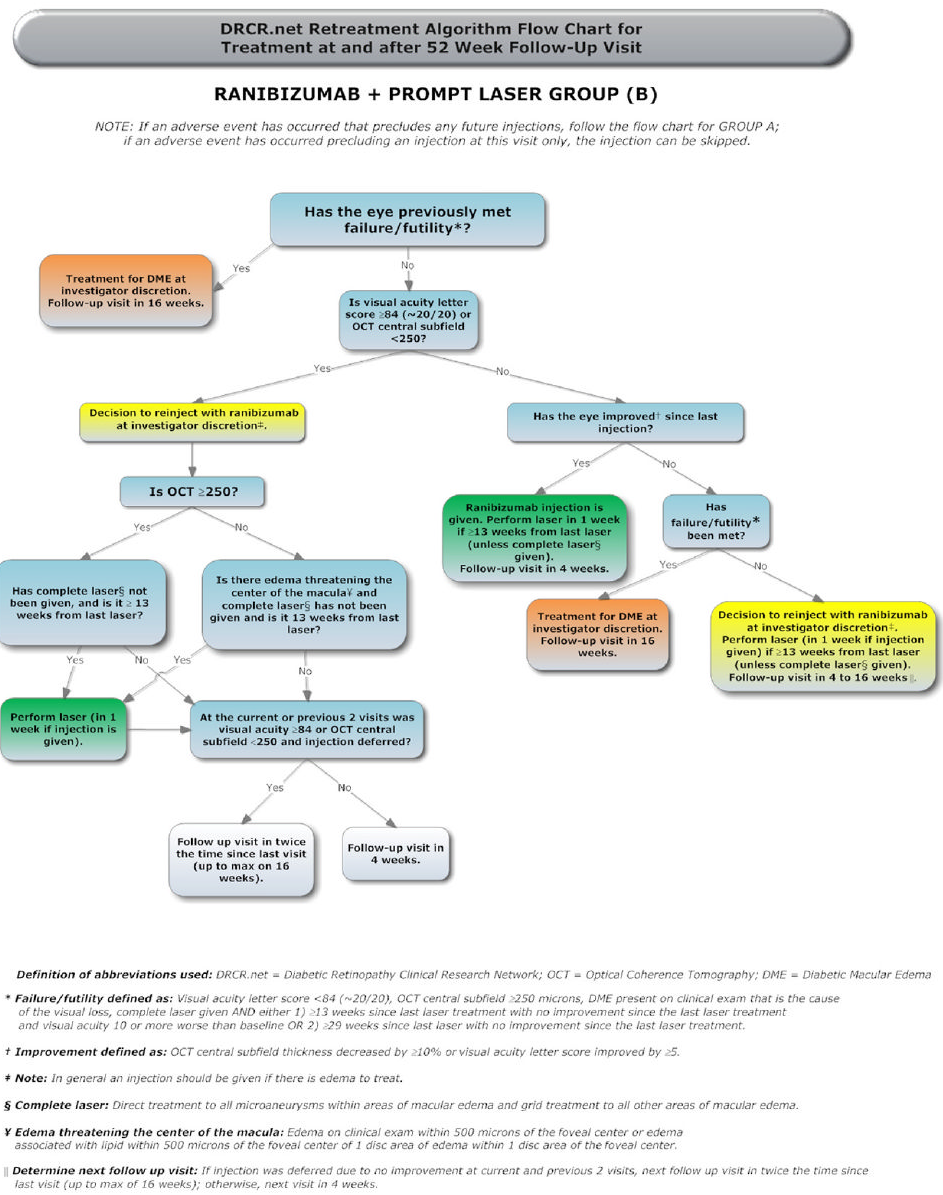




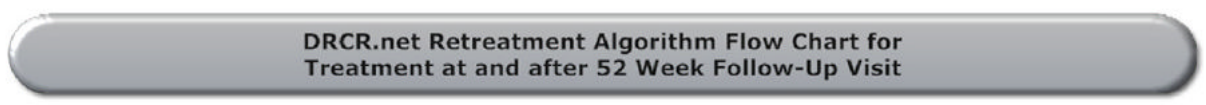

RANIBIZUMAB + DEFERRED LASER GROUP (C)

NOTE: If an adverse event has occurred that precludes any future injections, follow the flow chart for GROUP A if an adverse event has occurred precluding an injection at this visit only, the injection can be skipped.

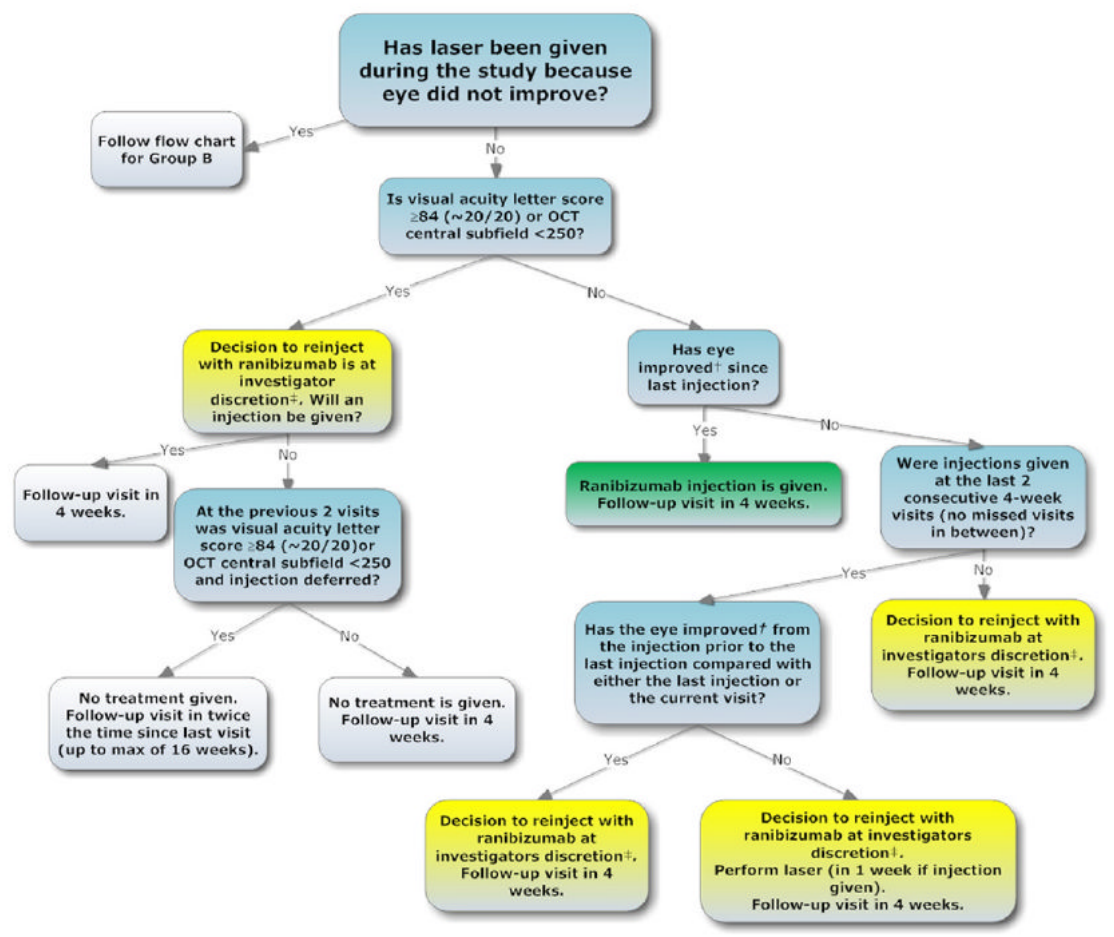

Definition of abbreviations used: $D R C R$.net = Diabetic Retinopathy Clinical Research Network; OCT = Optical Coherence Tomography; DME = Diabetic Macular Edema f Improvement defined as: OCT central subfield thickness decreased by $>10 \%$ or visual acuity letter score improved by $>5$.

* Note: In general an injection should be given if there is edema to treat 
DRCR.net Retreatment Algorithm Flow Chart for Treatment at and after $\mathbf{5 2}$ Week Follow-Up Visit

TRIAMCINOLONE + PROMPT LASER GROUP (D)

NOTE: If an adverse event has occurred that precludes any future injections, follow the flow chart for GROUP A; if an adverse event has occurred prectuding an injection at this visit only, the injection can be skipped.

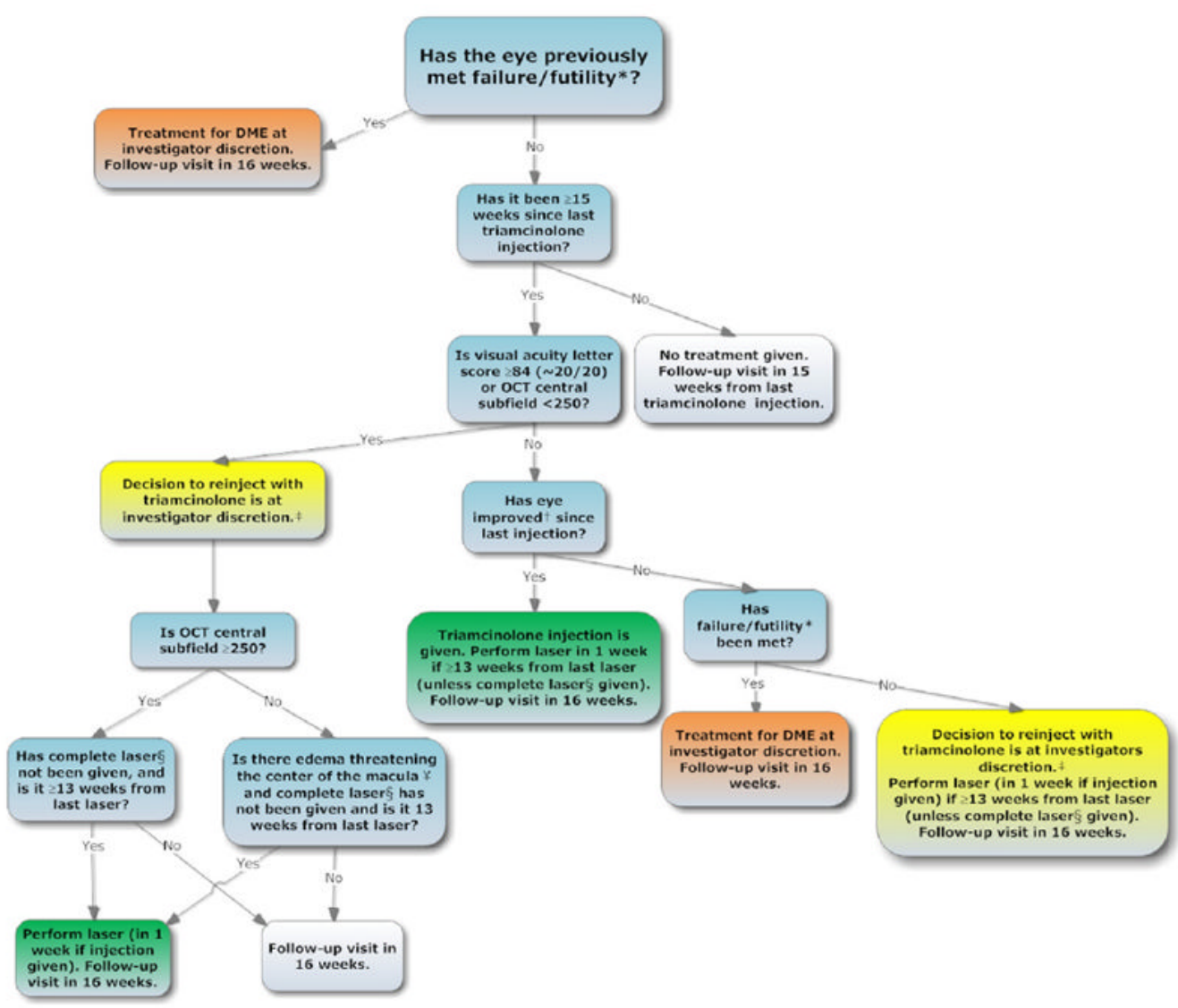

Definition of abbreviations used: DRCR net = Diabetic Retinopathy Cllnical Research Network. OCT = Ontical Coherence Tomography: DME = Diabetic Macular Edeme

* Failure/futility defined as: Visual acuity letter score <84 ( 20/20), OCT central subfiedd 250 microns, DME present on clinical exam that is the cause of the visual loss, complete laser given AND either 1) 13 weeks since last laser treatment with no improvement since the fast laser treatment and visual acuity 10 or more worse than baseline OR 2) 229 weeks since last laser with no improvement since the last laser treatment.

+ Improvement defined as: OCt central subficid thickness decreased by $210 \%$ or visual acuity letter score improved by 25.

* Note: In general an injection should be given if there is edema to treat.

$\S$ Complete laser: Direct treatment to all microaneurysms within areas of macular edema and grid treatment to all other areas of macular edema.

$\checkmark$ Edema threatening the center of the macula: Edema on cimical exam within 500 microns of the foveal center or edema associated with lipid within 500 microns of the foveal center of 1 disc area of edema within 1 disc area of the foveal center.

Ophthalmology. Author manuscript; available in PMC 2011 June 1. 


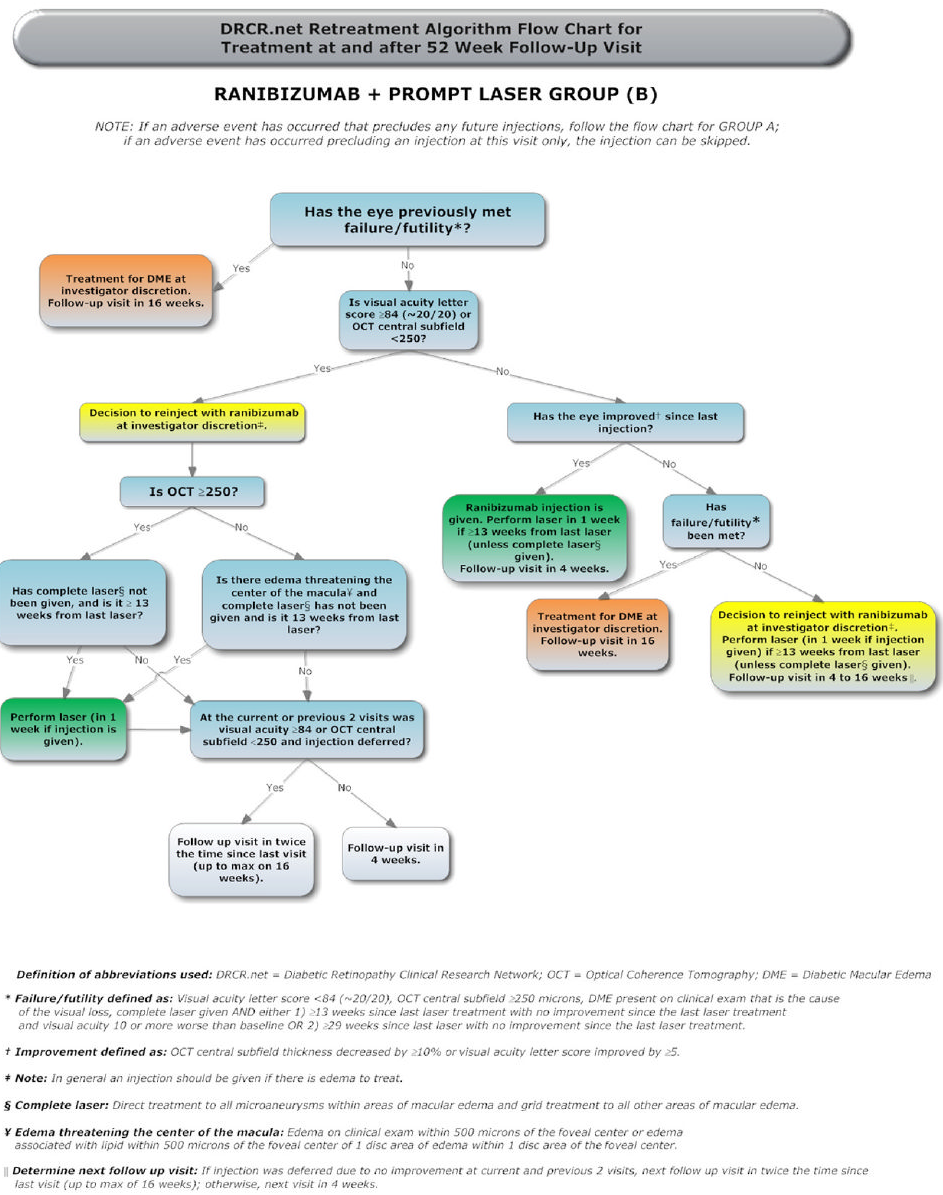




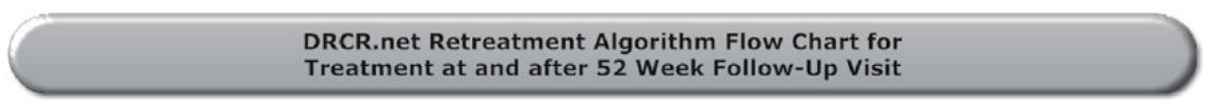

RANIBIZUMAB + DEFERRED LASER GROUP (C)

NOTE: If an adverse event has occurred that precludes any future injections, follow the flow chart for GROUP $A$ if an adverse event has occurred precluding an injection at this visit only, the injection can be skipped.

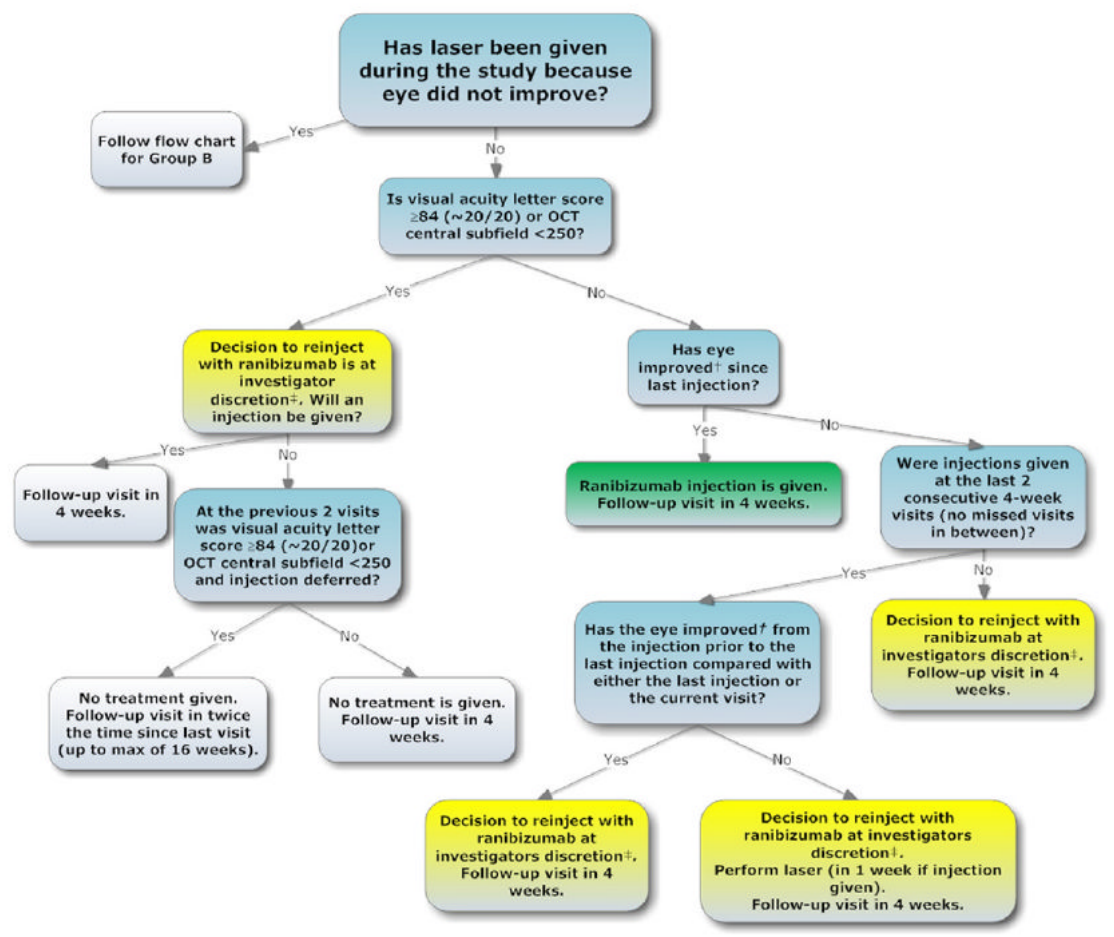

Definition of abbreviations used: $D R C R$.net = Diabetic Retinopathy Clinical Research Network; OCT = Optical Coherence Tomography; DME = Diabetic Macular Edema f Improvement defined as: OCT central subfield thickness decreased by $>10 \%$ or visual acuity letter score improved by $>5$.

* Note: In general an injection should be given if there is edema to treat 
DRCR.net Retreatment Algorithm Flow Chart for Treatment at and after $\mathbf{5 2}$ Week Follow-Up Visit

TRIAMCINOLONE + PROMPT LASER GROUP (D)

NOTE: If an adverse event has occurred that precludes any future injections, follow the flow chart for GROUP A; if an adverse event has occurred prectuding an injection at this visit only, the injection can be skipped.

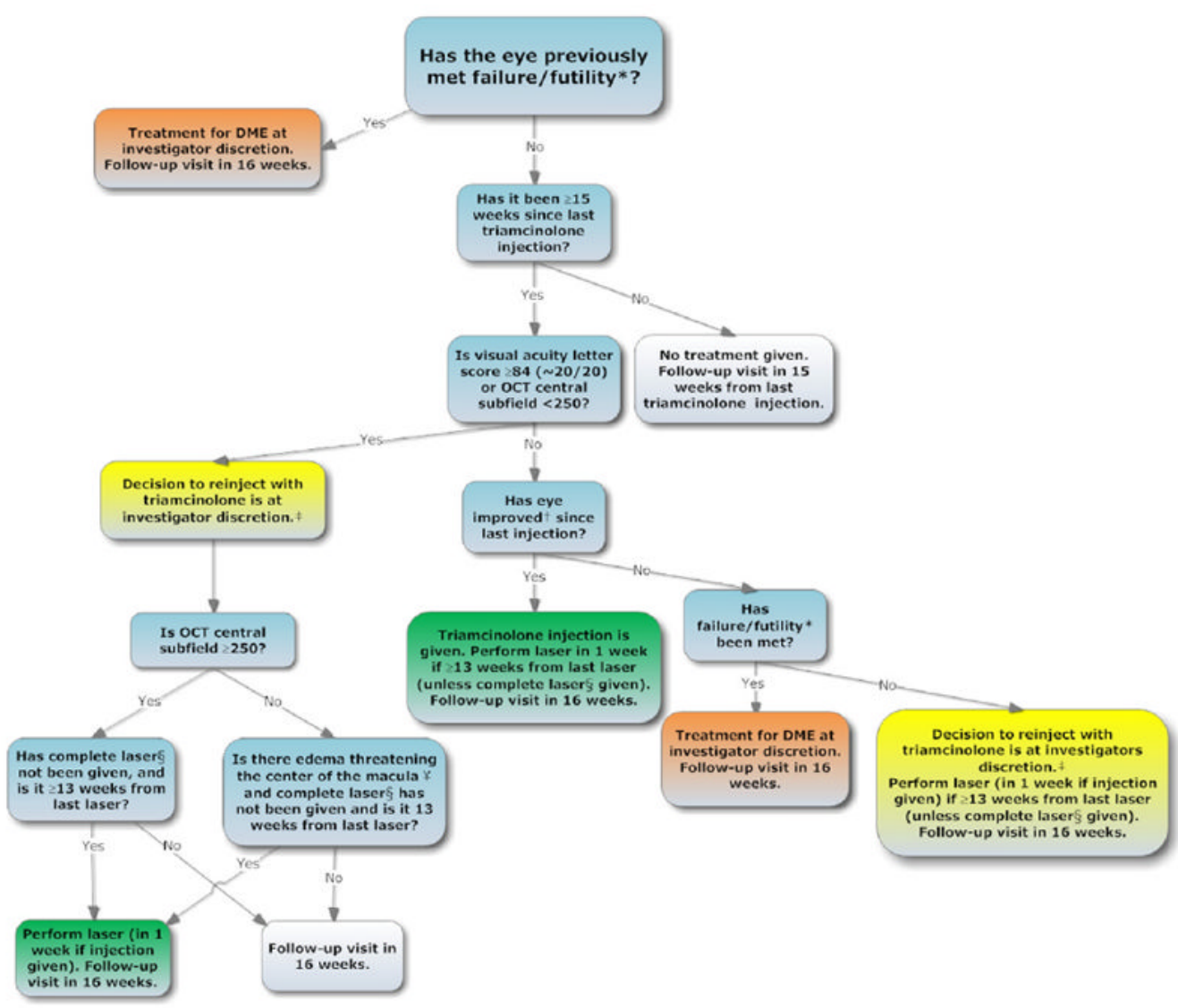

Definition of abbreviations used: DRCR net = Diabetic Retinopathy Cllnical Research Network. OCT = Ontical Coherence Tomography: DME = Diabetic Macular Edeme

* Failure/futility defined as: Visual acuity letter score <84 ( 20/20), OCT central subfiedd 250 microns, DME present on clinical exam that is the cause of the visual loss, complete laser given AND either 1) 13 weeks since last laser treatment with no improvement since the fast laser treatment and visual acuity 10 or more worse than baseline OR 2) 229 weeks since last laser with no improvement since the last laser treatment.

+ Improvement defined as: OCt central subficid thickness decreased by $210 \%$ or visual acuity letter score improved by 25.

* Note: In general an injection should be given if there is edema to treat.

$\S$ Complete laser: Direct treatment to all microaneurysms within areas of macular edema and grid treatment to all other areas of macular edema.

$\checkmark$ Edema threatening the center of the macula: Edema on cimical exam within 500 microns of the foveal center or edema associated with lipid within 500 microns of the foveal center of 1 disc area of edema within 1 disc area of the foveal center.

Ophthalmology. Author manuscript; available in PMC 2011 June 1. 


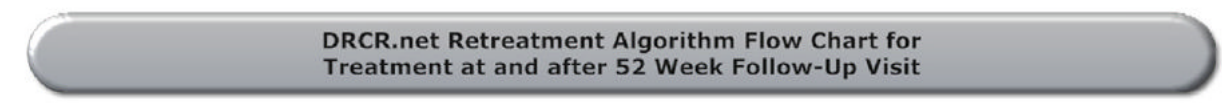

RANIBIZUMAB + DEFERRED LASER GROUP (C)

NOTE: If an adverse event has occurred that precludes any future injections, follow the flow chart for GROUP A if an adverse event has occurred precluding an injection at this visit only, the injection can be skipped.

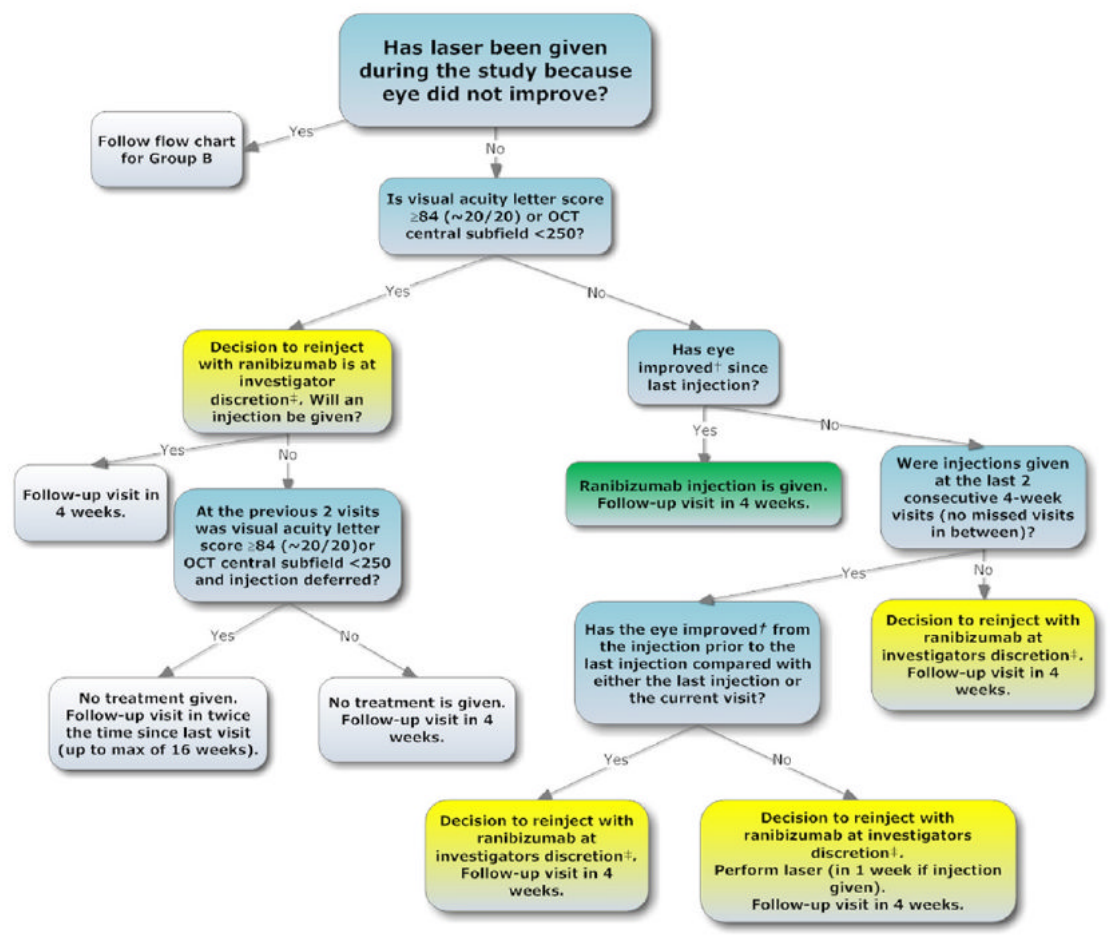

Definition of abbreviations used: DRCR.net = Diabetic Retinopathy Clinical Research Network; OCT = Optical Coherence Tomography; DME = Diabetic Macular Edema f Improvement defined as: OCT central subfield thickness decreased by $>10 \%$ or visual acuity letter score improved by $>5$.

* Note: In general an injection should be given if there is edema to treat 
DRCR.net Retreatment Algorithm Flow Chart for Treatment at and after $\mathbf{5 2}$ Week Follow-Up Visit

TRIAMCINOLONE + PROMPT LASER GROUP (D)

NOTE: If an adverse event has occurred that precludes any future injections, follow the flow chart for GROUP A; if an adverse event has occurred prectuding an injection at this visit only, the injection can be skipped.

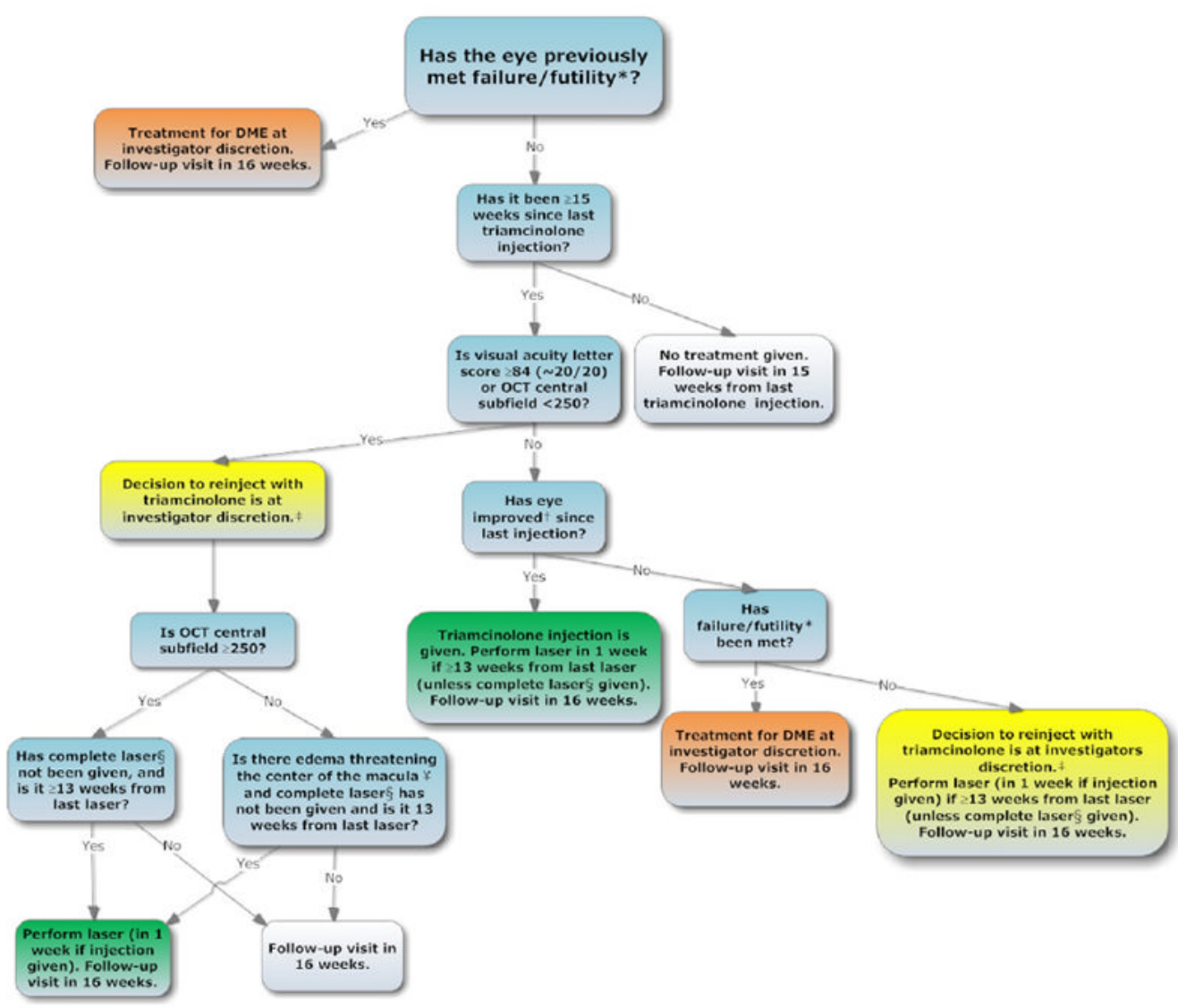

Definition of abbreviations used: DRCR net = Diabetic Retinopathy Clnical Research Network. OCT = Ontical Coherence Tomography: DME = Diabetic Macular Edeme

* Failure/futility defined as: Visual acuity letter score <84 ( 20/20), OCT central subfiedd 250 microns, DME present on clinical exam that is the cause of the visual loss, complete laser given AND either 1) 13 weeks since last laser treatment with no improvement since the fast laser treatment and visual acuity 10 or more worse than baseline OR 2) 229 weeks since last laser with no improvement since the last laser treatment.

+ Improvement defined as: OCt central subficid thickness decreased by $210 \%$ or visual acuity letter score improved by 25.

* Note: In general an injection should be given if there is edema to treat.

$\S$ Complete laser: Direct treatment to all microaneurysms within areas of macular edema and grid treatment to all other areas of macular edema.

$\checkmark$ Edema threatening the center of the macula: Edema on cimical exam within 500 microns of the foveal center or edema associated with lipid within 500 microns of the foveal center of 1 disc area of edema within 1 disc area of the foveal center.

Ophthalmology. Author manuscript; available in PMC 2011 June 1. 
DRCR.net Retreatment Algorithm Flow Chart for Treatment at and after $\mathbf{5 2}$ Week Follow-Up Visit

TRIAMCINOLONE + PROMPT LASER GROUP (D)

NOTE: If an adverse event has occurred that precludes any future injections, follow the flow chart for GROUP A; if an adverse event has occurred prectuding an injection at this visit only, the injection can be skipped.

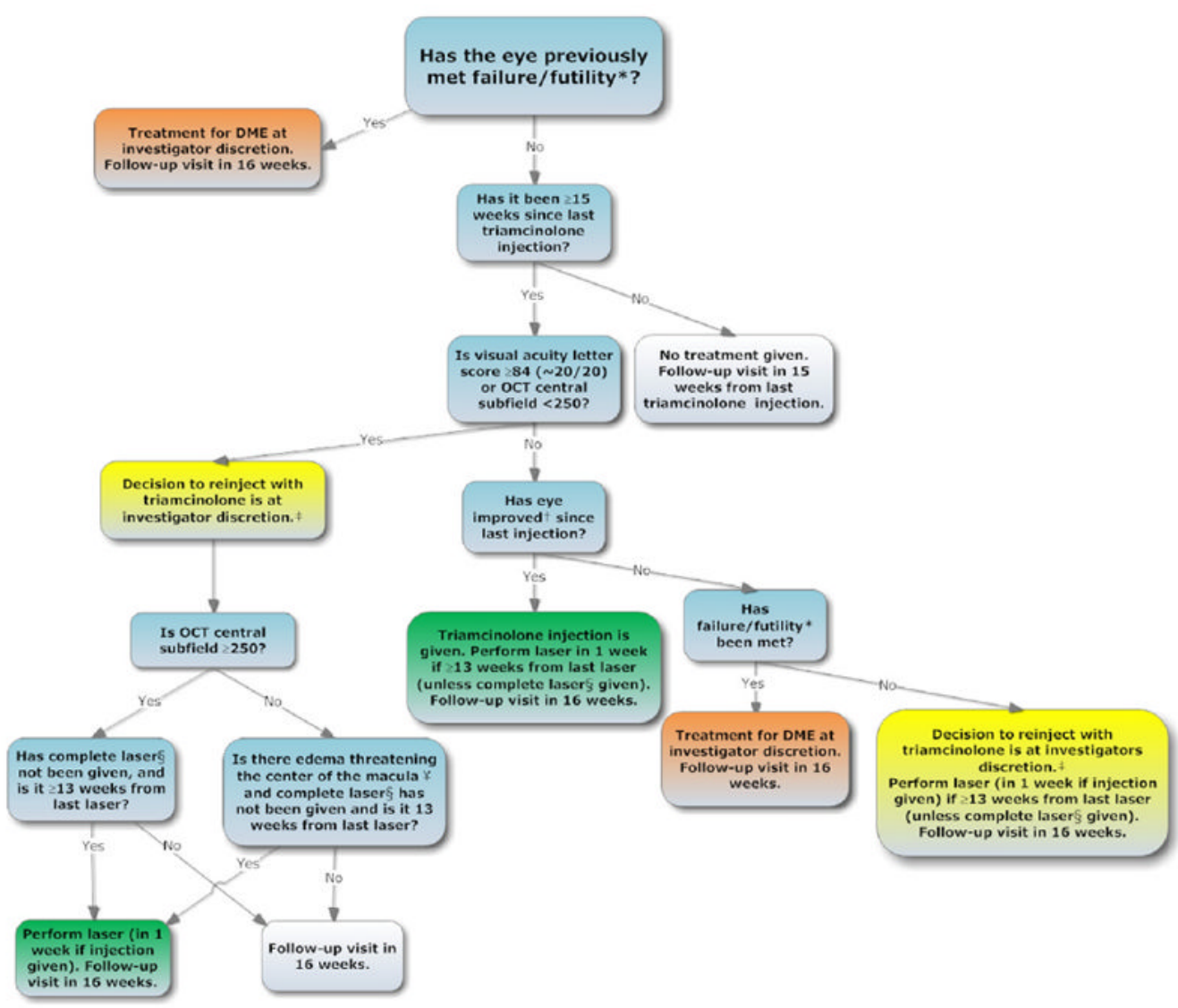

Definition of abbreviations used: DRCR net = Diabetic Retinopathy Clnical Research Network. OCT = Ontical Coherence Tomography: DME = Diabetic Macular Edeme

* Failure/futility defined as: Visual acuity letter score <84 ( 20/20), OCT central subfiedd 250 microns, DME present on clinical exam that is the cause of the visual loss, complete laser given AND either 1) 13 weeks since last laser treatment with no improvement since the fast laser treatment and visual acuity 10 or more worse than baseline OR 2) 229 weeks since last laser with no improvement since the last laser treatment.

+ Improvement defined as: OCt central subficid thickness decreased by $210 \%$ or visual acuity letter score improved by 25.

* Note: In general an injection should be given if there is edema to treat.

$\S$ Complete laser: Direct treatment to all microaneurysms within areas of macular edema and grid treatment to all other areas of macular edema.

$\checkmark$ Edema threatening the center of the macula: Edema on cimical exam within 500 microns of the foveal center or edema associated with lipid within 500 microns of the foveal center of 1 disc area of edema within 1 disc area of the foveal center.

Ophthalmology. Author manuscript; available in PMC 2011 June 1. 


\section{Appendix 4}

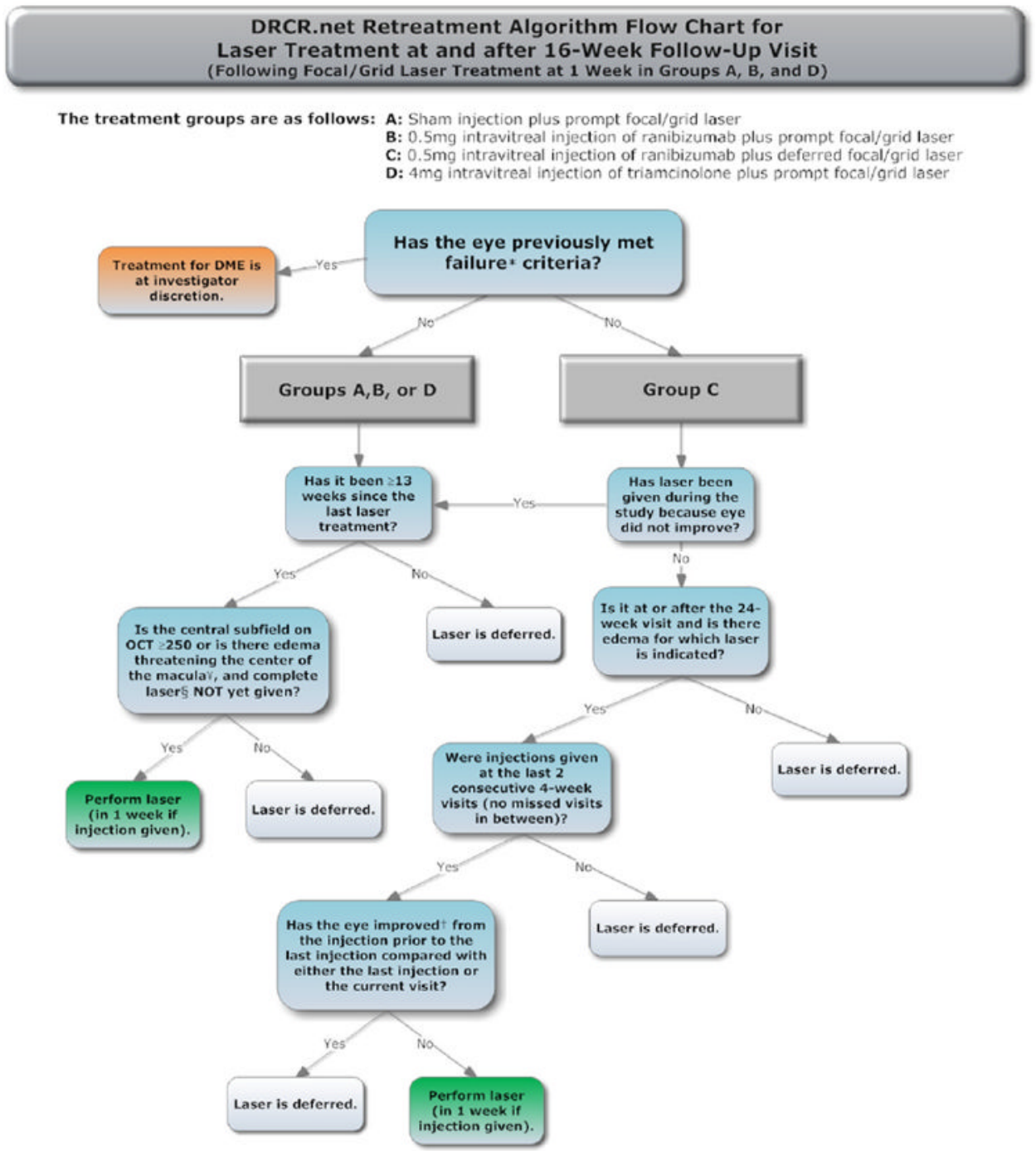

Definition of abbreviations used: ORCR.net $=$ Diabetic Retinopathy Clinical Research Network; OCT $=$ Optical Coherence Tomography; DME = Diabetic Macular Edema

* Failure is defined as: Visual acuity 10 or more letters worse than baseline, OCT central subfield 2250 microns, DME present on cinical exam that is the cause of the visual loss, complete laser given AND 213 weeks since last laser treatment with no improvement since the last laser treatment.

t Improvement defined as: OCT central subfield thickness decreased by $\geq 10 \%$ or visual acuity letter score improved by 25.

$\$$ Complete laser: Direct treatment to all microeneurysms within areas of macular edema and grid treatment to all other areas of

Y Edema threatening the center of the macula: Edema on clinical exam within 500 microns of the foveal center or edema associated with lipid within 500 microns of the foveal center of 1 disc area of edema within 1 disc area of the foveal center.

\section{Appendix 5(website) \\ Diabetic Retinopathy Clinical Research Network Clinical Sites that participated on this protocol}

Sites are listed in order by number of subjects enrolled into the study. The number of subjects enrolled is noted in parenthesis preceded by the site location and the site name. Personnel are 
listed as (I) for Study Investigator, (C) for Coordinator, (V) for Visual Acuity Tester, and (P) for Photographer.

Baltimore, MD Elman Retina Group, P.A. (90) Michael J. Elman (I); Michelle D. Sloan (C); Theresa M. Butcher (C); JoAnn Starr (C,V); Nancy Gore (V); Teresa Coffey (V); Pamela V. Singletary (V); Dena Y. Salfer-Firestone (V); Giorya Andreani (P); Daniel J. Ketner (P); Peter Sotirakos (P); Terri Cain (P) Jacksonville, FL University of Florida College of Med., Department of Ophthalmology, Jacksonville Health Science Cent (54) Kakarla V. Chalam (I); Sandeep Grover (I); Shailesh K. Gupta (I); Tamil M. Singh (C,P); Ravi Keshavamurthy (C,V); Swati Agarwal (C,P); William W. Phillips (C,P); Jason Sifrit (V); Manish C. Patel (V); Vikram S. Brar (P); John R. Carpentier (P) Indianapolis, IN Raj K. Maturi, M.D., P.C. (46) Raj K. Maturi (I); Thomas Ciulla (I); Nicholas F. Hrisomalos (I); Laura A. Bleau (C,P,V); Carolee K. Novak (V); Michelle Storie (V); Thomas Steele (P); Abby Maple (P); Jama L. Poston (P); Ashley Harless (P) Lakeland, FL Florida Retina Consultants (45) Scott M. Friedman (I); Oren Z. Plous (I); Kelly A. Blackmer (C); Jolleen S. Key (C,P,V); Karen Sjoblom $(\mathrm{P}, \mathrm{V})$; Jessica Maldonado (P); Sheila Walters-Treon (P); Allen McKinney (P,V); Katie Gostischa (P); Steve Carlton (P) Charlotte, NC Charlotte Eye, Ear, Nose and Throat Assoc., PA (31) David J. Browning (I); Justin C. Brown (I); Andrew N. Antoszyk (I); Danielle R. Brooks (C,V); Angela K. Price (C,V); Melissa K. Cowen (C,V); Jennifer V. Helms (C,V); Sarah A. Ennis (V); Rachel E. Pierce (V); Angella S. Karow (V); Wayne Lail (V); Michele E. Powers (P); Donna McClain (P); Richard J. George (P); Loraine M. Clark (P); Krystie A. Schlicker (P); Pearl A. Leotaud (P); Amanda R. Vittitow (P); Uma M. Balasubramaniam (P); Linda M. Davis (P); Michael D. McOwen (P); Jennifer A. Ballard (P) Portland, OR Casey Eye Institute (28) Andreas K. Lauer (I); Peter J. Francis (I); Steven T. Bailey (I); Thomas S. Hwang (I); Christina J. Flaxel (I); Susan I. Pope (C,V); Maureen D. Toomey (V); Susan K. Nolte (V); Shirley D. Ira (V); Teresa Liesegang (V); Ann D. Lundquist (V); Mitchell Schain (V); Debora R. Vahrenwald (V); Chris S. Howell (P); Joseph Cilio Rossi (P); Patrick R. Wallace (P); Kelly L. West (P); Peter N. Steinkamp (P); Patrick B. Rice (P); Scott R. Pickell (P) Lexington, KY Retina and Vitreous Associates of Kentucky (22) Thomas W. Stone (I); John W. Kitchens (I); William J. Wood (I); Rick D. Isernhagen (I); Diana M. Holcomb (C); Judith L. Cruz (V); Cathy A. Sears (V); Brenda VanHoose (V); Michelle Buck (V); Jenny L. Wolfe (V); Jeanne Van Arsdall (V); Wanda R. Heath (V); Edward A. Slade (P); Stephen T. Blevins (P); Terri Kidd (P) Knoxville, TN Southeastern Retina Associates, P.C. (19) Tod Alan McMillan (I); Stephen Lee Perkins (I); Nicholas Gray Anderson (I); Joseph M. Googe (I); Christina T. Higdon (C,V); Stephanie Evans (C); Charity D. Morris (C); Cecile Hunt (V); Misty Moore (V); Mary M. Johnson (V); Kristina Oliver (V); Vicky L. Seitz (V); Ann Arnold (V); Michael Jacobus (P); Jerry K. Whetstone (P); Paul A. Blais (P); Sarah M. Oelrich (P) West Columbia, SC Palmetto Retina Center (19) W. Lloyd Clark (I); John A. Wells (I); Mallie M. Taylor (C); Cassie P. Cahill (C,V); Marcia D. Gridine (C,V); Peggy D. McDougal (V); Kayla L. Henry (V); Robbin Spivey (P); Melissa L. Henderson (P); Pennie Tankersley (P); LaDetrick L. Oliver (P); Amy B. Hickman (P) Artesia, CA Sall Research Medical Center (18) Joseph B. Michelson (I); Laura Anne Teasley (I); Patricia Manjarrez (C); Anabelle Garcia (C,P); Cindy Lee (C); Gabriela Suderno (V); Jenny Keppler (V); Paul Yoo (V); Paul Paquette (P) Walnut Creek, CA Bay Area Retina Associates (18) Stewart A. Daniels (I); T. Daniel Ting (I); Subhransu K. Ray (I); Craig J. Leong (I); Maria Carmencita Aguilos (C); Kathleen J. Dowell (C); Grace M. Marudo (C,V); Cindy M. Moreci (C); Rouella J. Tejada (V); Tia H. Nguyen (V); Sean M. Teshima-McCormick (V); Ashley Schrock (V); William M. Combs (V); Nicole Hom (V); Matthew D. Hughes (P); Fred Hanamoto (P) Ft. Lauderdale, FL Retina Group of Florida (17) Mandeep Singh Dhalla (I); W. Scott Thompson (I); Scott Anagnoste (I); Jaclyn A. Brady-Lopez (C); Cindy V. Fernandez (C); Evelyn Quinchia (V); Jamie Mariano (V); Clifford M. Sherley (V); Patricia Aramayo (P); Melissa L. Ritchie (P); Karen L. McHugh (P); Brian M. Fernandez (P) Houston, TX Retina and Vitreous of Texas (16) H. Michael Lambert (I); Arthur W. Willis (I); Joseph A. Khawly (I); Roberto Diaz-Rohena (I); Pam S. 
Miller (C,V); Susan K. Busch (C,P,V); Debbie Fredrickson (V); Valerie N. Lazarte (V); Kevin L. Davis (V); Joseph A. Morales (P); Kristopher J. Chase (P); Donald K. Lowd (P); Jason E. Muniz (P); Allison W. Schmidt (P) Minneapolis, MN Retina Center, PA (16) Abdhish R. Bhavsar (I); Geoffrey G. Emerson (I); Michael Vaughn Emerson (I); Vu T. Huynh (C,P,V); Tanya M. Olson (C); DeAndra J. Boll (C); Miguelina Yafchak (C); Craig H. Hager (V); Samillya L. Pearson (V); Dwight L. Selders (V); Christopher M. Smith (P); Carmen ChanTram (P); William B. Carli (P); Jessica A. Kells (P); Laura Taylor-Reetz (P) Baltimore, MD Wilmer Eye Institute at Johns Hopkins (15) Sharon D. Solomon (I); Adrienne Williams Scott (I); Neil M. Bressler (I); Diana V. Do (I); Susan Bressler (I); Mary Frey (C,V); Sandra West (C,V); Deborah Donohue (V); Vanessa Kellner (V); Dennis Cain (P); Janis Graul (P); Jacquelyn Mc-Donald (P); David Emmert (P); Syed M. Shah (P); Judith Belt (P); Charles Herring (P) Loma Linda, CA Loma Linda University Health Care, Department of Ophthalmology (14) Joseph T. Fan (I); Mukesh Bhogilal Suthar (I); Michael E. Rauser (I); Cara L. Davidson (C,V); Gisela Santiago (C); Kara E. Rollins (C,P,V); Carrousel J. Corliss (C); Christy G. Quesada (C,V); William H. Kiernan (V); Rene G. Obispo (P); Jesse Knabb (P) Paducah, KY Paducah Retinal Center (14) Carl W. Baker (I); Tracey M. Caldwell (C); Tracey R. Martin (V); Mary J. Palmer (V); Lynnette F. Lambert (V); Tana R. Williams (P); Alecia B. Travis (P); Dawn D. Darden (P) Austin, TX Retina Research Center (12) Brian B. Berger (I); Eric Chen (I); Robert W. Wong (I); Kristen Davis (C); Julie R. Lummus (C); Ginger J. Manhart (C); Telisa L. Clevenger-Smith (C); Nicole Callen (V); Michael T. Gartner (V); Jamie L. Sun (V); Gilbert L. Abeyta (V); Ben Ostrander (P); Yong Ren (P) Columbia, SC Carolina Retina Center (11) Jeffrey G. Gross (I); Michael A. Magee (I); Amy M. Flowers (C,P,V); Kayla L. Henry (C,V); Angelique SA McDowell (V); Cori M. Fore (V); Heidi K. Lovit (V); Jason C. Rohrer (V); Kristin K. Bland (V); Ally M. Paul (P); Chris N. Mallet (P); Rick Christoff (P); Randall L. Price (P) Madison, WI University of Wisconsin-Madison, Dept of Ophthalmology/Retina Service (11) Justin L. Gottlieb (I); Barbara A. Blodi (I); Michael S. Ip (I); Kathryn F. Burke (C,V); Barbara H. Soderling (C,V); Shelly R. Olson (V); Angela M. Wealti (V); Guy F. Somers (V); Kristine A. Dietzman (V); Gene E. Knutson (P); Denise A. Krolnik (P); John C. Peterson (P) Beachwood, OH Retina Associates of Cleveland, Inc. (10) Michael A. Novak (I); Joseph M. Coney (I); David G. Miller (I); Lawrence J. Singerman (I); Larraine Stone (C); Elizabeth McNamara (C,P,V); Trina M. Nitzsche (V); Kimberly A. Dubois (V); Vivian Tanner (V); Tamara L. Cunningham (P); Sheila K. SmithBrewer (P); John C. DuBois (P); Gregg A. Greanoff (P) Boston, MA Joslin Diabetes Center (10) Jennifer K. Sun (I); Lloyd Paul Aiello (I); Deborah K. Schlossman (I); Sabera T. Shah (I); Paul G. Arrigg (I); Paolo S. Silva (I); George S. Sharuk (I); Timothy J. Murtha (I); Margaret E. Stockman (C,V); Julie A. Barenholtz (C,V); Rita K. Kirby (V); Richard M. Calderon (P); Jerry D. Cavallerano (V); John C. BuAbbud (V); Elizabeth S. Weimann (P); Leila Bestourous (V); Robert W. Cavicchi (P); Ann Koplle (C) Lubbock, TX Texas Retina Associates (10) Michel Shami (I); Stephen R. Smith (I); Yolanda Saldivar (C); Phyllis Pusser (C); Ashaki Meeks (V); Natalie R. Garcia (V); Linda Squires (V); Carrie L. Tarter (V); Thom F. Wentlandt (P) Portland, OR Retina Northwest, PC (9) Mark A. Peters (I); Craig A. Lemley (I); Michael S. Lee (I); Irvin L. Handelman (I); Richard F. Dreyer (I); Stephen Hobbs (C,P,V); Dawn A. Brunelle (C,P,V); Marcia Kopfer (V); Wendy Raunig (V); Gina Durbin (V); Howard Daniel (P); Joe Logan (P); Christophe N. Mallet (P); Harry Wohlsein (P) Santa Barbara, CA California Retina Consultants (9) Dante J. Pieramici (I); Ma'an A. Nasir (I); Alessandro A. Castellarin (I); Melvin D. Rabena (C); Jerry Smith (C,V); Amy L. Sterling (V); Debbie Hernandez (V); Kelly Avery (V); Jessica C. Basefsky (V); Liz Tramel (V); Karen Boyer (P); Sarah M. Risard (P); Matthew Giust (P) Winston-Salem, NC Wake Forest University Eye Center (9) Craig Michael Greven (I); Madison M. Slusher (I); Joan Fish (C,V); Cara Everhart $(\mathrm{C}, \mathrm{V})$; Frances Marie Ledbetter (C,V); Lori N. Cooke (C,V); David T. Miller (P); Mark D. Clark (P); Marshall Tyler (P) Augusta, GA Southeast Retina Center, P.C. (8) Dennis M. Marcus (I); Harinderjit Singh (I); Graciela R. Zapata (C); Mari Carrie McAteer (C); Donyale Blair (C); Kasie A. Leverett (V); Catherine Powell (V); Carrie M. Hill (V); Kimbi Y. Overton 
(V); Julie C. Coxville (V); Ken Ivey (P); Victoria Lynne Oldag (P) Fort Myers, FL Retina Consultants of Southwest Florida (8) Thomas A. Ghuman (I); Glenn Wing (I); Joseph P. Walker (I); Paul A. Raskauskas (I); Ashish G. Sharma (I); Richard W. Grodin (I); Cheryl Kiesel (C); Jennifer L. Frederick (C); Eileen Knips (C,P); Cheryl Ryan (C); Crystal Y. Peters (C); Jennifer M. Banks (V); Danielle Dyshanowitz (V); Etienne C. Schoeman (P) Syracuse, NY Retina-Vitreous Surgeons of Central New York, PC (8) Robert G. Hampton (I); Paul F. Torrisi (I); Bryan K. Rutledge (I); Samuel C. Spalding (I); Cindy J. Grinnell (C); Michelle L. Manley (V); Lynn M. Kwasniewski (V); Peter B. Hay (P); Lynn A. Capone (P); Kelly M. Harrison (P) Beverly Hills, CA Retina-Vitreous Associates Medical Group (7) Roger L. Novack (I); David Boyer (I); Homayoun Tabandeh (I); Amanda Tam (C); Saba Mukarram (C); Tamara Gasparyan (C); Jaime K. Gilmour (V); Jackie Sanguinet (V); Julio Sierra (V); Sarah E. Pachman (V); Eric G. Protacio (P); Jeff Kessinger (P); Adam Smucker (P) Chapel Hill, NC University of North Carolina, Dept of Ophthalmology (7) Mary Elizabeth R. Hartnett (I); Travis A. Meredith (I); Seema Garg (I); Odette M. Houghton (I); Cassandra J. Barnhart (C,V); Fatoumatta N'Dure (C,V); Debbie Morck (V); Debra Cantrell (P); Rona Lyn Esquejo (P)

Seattle, WA University of Washington Medical Center (7) James L. Kinyoun (I); Gurunadh Atmaram Vemulakonda (I); Susan A. Rath (C,V); Pendra Kay Burrows (V); Patricia K. Ernst (V); Juli A. Pettingill (V); Brad C. Clifton (P); James D. Leslie (P); Chuck Stephens (P) Boston, MA Ophthalmic Consultants of Boston (6) Trexler M. Topping (I); Tina A. Cleary (I); Lesley-Anne Freese (C,V); Lindsey Williams (C,V); Victoria M. Hurley (C); Paula P. Zand (C); Emily A. Corey (V); Jennifer L. Stone (V); Taneika N. Howard (V); Robin Ty (V); Sandy G. Chong (V); Katie L. Moses (V); Margie Graham (P); Steve A. Bennett (P); Michael Cullen Jones (P) Dubuque, IA Medical Associates Clinic, P.C. (6) Michael H. Scott (I); Philomina M. Wiegman (C); Maureen M. Runde (C); Thomas R. Dvorak (V); Marcia J. Humphrey (P); Brenda L. Tebon (P) Milwaukee, WI Medical College of Wisconsin (6) Judy E. Kim (I); Dennis P. Han (I); David V. Weinberg (I); Thomas B. Connor (I); William Wirostko (I); Kimberly E. Stepien (I); Vesper V. Williams (C); Jeanette Graf (C); Krissa L. Packard (C); Sharon Rekow (C); Dawn Alvarez (C,V); Judy Flanders (V); Vicki Barwick (V); Dennis B. Backes (P); Joseph R. Beringer (P); Kristy L. Keller (P); Kathy J. Selchert (P) Cleveland, OH Case Western Reserve University (5) Suber S. Huang (I); Shawn C. Wilker (I); Johnny Tang, MD (I); Anchal Malik (C); Kathy Carlton (V); Claudia Clow (V); Stephanie Burke (P);

Geoffrey Pankhurst (P); Mark A. Harrod (P) Dallas, TX Texas Retina Associates (5) Gary E. Fish (I); Robert C. Wang (I); Jean Arnwine (C); Carrie L. Tarter (C); Brenda Sanchez (V); Sally Arceneaux (V); Hank Aguado (P); Kimberly Cummings (P); Keith Gray (P); Michael Mackens (P); Betsy L. Hendrix (P); Diana Jaramillo (P) Philadelphia, PA University of Pennsylvania Scheie Eye Institute (5) Alexander J. Brucker (I); Sheri Grand Drossner (C,V); Joan C. DuPont (C,V); Wei Xu (V); Cheryl Devine (P); William Nyberg (P); Laurel Weeney (P); Jim M. Berger (P) San Antonio, TX Retinal Consultants of San Antonio (5) Calvin E. Mein (I); Moises A. Chica (I); Lita Kirschbaum (C,V); Ercilia Riff (C); Marianne F. Tadros (C,P); Christopher Sean Weineke (P); Brenda Nakoski (P) Chicago, IL Illinois Retina Associates, S.C. (4) Mathew W. MacCumber (I); Katherine Lluen-Nunez (C); Chris Droira (V); Joanne Pleskovich (P) Hershey, PA Penn State College of Medicine (4) Kimberly A. Neely (I); Ingrid U. Scott (I); Thomas W. Gardner (I); Susan M. Chobanoff (C,V); Laura E. Walter (V); Mary Hershey (V); James D. Strong (P); Timothy J. Bennett (P) New Albany, IN John-Kenyon American Eye Institute (4) Howard S. Lazarus (I); Debra Paige Bunch (C,V); Angela D. Ridge (C,V); Kelly Booth (V); Jay Moore (P); Margaret Trimble (P) Irvine, CA University of California, Irvine (3) Baruch D. Kuppermann (I); Jeff Grijalva (C); Rosie Magallon (V); Bret Trump (P) Kingsport, TN Southeastern Retina Associates, PC (3) Howard L. Cummings (I); Deanna Jo Long (C,P); Jeni Jill Vermillion (C); Stacy Carpenter (V); Julie P. Berry (P) New York, NY The New York Eye and Ear Infirmary/Faculty Eye Practice (3) Ronald C. Gentile (I); Estuardo Alfonso Ponce (I); Anita Ou (C,V); Peggy Guerrero (C); Catiria Guerrero (V); Jenny M. Gallardo (V); Violete Perez (V); Katy W. Tai (V); Julie A. Paa (V); Dominique Jampol (P); Robert Masini (P); Paul Whitten (P); Wanda 
Carrasquillo-Boyd (P); Kenneth Boyd (P) Palm Desert, CA Southern California Desert Retina Consultants, MC (3) Clement K. Chan (I); David M. Salib (I); Steven G. Lin (I); Asha S.D. Nuthi (I); Kimberly S. Walther (C); Isela Aldana (C); Eric D. Dickerson (C); Lenise E. Myers (V); Sara Warren (V); Sandra U. Castillo (V); Kenneth M. Huff (P); Donna J.

Chesbrough (P) Chicago, IL University of Illinois at Chicago Medical Center (2) Michael Blair (I); Jennifer I. Lim (I); Marcia Niec (C); Tametha Johnson (V); Yesenia Ovando (V); Mark Janowicz (P); Catherine Carroll (P) Denver, CO Denver Health Medical Center (2) Jon M. Braverman (I); Antonio P. Ciardella (I); Hugo Quiroz-Mercado (I); Leif S. Ryman (C); Rosemary C. Rhodes (V); Sasha I. Montalvo (V); Scott R. Harloff (P); Debbie M. Brown (P) Hermitage, PA Vitreo-Retinal Consultants, Inc. (2) Stephen R. Kaufman (I); Marc F.G. Estafanous (I); Kathleen A. Huff (C); Amy E. Lamancusa (C); Rhonda Fill (V); Meagan Peace (V); Denise M. Williams (P) Joliet, IL Illinois Retina Associates (2) John S. Pollack (I); Mathew W. MacCumber (I); Barbara J. Ciscato (C,V); Katherine Lluen-Nunez (C); Belinda M. Kosinski (V); Chris Droira (V); Daniel W. Muir (P); Joanne Pleskovich (P) Portsmouth, NH Eyesight Ophthalmic Services, PA (1) Richard Chace (I); Sunny Kallay (C); Nicole Dolbec (V); Kirsten Stevens (V); Ronda Baker-Hill (V); Janea Halbmaier (P) Providence, RI Retina Consultants (1) Caldwell W. Smith (I); Harold A. Woodcome (I); Edwina Rego (C); Collin L. DuCoty (C); Sylvia Varadian (C); Claudia Salinas (V); Erika Banalewicz (V); Alex L. Nagle (P); Mark Hamel (P)

\section{DRCR.net Coordinating Center}

Jaeb Center for Health Research, Tampa, FL (staff as of 02/10/2010): Adam R. Glassman (Director and Principal Investigator), Roy W. Beck (Executive Director) Talat Almukhtar, Bambi J. Arnold, Brian B. Dale, Alyssa Baptista, Lina Caicedo, Sharon R. Constantine, Simone S. Dupre, Allison R. Edwards, Lauren Huffman, Meagan L. Huggins, Paula A. Johnson, Lee Anne Lester, Brenda L. Loggins, Shannon L. McClellan, Michele Melia, Kellee M. Miller, Pamela S. Moke, Haijing Qin, Rosa Pritchard, Eureca Scott, Cynthia R. Stockdale, Emily Williams

\section{Fundus Photograph Reading Center}

University of Wisconsin-Madison, Madison, WI (staff as of 02/10/10): Matthew D. Davis (Director Emeritus), Ronald P. Danis (Director and Principal Investigator), Larry Hubbard (Associate Director), James Reimers (Lead Color Photography Evaluator), Pamela Vargo (Lead Photographer), Ericka Moeller (Digital Imaging Specialist), Dawn Myers (Lead OCT Evaluator), Kristjan Burmeister (Project Manager)

\section{DRCR.net Operations Center}

Johns Hopkins University School of Medicine, Baltimore, MD (staff as of February 10, 2010): Neil M. Bressler (Network Chair and Principal Investigator), Connie Lawson, Peggy R. Orr.

\section{DRCR.net Vice Chairs}

Susan B. Bressler (2009-current), Scott Friedman (2009-current), Ingrid U. Scott (2009Current).

\section{National Eye Institute}

Eleanor Schron (2009-current), Donald F. Everett (2003-2006, 2007-2009), Päivi H. Miskala (2006-2007) 


\title{
Executive Committee
}

Raj K. Maturi (2009-present; Chair 2010) Neil M. Bressler (2006-Current; Chair 2006-2008), Lloyd Paul Aiello (2002-present; Chair 2002-2005), Carl Baker (2009-present), Roy W. Beck (2002-present), Susan B. Bressler (2009-Present), Alexander J. Brucker (2009-present), Kakarla V. Chalam (2009-present), Ronald P. Danis (2004-present), Matthew D. Davis (2002present), Michael J. Elman (2006-present; Chair 2009), Frederick L. Ferris III (2002-present), Scott Friedman (2007-present), Adam R. Glassman (2005-present), Joseph Googe, Jr. (2009present), Eleanor Schron (2009-present), Ingrid U. Scott (2009-Present), JoAnn Starr (2009present), Jennifer K. Sun (2009-present). Prior Members: Andrew N. Antoszyk (2009), Abdhish Bhavsar (2007-2008), David M. Brown (2006-2007), David J. Browning (20052006), Donald F. Everett (2002-2009), Joan Fish (2008-2009), Andreas Lauer (2007-2008), Kim McLeod (2002-2006), Päivi H. Miskala (2005-2007), Cynthia J. Grinnell (2006-2007).

\section{DRCR.net Data and Safety Monitoring Committee}

John Connett, (Chair 2003-Current), Deborah Barnbaum (2006-Current), Harry W. Flynn, Jr. (2003-Current), Robert N. Frank (2003-Current), Saul Genuth (2003-Current), Lee Jampol (2003-Current), Stephen Wisniewski (2003-Current),

Prior Member: Jeanette Resnick (2003-2006)

\section{Prior DRCR.net VEGF Steering Committee Members}

Alexander J. Brucker (2007-2008), Michael J. Elman (2007-2008), Joseph Googe, Jr. (2008), Lloyd P. Aiello (2006-2008), Roy W. Beck (2006-2008), Neil M. Bressler (2006-2008), Kakarla V. Chalam (2008), Ronald P. Danis (2006-2008), Donald F. Everett (2006-2008), Frederick L. Ferris III (2006-2008), Adam Glassman (2006-2008), Tina Higdon (2008), Abdhish Bhavsar (2006-2007), David Browning (2006-2008), Peter Campochiaro (20062007), Joan Fish (2006-2007), Scott M. Friedman (2006-2008), Mary Elizabeth R. Hartnett (2006-2007), Raj Maturi (2008-2008), Päivi Miskala (2006-2007), Ingrid Scott (2006-2008).

\section{Acknowledgments}

Supported through a cooperative agreement from the National Eye Institute and the National Institute of Diabetes and Digestive and Kidney Diseases, National Institutes of Health, Department of Health and Human Services EY14231, EY14229, and EY018817.

\begin{abstract}
The funding organization (National Institutes of Health) participated in oversight of the conduct of the study and review of the manuscript but not directly in the design or conduct of the study; the collection, management, analysis, or interpretation of the data; or the preparation of the manuscript. Genentech provided the ranibizumab for the study, and Allergan, Inc., provided the triamcinolone for the study. In addition, Genentech and Allergan, Inc., provided funds to the DRCR.net to defray the study's clinical site costs. As described in the DRCR.net Industry Collaboration Guidelines (available at www.drcr.net), the DRCR.net had complete control over the design of the protocol, the ownership of the data, and all editorial content of presentations and publications related to the protocol. A complete list of all DRCR.net investigator financial disclosures can be found at www.drcr.net.
\end{abstract}

Neil M. Bressler:

Grants to investigators at The Johns Hopkins University are negotiated and administered by the institution (e.g., the School of Medicine) that receives the grants, typically through the Office of Research Administration. Individual investigators who participate in the sponsored project(s) are not directly compensated by the sponsor but may receive salary or other support from the institution to support their effort on the projects(s).

Dr. Neil M. Bressler is Principal Investigator of grants at The Johns Hopkins University sponsored by the following entities (not including the National Institutes of Health): Allergan, Bausch \& Lomb, Carl Zeiss Meditec, EMMES Corporation, Genentech, Lumenis, Notal Vision Ltd.,* Novartis, QLT, Regeneron, Steba Biotech, Abbott Medical Optics, ForSight Labs, LLC, and Genzyme Corporation. Dr. Susan B. Bressler's consulting arrangement with Notal 
Vision in connection with Dr. Neil M. Bressler's role as principal investigator on a Notal Vision-sponsored research grant has been reviewed and managed by The Johns Hopkins University School of Medicine in accordance with its conflict of interest policy.

\section{References}

1. Klein R, Klein BE, Moss SE, et al. The Wisconsin Epidemiologic Study of Diabetic Retinopathy. IV Diabetic macular edema. Ophthalmology 1984;91:1464-74. [PubMed: 6521986]

2. Moss SE, Klein R, Klein BE. The 14-year incidence of visual loss in a diabetic population. Ophthalmology 1998;105:998-1003. [PubMed: 9627648]

3. Moss SE, Klein R, Klein BE. Ten-year incidence of visual loss in a diabetic population. Ophthalmology 1994;101:1061-70. [PubMed: 8008348]

4. Early Treatment Diabetic Retinopathy Study Research Group. Photocoagulation for diabetic macular edema: Early Treatment Diabetic Retinopathy Study report number 1. Arch Ophthalmol 1985;103:1796-806. [PubMed: 2866759]

5. Diabetic Retinopathy Clinical Research Network. A randomized trial comparing intravitreal triamcinolone acetonide and focal/grid photocoagulation for diabetic macular edema. Ophthalmology 2008;115:1447-59. [PubMed: 18662829]

6. Aiello LP, Avery RL, Arrigg PG, et al. Vascular endothelial growth factor in ocular fluid of patients with diabetic retinopathy and other retinal disorders. N Engl J Med 1994;331:1480-7. [PubMed: 7526212]

7. Antonetti DA, Barber AJ, Hollinger LA, et al. Vascular endothelial growth factor induces rapid phosphorylation of tight junction proteins occludin and zonula occluden 1: a potential mechanism for vascular permeability in diabetic retinopaty and tumors. J Bio Chem 1999;274:23463-7. [PubMed: 10438525]

8. Macugen Diabetic Retinopathy Study Group. Changes in retinal neovascularization after pegaptanib (Macugen) therapy in diabetic individuals. Ophthalmology 2006;113:23-8. [PubMed: 16343627]

9. Nguyen QD, Shah SM, Heier JS, et al. READ-2 Study Group. Primary end point (six months) results of the Ranibizumab for Edema of the mAcula in Diabetes (READ-2) Study. Ophthalmology 2009;116:2175-81. [PubMed: 19700194]

10. Kang SW, Sa HS, Cho HY, Kim JI. Macular grid photocoagulation after intravitreal triamcinolone acetonide for diffuse diabetic macular edema. Arch Ophthalmol 2006;124:653-8. [PubMed: 16682586]

11. Beck RW, Moke PS, Turpin AH, et al. A computerized method of visual acuity testing: adaptation of the Early Treatment of Diabetic Retinopathy Study testing protocol. Am J Ophthalmol 2003;135:194-205. [PubMed: 12566024]

12. Diabetic Retinopathy Clinical Research Network. Relationship between optical coherence tomography-measured central retinal thickness and visual acuity in diabetic macular edema. Ophthalmology 2007;114:525-36. [PubMed: 17123615]

13. Early Treatment Diabetic Retinopathy Study Research Group. Fundus photographic risk factors for progression of diabetic retinopathy. ETDRS report number 12. Ophthalmology 1991;98(suppl):82333. [PubMed: 2062515]

14. Little, RJ.; Rubin, DB.; Barnett, V. Wiley Series in Probability and Mathematical Statistics. New York: Wiley; 1987. Statistical analysis with missing data; p. 255-9.

15. Moradian S, Ahmadieh H, Malihi M, et al. Intravitreal bevacizumab in active progressive proliferative diabetic retinopathy. Graefes Arch Clin Exp Ophthalmol 2008;246:1699-705. [PubMed: 18696095]

16. Arevalo JF, Maia M, Flynn HW Jr, et al. Tractional retinal detachment following intravitreal bevacizumab (Avastin) in patients with severe proliferative diabetic retinopathy. Br J Ophthalmol 2008;92:213-6. [PubMed: 17965108]

17. Laser-Ranibizumab-Triamcinolone for Proliferative Diabetic Retinopathy (LRTforDME+PRP). [January 5, 2010]. ClinicalTrials.govNCT00445003. Available at: http://public.drcr.net/Studies.aspx?ReclD5147

18. Sabet-Peyman EJ, Heussen FM, Thorne JE, et al. Progression of macular ischemia following intravitreal bevacizumab. Ophthalmic Surg Lasers Imaging 2009;40:316-8. [PubMed: 19485300] 
19. Ockrim ZK, Sivaprasad S, Falk S, et al. Intravitreal triamcinolone versus laser photocoagulation for persistent diabetic macular oedema. Br J Ophthalmol 2008;92:795-9. [PubMed: 18420749]

20. Gillies MC, Sutter FK, Simpson JM, et al. Intravitreal triamcinolone for refractory diabetic macular edema: two-year results of a double-masked, placebo-controlled, randomized clinical trial. Ophthalmology 2006;113:1533-8. [PubMed: 16828501]

21. Martidis A, Duker JS, Greenberg PB, et al. Intravitreal triamcinolone for refractory diabetic macular edema. Ophthalmology 2002;109:920-7. [PubMed: 11986098]

22. Diabetic Retinopathy Clinical Research Network. A phase II randomized clinical trial of intravitreal bevacizumab for diabetic macular edema. Ophthalmology 2007;114:1860-7. [PubMed: 17698196]

23. Efficacy and safety of ranibizumab (intravitreal injections) in patients with visual impairment due to diabetic macular edema (RESTORE). [January 5, 2010]. ClinicalTrials.govNCT00687804. Available at: http://www.clinicaltrials.gov/ct2/show/NCT00687804?term=nct00687804

24. A study of ranibizumab injection in subjects with clinically significant macular edema with center involvement secondary to diabetes mellitus (RIDE). [January 5, 2010].

ClinicalTrials.govNCT00473382. Available at: http://www.clinicaltrials.gov/ct2/show/NCT00473382?term=NCT00473382

25. A study of ranibizumab injection in subjects with clinically significant macular edema with center involvement secondary to diabetes mellitus (RISE). [January 5, 2010].

ClinicalTrials.govNCT00473330. Available at: http://www.clinicaltrials.gov/ct2/show/NCT00473330

26. Fong DS, Strauber SF, Aiello LP, et al. Writing Committee for the Diabetic Retinopathy Clinical Research Network. Comparison of the modified Early Treatment Diabetic Retinopathy Study and mild macular grid laser photocoagulation strategies for diabetic macular edema. Arch Ophthalmol 2007;125:469-80. [PubMed: 17420366] 


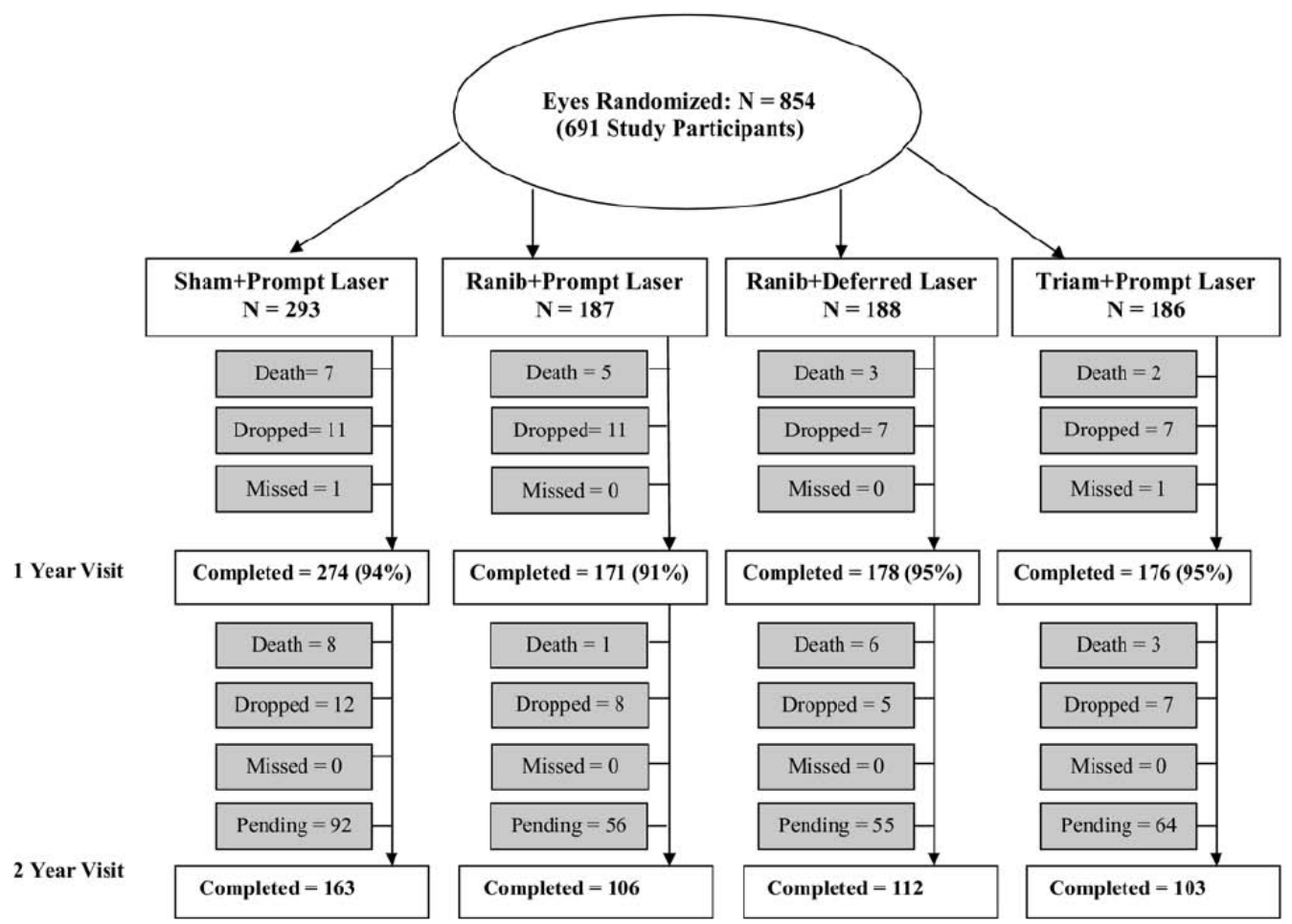

Figure 1.

Completion of follow-up for study eyes. One-year completed visits include those that occurred between 308 and 420 days (between 44 and 60 weeks) from randomization. Two-year completed visits include those that occurred between 616 and 840 days (between 88 and 120 weeks) from randomization. Ranib $=$ ranibizumab; Triam $=$ triamcinolone. 


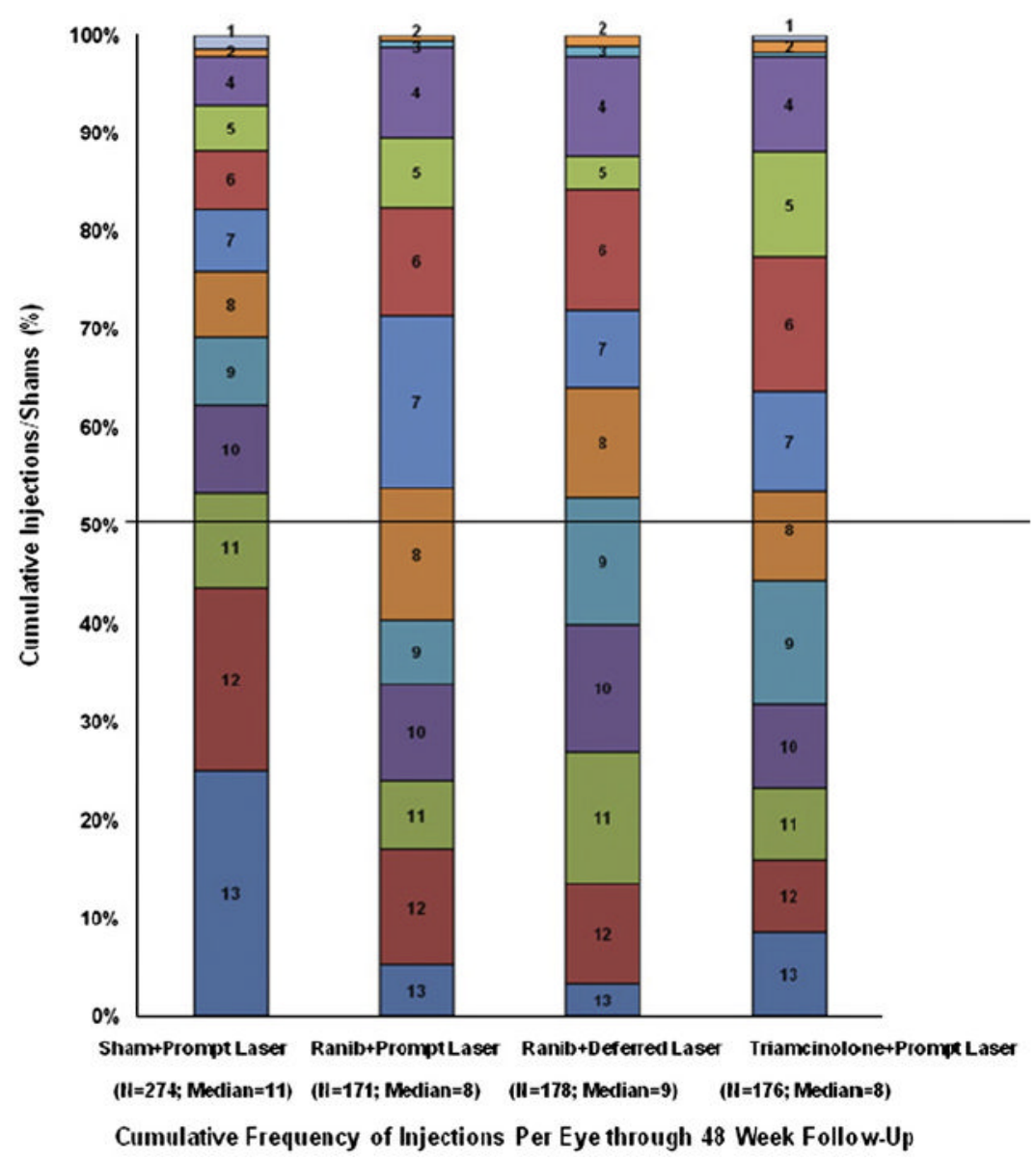

Figure 2.

Cumulative distribution of injections/sham with randomized assigned treatment before the 52week study visit. Includes eyes that completed the 52-week study visit; 56 eyes in sham group with other eye in the ranibizumab + deferred laser group are not included in figure because they were unmasked and a sham injection was not required per protocol. There were 13 possible sham or study drug injections. Study drug injections and sham injections included a baseline treatment and monthly retreatments through 12 weeks. After 16 weeks, eyes assigned to one of the ranibizumab groups could receive ranibizumab as often as every 4 weeks; eyes assigned to intravitreal triamcinolone could receive triamcinolone as often as every 16 weeks with sham injections as often as every 4 weeks in between triamcinolone injections; eyes assigned to sham + prompt laser could receive sham injections as often as every 4 weeks. Of 503 injections given in triamcinolone group before 1 year, $36 \%$ were triamcinolone injections. Ranib = ranibizumab. 


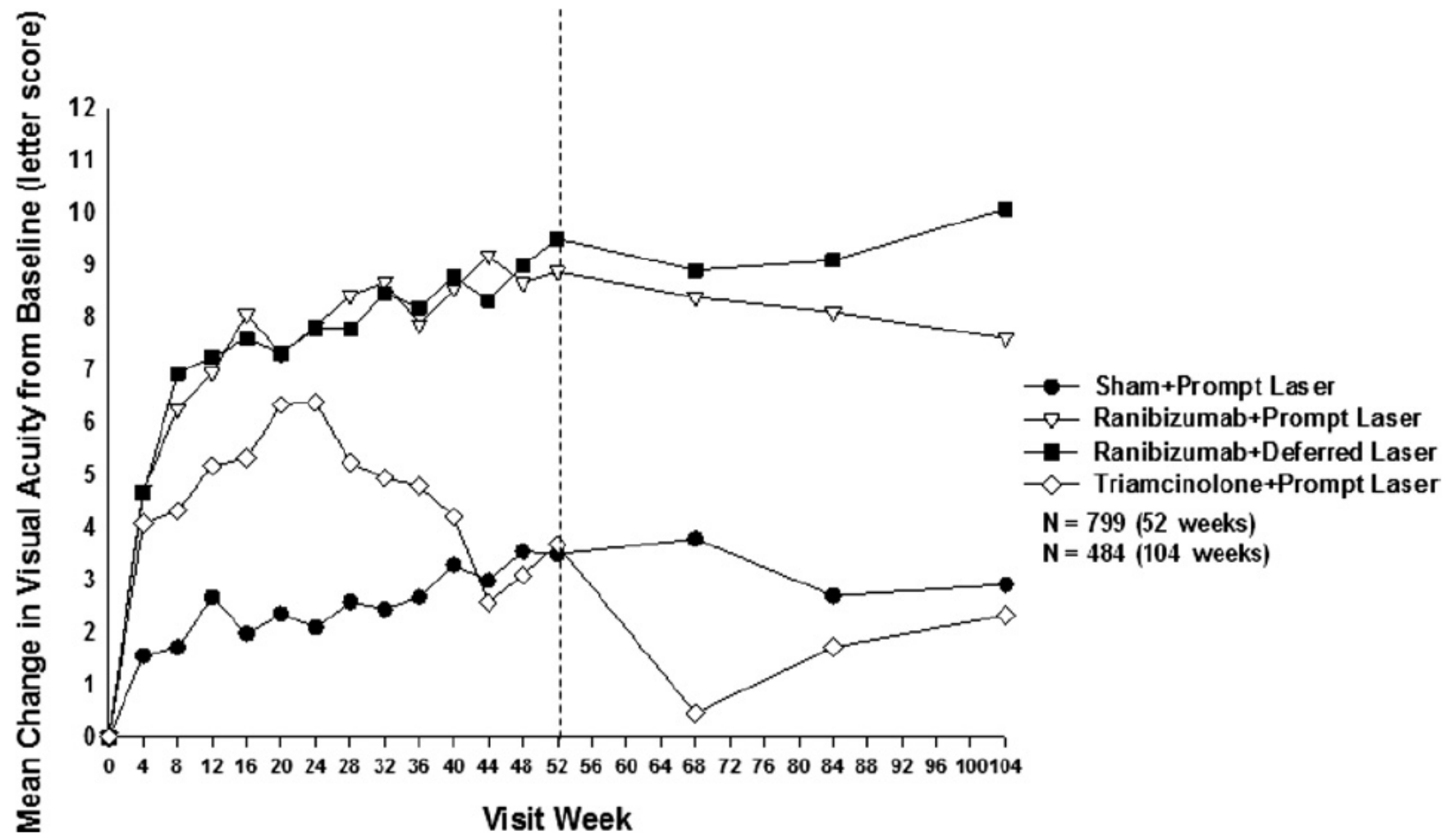

Figure 3.

Mean change in visual acuity at follow-up visits. Values that were \pm 30 letters were assigned a value of 30. $P$ values for difference in mean change in visual acuity from sham + prompt laser at 52 weeks: ranibizumab + prompt laser $<0.001$, ranibizumab + deferred laser $<0.001$, and triamcinolone + prompt laser groups $=0.31$. Each visit week includes visits that are \pm 14 days, except the 52-week visit, which includes visits that occur between 308 and 420 days (between 44 and 60 weeks) from randomization, and the 104-week visit, which includes visits that occur between 616 and 840 days (between 88 and 120 weeks) from randomization. 


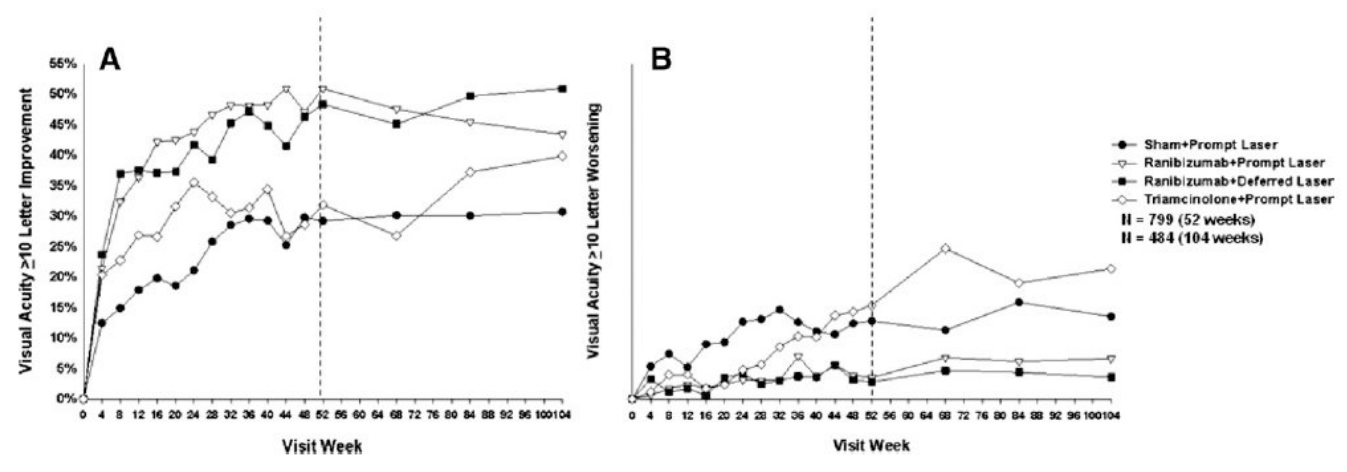

Figure 4.

A, Ten letter or greater improvement in visual acuity at follow-up visits. $P$ values for difference in proportion of $\geq 10$ letter improvement in visual acuity from sham + prompt laser at the 52week visit: ranibizumab + prompt laser $<0.001$, ranibizumab + deferred laser <0.001, and triamcinolone + prompt laser $=0.16$. Each visit week includes visits that are \pm 14 days, except the 52-week visit, which includes visits that occur between 308 and 420 days (between 44 and 60 weeks) from randomization, and the 104-week visit, which includes visits that occur between 616 and 840 days (between 88 and 120 weeks) from randomization. B, Ten letter or greater loss in visual acuity at follow-up visits. $P$ values for difference in proportion of 10 letter loss in visual acuity from sham + prompt laser at the 52-week visit: ranibizumab + prompt laser $<0.001$, ranibizumab + deferred laser $<0.001$, and triamcinolone + prompt laser $=0.75$. Each visit week includes visits that are \pm 14 days, except the 52 -week visit, which includes visits that occur between 308 and 420 days (between 44 and 60 weeks) from randomization, and the 104-week visit, which includes visits that occur between 616 and 840 days (between 88 and 120 weeks) from randomization. 


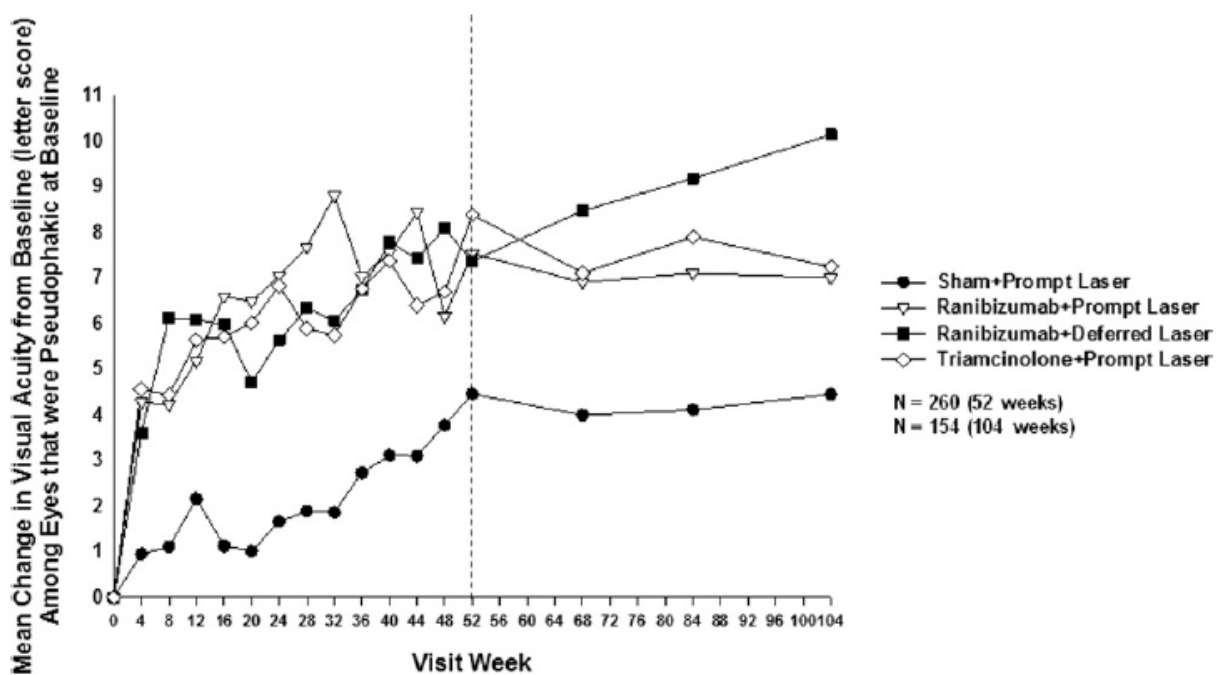

Figure 5.

Mean change in visual acuity at follow-up visits among eyes that were pseudophakic at baseline. Values of \pm 30 or more letters were assigned a value of 30 . Each visit week includes visits that are \pm 14 days, except the 52-week visit, which includes visits that occur between 308 and 420 days (between 44 and 60 weeks) from randomization, and the 104-week visit, which includes visits that occur between 616 and 840 days (between 88 and 120 weeks) from randomization. 


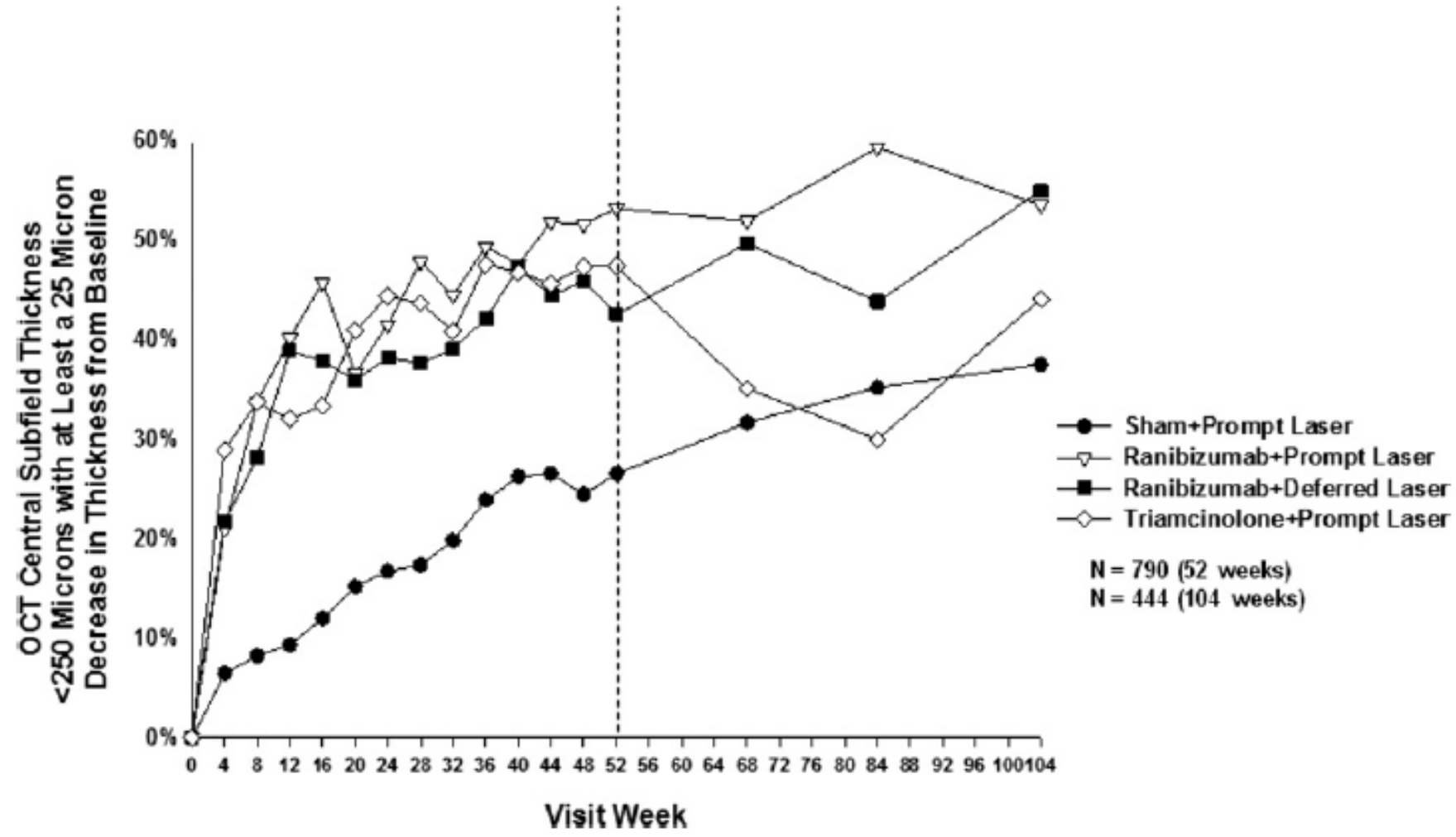

Figure 6.

Optical coherence tomography central subfield thickness $<250 \mu \mathrm{m}$ with at least a $25 \mu \mathrm{m}$ decrease in thickness from baseline at follow-up visits. $P$ values for difference in proportion in OCT central subfield thickness $<250 \mu \mathrm{m}$ with at least a $25 \mu \mathrm{m}$ decrease in thickness from sham + prompt laser at the 52-week visit: ranibizumab + prompt laser $<0.001$, ranibizumab + deferred laser $=0.001$, and triamcinolone + prompt laser $<0.001$. Each visit week includes visits that are \pm 14 days, except the 52-week visit, which includes visits that occur between 308 and 420 days (between 44 and 60 weeks) from randomization, and the 104-week visit, which includes visits that occur between 616 and 840 days (between 88 and 120 weeks) from randomization. $\mathrm{OCT}=$ optical coherence tomography. 


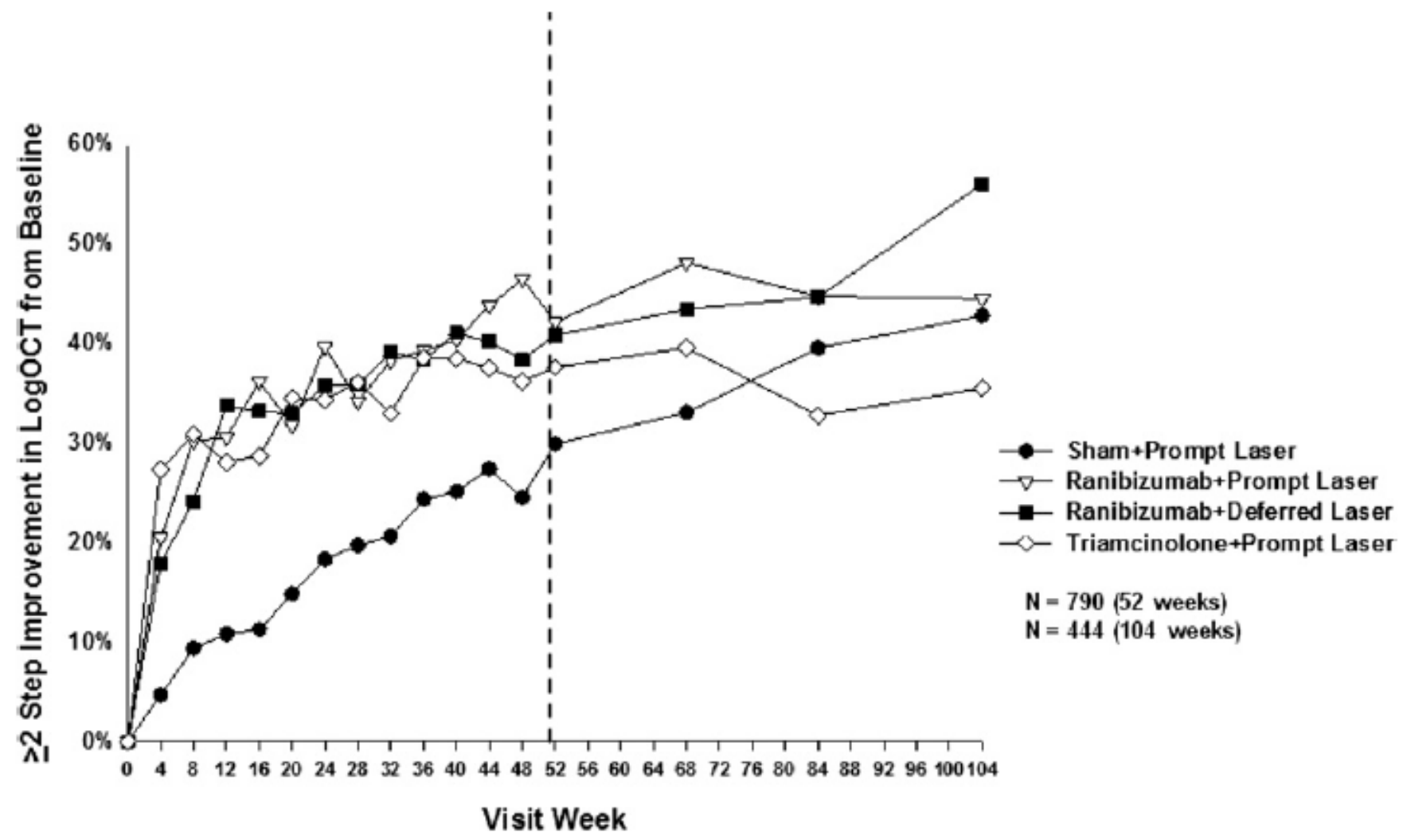

Figure 7.

Two or more step improvement in the logarithmic transformation of OCT central subfield thickness from baseline. Each visit week includes visits that are \pm 14 days, except the 52-week visit, which includes visits that occur between 308 and 420 days (between 88 and 120 weeks) from randomization, and the 104-week visit, which includes visits that occur between 616 and 840 days (between 88 and 120 weeks) from randomization. $\log \mathrm{OCT}=\log$ arithmic transformation of optical coherence tomography calculated by taking the log base 10 of the ratio of the central subfield thickness divided by 200 and rounded to the nearest hundredth. (Ferris FL III, Miller KM, Glassman AR, Beck RW. A proposed method of logarithmic transformation of optical coherence tomography data for use in clinical research.

Ophthalmology. In Press.) 


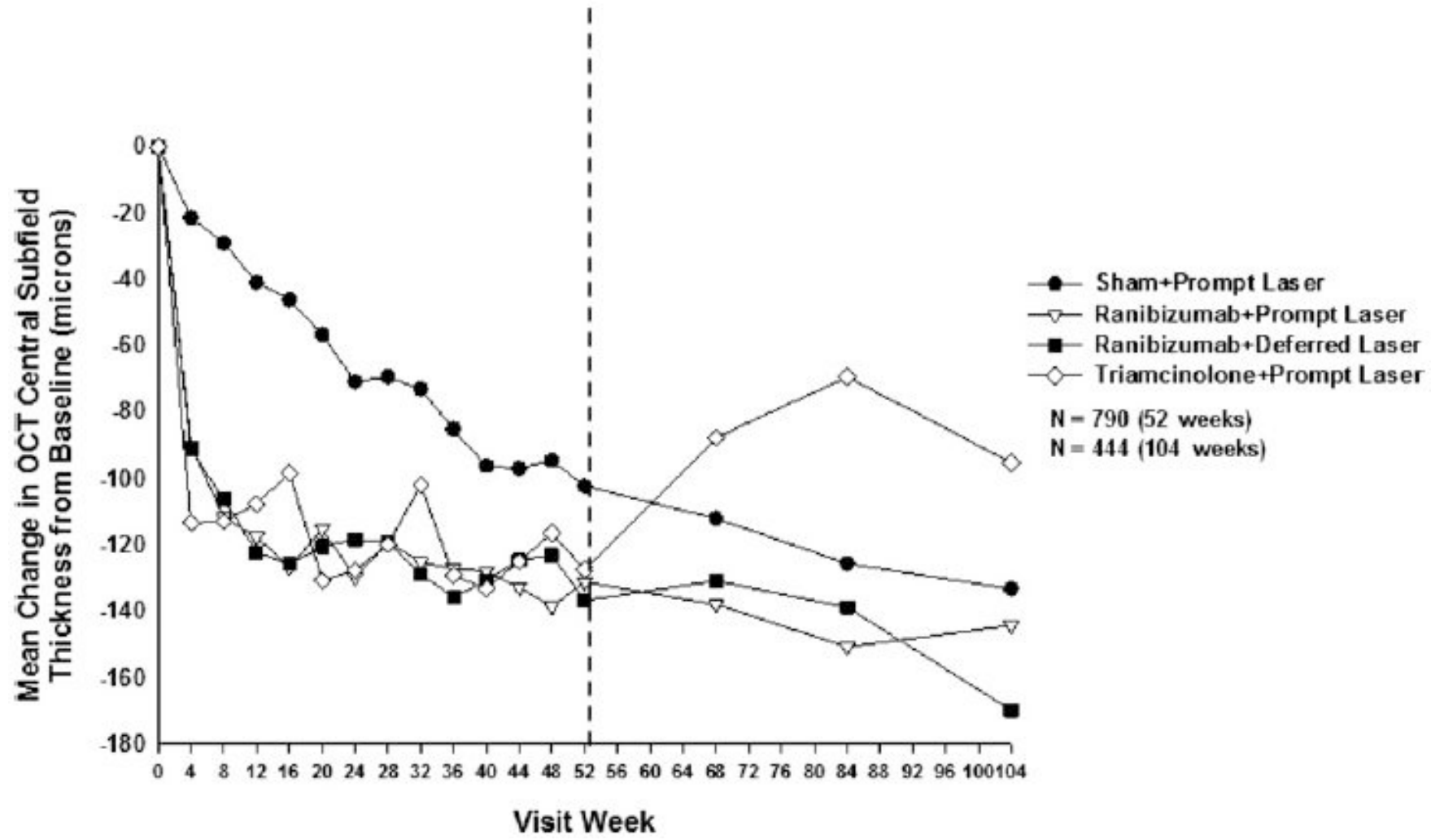

Figure 8.

Mean change in OCT central subfield retinal thickening at follow-up visits. $P$ values for difference in mean change in OCT central subfield retinal thickness from sham + prompt laser at the 52-week visit: ranibizumab + prompt laser $<0.001$, ranibizumab + deferred laser $<0.001$, and triamcinolone + prompt laser $<0.001$. Each visit week includes visits that are \pm 14 days, except the 52-week visit, which includes visits that occur between 308 and 420 days (between 44 and 60 weeks) from randomization, and the 104-week visit, which includes visits that occur between 616 and 840 days (between 88 and 120 weeks) from randomization. OCT = optical coherence tomography. 


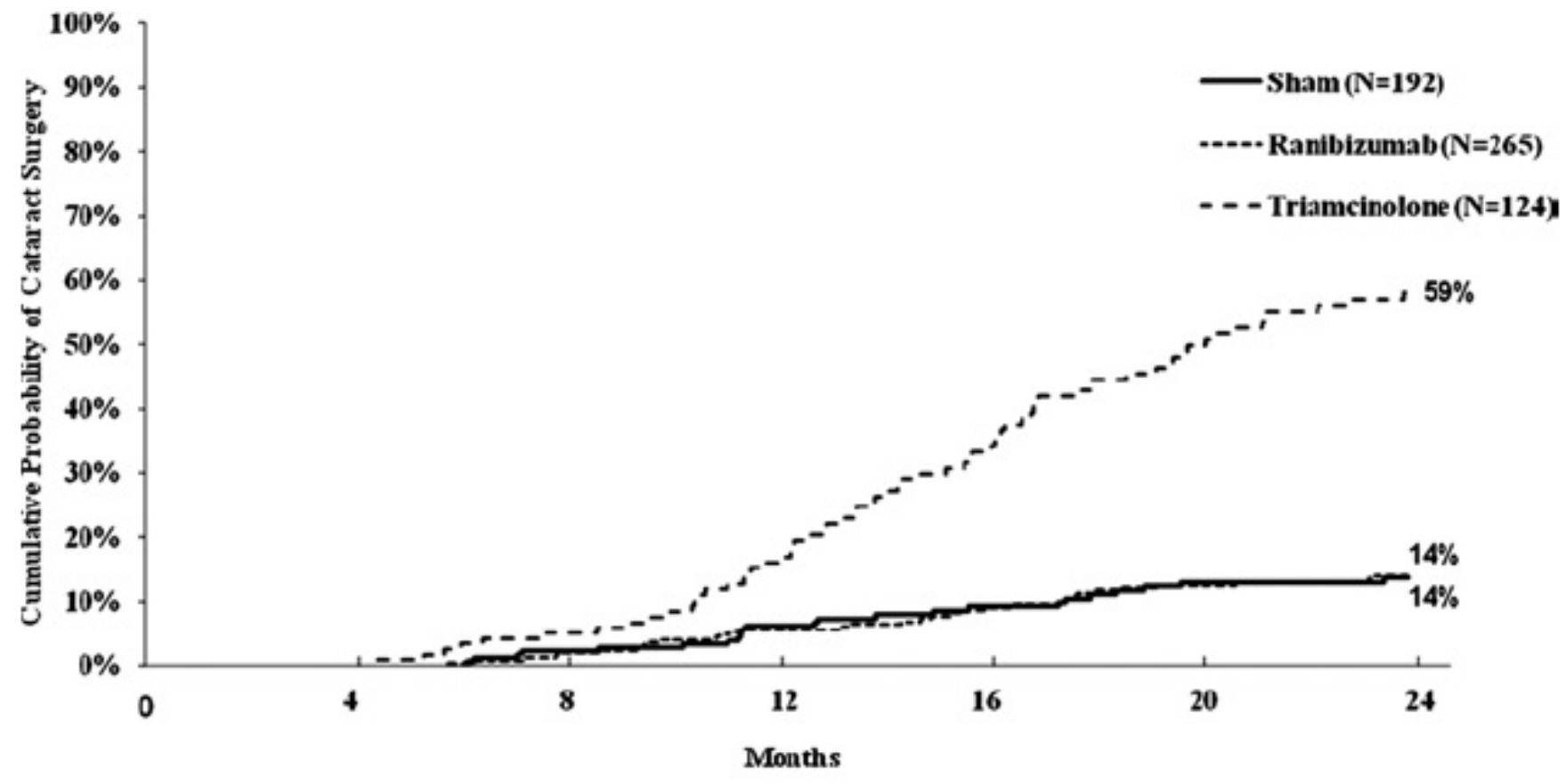

Sham

\# eyes at risk ${ }^{\star} \quad 192$

\# cataract sur geries*^ 0

Ranibizumab

\# eyes at risk* 265

\# catnract surgeries ${ }^{\star \wedge} 0$

Triamennolme

\# eyes at risk ${ }^{n}$

\# cataract surgeries ${ }^{\text {* }}$ 0

$\begin{array}{ll}183 & 174 \\ 4 & 7 \\ 252 & 242 \\ 5 & 9 \\ & \\ 120 & 112 \\ 6 & 13\end{array}$

174

242

112

13
163

5

231

8

93

20
148

6

213

8

77

19
140

1

201

3

57

10

Figure 9.

Cumulative probability of cataract surgery through 2 years of follow-up for all eyes phakic at baseline. Eyes pending a 2-year visit or that were lost to follow-up were censored at their last visit. $\mathrm{N}$ is the number of eyes phakic at baseline. *Number of eyes at the start of the interval without previous cataract surgery. **Number of eyes with cataract surgery during the subsequent 4-month period. 
Table 1

Diabetic Retinopathy Clinical Research Network Definitions for Laser-Ranibizumab-Triamcinolone Treatment for Diabetic Macular Edema

\begin{tabular}{|c|c|}
\hline Term & Definition \\
\hline Sham + Prompt Laser group & $\begin{array}{l}\text { Eyes assigned to receive sham injection plus prompt (within one week) focal/grid } \\
\text { photocoagulation }\end{array}$ \\
\hline Ranibizumab + Prompt Laser group & $\begin{array}{l}\text { Eyes assigned to receive } 0.5 \mathrm{mg} \text { intravitreal ranibizumab plus prompt (within one } \\
\text { week) focal/grid photocoagulation }\end{array}$ \\
\hline Ranibizumab + Deferred Laser group & $\begin{array}{l}\text { Eyes assigned to receive } 0.5 \mathrm{mg} \text { intravitreal ranibizumab with deferred ( } \geq 24 \text { weeks) } \\
\text { focal/grid photocoagulation }\end{array}$ \\
\hline Triamcinolone + Prompt Laser group & $\begin{array}{l}\text { Eyes assigned to receive } 4 \mathrm{mg} \text { intravitreal triamcinolone plus prompt (within one } \\
\text { week) focal/grid photocoagulation }\end{array}$ \\
\hline Focal/grid laser & Focal/grid photocoagulation administered using modified ETDRS protocol \\
\hline 'Complete laser' & $\begin{array}{l}\text { Direct treatment to all microaneurysms within areas of macular edema and grid } \\
\text { treatment to all other areas of macular edema }\end{array}$ \\
\hline 'Success' criteria relative to retreatment decisions & $\begin{array}{l}\text { Either visual acuity letter score } \geq 84(20 / 20) \text { or OCT central subfield thickness }<250 \\
\text { microns since the last non-sham injection or since baseline for the sham+prompt } \\
\text { laser group }\end{array}$ \\
\hline 'Improvement' criteria relative to retreatment decisions & $\begin{array}{l}\text { Either visual acuity improved by } \geq 5 \text { letters or OCT central subfield thickness } \\
\text { improved by } \geq 10 \% \text { since the last non-sham injection or since baseline for the sham } \\
\text { +prompt laser group }\end{array}$ \\
\hline 'No improvement' criteria relative to retreatment decisions & $\begin{array}{l}\text { Success and failure/futility criteria not met and visual acuity letter score improved } \\
\text { by }<5 \text { letters (or worsened) and OCT central subfield thickness decreased by }<10 \% \\
\text { (or increased) since the last non-sham injection or since baseline for the sham } \\
\text { +prompt laser group }\end{array}$ \\
\hline 'Failure' criteria relative to retreatment decisions & $\begin{array}{l}\text { Visual acuity } 10 \text { or more letters worse than baseline, OCT central subfield thickness } \\
\geq 250 \text { um, DME judged to be the cause of visual acuity loss, and at least } 13 \text { weeks } \\
\text { since 'complete laser' had been given with 'no improvement' since the last laser } \\
\text { treatment }\end{array}$ \\
\hline 'Futility' criteria relative to retreatment decisions & $\begin{array}{l}\text { After } 52 \text { week visit: OCT central subfield } \geq 250 \text { um, DME judged to be the cause of } \\
\text { visual acuity loss, and at least } 29 \text { weeks since 'complete laser' had been given with } \\
\text { 'no improvement' since the last laser treatment }\end{array}$ \\
\hline 'Extended follow-up' & $\begin{array}{l}\text { After } 52 \text { week visit: Follow-up visit in twice the time interval since the last visit, up } \\
\text { to a maximum of } 16 \text { weeks between study visits (applies to eyes assigned to } \\
\text { ranibizumab in which the injection was repeatedly deferred either due to 'success' } \\
\text { or 'no improvement') }\end{array}$ \\
\hline 'Alternative treatment' & Treatment for DME other than the randomization-assigned regimen \\
\hline 'Edema involving the center of the macula' & OCT central subfield thickness $\geq 250$ um \\
\hline 'Edema threatening the center of the macula' & $\begin{array}{l}\text { Edema on clinical exam within } 500 \text { microns of the foveal center or edema associated } \\
\text { with lipid within } 500 \text { microns of the foveal center or } 1 \text { disc area of edema within } 1 \\
\text { disc area of the foveal center }\end{array}$ \\
\hline
\end{tabular}

$\mathrm{DME}=$ diabetic macular edema; ETDRS $=$ Early Treatment Diabetic Retinopathy Study; OCT = optical coherence tomography. 
Table 2

Baseline Study Participant and Ocular Characteristics

\begin{tabular}{|c|c|c|c|c|}
\hline & $\begin{array}{l}\text { Sham + Prompt } \\
\text { Laser N = 293 }\end{array}$ & $\begin{array}{c}\text { Ranibizumab + } \\
\text { Prompt Laser N = } \\
187\end{array}$ & $\begin{array}{c}\text { Ranibizumab }+ \\
\text { Deferred Laser } N= \\
188\end{array}$ & $\begin{array}{c}\text { Triamcinolone + } \\
\text { Prompt Laser N = } \\
186\end{array}$ \\
\hline Women, no. (\%) & $123(42 \%)$ & $85(45 \%)$ & $78(41 \%)$ & $86(46 \%)$ \\
\hline Age (yrs) Median (25th, 75th percentile) & $63(57,69)$ & $62(56,70)$ & $64(58,70)$ & $62(55,70)$ \\
\hline \multicolumn{5}{|l|}{ Race, no. (\%) } \\
\hline White & $202(69 \%)$ & $131(70 \%)$ & $134(71 \%)$ & $134(72 \%)$ \\
\hline African-American & $51(17 \%)$ & $30(16 \%)$ & $25(13 \%)$ & $32(17 \%)$ \\
\hline Hispanic or Latino & $34(12 \%)$ & $21(11 \%)$ & $25(13 \%)$ & $15(8 \%)$ \\
\hline Asian & $4(1 \%)$ & $1(1 \%)$ & $2(1 \%)$ & $4(2 \%)$ \\
\hline Native Hawaiian/Other Pacific Islander & 0 & $1(1 \%)$ & 0 & 0 \\
\hline More than one race & $1(<1 \%)$ & $1(1 \%)$ & $1(1 \%)$ & 0 \\
\hline Unknown/ not reported & $1(<1 \%)$ & $2(1 \%)$ & $1(1 \%)$ & $1(1 \%)$ \\
\hline \multicolumn{5}{|l|}{ Diabetes type, no. (\%) } \\
\hline Type 1 & $25(9 \%)$ & $11(6 \%)$ & $15(8 \%)$ & $14(8 \%)$ \\
\hline Type 2 & $260(89 \%)$ & $172(92 \%)$ & $170(90 \%)$ & $166(89 \%)$ \\
\hline Uncertain & $8(3 \%)$ & $4(2 \%)$ & $3(2 \%)$ & $6(3 \%)$ \\
\hline $\begin{array}{l}\text { Duration of diabetes (yrs) Median (25th, 75th } \\
\text { percentile) }\end{array}$ & $16(9,22)$ & $18(12,24)$ & $17(11,22)$ & $17(11,24)$ \\
\hline HbA1c Median (25th, 75th percentile) ${ }^{*}$ & $7.3(6.6,8.3)$ & $7.3(6.6,8.4)$ & $7.5(6.7,8.4)$ & $7.4(6.5,8.6)$ \\
\hline Prior cardiovascular event, no. $(\%)^{\dagger}$ & $93(32 \%)$ & $66(35 \%)$ & $61(32 \%)$ & $61(33 \%)$ \\
\hline Hypertension, no. $(\%)^{\dagger}$ & $240(82 \%)$ & $154(82 \%)$ & $156(83 \%)$ & $148(80 \%)$ \\
\hline \multicolumn{5}{|l|}{ Number of study eyes, no. (\%) } \\
\hline 1 study eye & $130(44 \%)$ & $131(70 \%)$ & $132(70 \%)$ & $135(73 \%)$ \\
\hline 2 study eyes & $163(56 \%)$ & $56(30 \%)$ & $56(30 \%)$ & $51(27 \%)$ \\
\hline Prior panretinal photocoagulation, no. (\%) & $48(16 \%)$ & $36(19 \%)$ & $31(16 \%)$ & $37(20 \%)$ \\
\hline No prior treatment for DME, no. (\%) & $105(36 \%)$ & $74(40 \%)$ & $74(39 \%)$ & $61(33 \%)$ \\
\hline Prior laser for DME, no. (\%) & $173(59 \%)$ & $101(54 \%)$ & $101(54 \%)$ & $114(61 \%)$ \\
\hline Prior IVT for DME, no. (\%) & $39(13 \%)$ & $22(12 \%)$ & $36(19 \%)$ & $31(17 \%)$ \\
\hline Prior vitrectomy for DME, no. (\%) & $15(5 \%)$ & $7(4 \%)$ & $5(3 \%)$ & $12(6 \%)$ \\
\hline $\begin{array}{l}\text { Prior peribulbar triamcinolone for DME, } \\
\text { no. }(\%)\end{array}$ & $12(4 \%)$ & $9(5 \%)$ & $5(3 \%)$ & $5(3 \%)$ \\
\hline Prior anti-VEGF for DME, no. (\%) & $24(8 \%)$ & $24(13 \%)$ & $21(11 \%)$ & $20(11 \%)$ \\
\hline $\begin{array}{l}\text { Intraocular pressure (mmHg) Median (25th, } \\
\text { 75th percentile) }\end{array}$ & $16(14,18)$ & $16(14,18)$ & $16(14,18)$ & $16(14,18)$ \\
\hline $\begin{array}{l}\text { Currently on IOP lowering medicine for } \\
\text { glaucoma or ocular hypertension, no. (\%) }\end{array}$ & $5(2 \%)$ & $6(3 \%)$ & $4(2 \%)$ & $2(1 \%)$ \\
\hline \multicolumn{5}{|l|}{ Lens status (clinical exam), no. (\%) } \\
\hline Phakic & $192(66 \%)$ & $131(70 \%)$ & $134(71 \%)$ & $124(67 \%)$ \\
\hline AC IOL & $3(1 \%)$ & $1(1 \%)$ & $1(1 \%)$ & 0 \\
\hline PC IOL & $98(33 \%)$ & $55(29 \%)$ & $53(28 \%)$ & $62(33 \%)$ \\
\hline
\end{tabular}

Classification of DME (clinical exam), no. $(\%)$ 


\begin{tabular}{|c|c|c|c|c|}
\hline & $\begin{array}{l}\text { Sham + Prompt } \\
\text { Laser N = 293 }\end{array}$ & $\begin{array}{c}\text { Ranibizumab + } \\
\text { Prompt Laser N = } \\
187\end{array}$ & $\begin{array}{c}\text { Ranibizumab + } \\
\text { Deferred Laser } \mathbf{N}= \\
\mathbf{1 8 8}\end{array}$ & $\begin{array}{c}\text { Triamcinolone + } \\
\text { Prompt Laser N = } \\
186\end{array}$ \\
\hline Predominantly focal & $78(27 \%)$ & $60(32 \%)$ & $68(36 \%)$ & $53(28 \%)$ \\
\hline Neither predominantly focal or diffuse & $71(24 \%)$ & $46(25 \%)$ & $41(22 \%)$ & $48(26 \%)$ \\
\hline Predominantly diffuse & $144(49 \%)$ & $81(43 \%)$ & $79(42 \%)$ & $85(46 \%)$ \\
\hline \multicolumn{5}{|l|}{$\begin{array}{l}\text { Visual acuity letter score (approximate } \\
\text { Snellen equivalent) by randomization strata }\end{array}$} \\
\hline Median (25th, 75th percentile) & $65(56,73)$ & $66(55,72)$ & $66(58,72)$ & $66(57,72)$ \\
\hline$\geq 66$ (better than 20/50) & $146(50 \%)$ & $95(51 \%)$ & $95(51 \%)$ & $93(50 \%)$ \\
\hline$\leq 65(20 / 50$ or worse $)$ & $147(50 \%)$ & $92(49 \%)$ & $93(49 \%)$ & $93(50 \%)$ \\
\hline \multicolumn{5}{|l|}{$\begin{array}{l}\text { Visual acuity letter score (approximate } \\
\text { Snellen equivalent) }\end{array}$} \\
\hline $78-74(20 / 32)$ & $61(21 \%)$ & $34(18 \%)$ & $32(17 \%)$ & $38(20 \%)$ \\
\hline $73-69(20 / 40)$ & $57(19 \%)$ & $36(19 \%)$ & $37(20 \%)$ & $36(19 \%)$ \\
\hline $68-64(20 / 50)$ & $41(14 \%)$ & $37(20 \%)$ & $36(19 \%)$ & $31(17 \%)$ \\
\hline $63-59(20 / 63)$ & $47(16 \%)$ & $22(12 \%)$ & $33(18 \%)$ & $24(13 \%)$ \\
\hline $58-54(20 / 80)$ & $33(11 \%)$ & $20(11 \%)$ & $13(7 \%)$ & $19(10 \%)$ \\
\hline $53-49(20 / 100)$ & $18(6 \%)$ & $16(9 \%)$ & $12(6 \%)$ & $16(9 \%)$ \\
\hline $48-44(20 / 125)$ & $16(5 \%)$ & $6(3 \%)$ & $10(5 \%)$ & $6(3 \%)$ \\
\hline $43-39(20 / 160)$ & $10(3 \%)$ & $5(3 \%)$ & $11(6 \%)$ & $6(3 \%)$ \\
\hline$\leq 38(\leq 20 / 200)$ & $10(3 \%)$ & $11(6 \%)$ & $4(2 \%)$ & $10(5 \%)$ \\
\hline $\begin{array}{l}\text { Central subfield thickness (microns) on } \\
\text { OCT Median (25th, 75th percentile) } \$ \text { \$ }\end{array}$ & $407(309,505)$ & $371(302,464)$ & $382(298,488)$ & $374(298,463)$ \\
\hline $\begin{array}{l}\text { Retinal volume }\left(\mathbf{m m}^{3}\right) \text { on } \mathbf{O C T}^{\S} \text { Median } \\
(25 \text { th, } 75 \text { th percentile })\end{array}$ & $8.7(7.8,10.0)$ & $8.4(7.5,9.6)$ & $8.4(7.4,9.8)$ & $8.5(7.8,9.7)$ \\
\hline $\begin{array}{l}\text { OCT cystoid abnormality (questionable or } \\
\text { definite), no. (\%) }\end{array}$ & $274(93 \%)$ & $171(91 \%)$ & $174(92 \%)$ & $177(95 \%)$ \\
\hline $\begin{array}{l}\text { OCT subretinal fluid present (questionable } \\
\text { or definite), no. (\%) }\end{array}$ & $70(24 \%)$ & $36(20 \%)$ & $45(25 \%)$ & $38(21 \%)$ \\
\hline \multicolumn{5}{|l|}{$\begin{array}{l}\text { ETDRS Retinopathy severity level (ETDRS } \\
\text { description), no. }(\%)^{\S}\end{array}$} \\
\hline Level 10, 12 (diabetic retinopathy absent) & $5(2 \%)$ & $4(2 \%)$ & $3(2 \%)$ & $1(1 \%)$ \\
\hline Level 14, 15, 20 (minimal NPDR) & $2(1 \%)$ & $2(1 \%)$ & $3(2 \%)$ & $3(2 \%)$ \\
\hline $\begin{array}{l}\text { Level 35, 43, } 47 \text { (mild to moderately severe } \\
\text { NPDR) }\end{array}$ & $171(59 \%)$ & $103(55 \%)$ & $107(57 \%)$ & $95(51 \%)$ \\
\hline Level 53 (severe NPDR) & $22(8 \%)$ & $16(9 \%)$ & $11(6 \%)$ & $15(8 \%)$ \\
\hline $\begin{array}{l}\text { Level } 60 \text { (scars of full or partial PRP present; } \\
\text { abnormalities of PDR absent) }\end{array}$ & $38(13 \%)$ & $30(16 \%)$ & $30(16 \%)$ & $29(16 \%)$ \\
\hline Level 61, 65 (mild to moderate PDR) & $33(11 \%)$ & $24(13 \%)$ & $22(12 \%)$ & $34(18 \%)$ \\
\hline Level 71, 75 (high risk PDR) & $7(2 \%)$ & $4(2 \%)$ & $1(1 \%)$ & $3(2 \%)$ \\
\hline
\end{tabular}

DME $=$ diabetic macular edema; E-ETDRS ${ }^{\complement}=$ electronic Early Treatment Diabetic Retinopathy Study; ETDRS = Early Treatment Diabetic Retinopathy Study; HbA1c = hemoglobin A1c; IOP = intraocular pressure; IVT = intravitreal triamcinolone; NPDR = non-proliferative diabetic retinopathy; OCT $=$ optical coherence tomography; $\mathrm{PDR}=$ proliferative diabetic retinopathy; $\mathrm{PRP}=$ panretinal photocoagulation; $\mathrm{VEGF}=$ vascular endothelial growth factor.

* Missing HbA1c data for 17, 3,7 and 8 study participants in the sham+prompt laser, ranibizumab + prompt laser, ranibizumab+deferred laser, and triamcinolone + prompt laser groups, respectively.

${ }^{\dagger}$ Medical history of condition. 
F One OCT central subfield thickness (CST) had an ineligible site OCT value $(<250)$ and 60 had an ineligible OCT CST from reading center grading. All are included in this table.

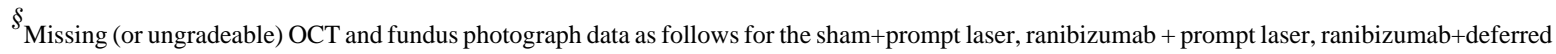
laser, and triamcinolone+prompt laser groups, respectively: central subfield ( 1 in the ranibizumab+deferred laser), retinal volume $(73,49,42,48)$, and retinopathy severity $(5,3,9,2)$. 


\section{Table 3}

Distribution of Focal/Grid Laser Treatments Received

\begin{tabular}{|c|c|c|c|c|}
\hline & $\begin{array}{l}\text { Sham + Prompt } \\
\text { Laser }\end{array}$ & $\begin{array}{l}\text { Ranibizumab + } \\
\text { Prompt Laser }\end{array}$ & $\begin{array}{l}\text { Ranibizumab + } \\
\text { Deferred Laser } / l\end{array}$ & $\begin{array}{l}\text { Triamcinolone }+ \\
\text { Prompt Laser }\end{array}$ \\
\hline $\begin{array}{l}\text { Number of laser treatments received } \\
\text { prior to the } 1 \text { year visit, no. }(\%)^{*}\end{array}$ & $N=274$ & $N=171$ & $N=178$ & $N=176$ \\
\hline 0 & $1(<1 \%)^{\dagger}$ & 0 & $124(70 \%)$ & $1(1 \%)^{*}$ \\
\hline 1 & $35(13 \%)$ & $53(31 \%)$ & $36(20 \%)$ & $46(26 \%)$ \\
\hline 2 & $75(27 \%)$ & $54(32 \%)$ & $17(10 \%)$ & $53(30 \%)$ \\
\hline 3 & $107(39 \%)$ & $46(27 \%)$ & $1(1 \%)$ & $49(28 \%)$ \\
\hline 4 & $56(20 \%)$ & $18(11 \%)$ & 0 & $27(15 \%)$ \\
\hline $\begin{array}{l}\text { Proportion of eyes receiving laser at } \\
48 \text { week visit, no. }(\%)^{*}\end{array}$ & $242(26 \%)$ & $155(16 \%)$ & $160(8 \%)$ & $154(21 \%)$ \\
\hline $\begin{array}{l}\text { Number of laser treatments received } \\
\text { prior to the } 2 \text { year visit, no. }(\%)^{\S}\end{array}$ & $N=163$ & $N=106$ & $\mathrm{~N}=112$ & $N=103$ \\
\hline 0 & $1(1 \%)$ & 0 & $65(58 \%)$ & 0 \\
\hline 1 & $14(9 \%)$ & $21(20 \%)$ & $21(19 \%)$ & $16(16 \%)$ \\
\hline 2 & $28(17 \%)$ & $24(23 \%)$ & $7(6 \%)$ & $23(22 \%)$ \\
\hline 3 & $38(23 \%)$ & $23(22 \%)$ & $11(10 \%)$ & $28(27 \%)$ \\
\hline 4 & $29(18 \%)$ & $22(21 \%)$ & $8(7 \%)$ & $13(13 \%)$ \\
\hline 5 & $25(15 \%)$ & $9(8 \%)$ & 0 & $11(11 \%)$ \\
\hline 6 & $13(8 \%)$ & $5(5 \%)$ & 0 & $7(7 \%)$ \\
\hline 7 & $15(9 \%)$ & $2(2 \%)$ & 0 & $5(5 \%)$ \\
\hline \multicolumn{5}{|c|}{ Includes study participants completing the 1-year (52 week) visit. } \\
\hline
\end{tabular}

Ophthalmology. Author manuscript; available in PMC 2011 June 1. 
Table 4

Alternative Treatments Received for Diabetic Macular Edema

\begin{tabular}{|c|c|c|c|c|}
\hline & $\begin{array}{l}\text { Sham + } \\
\text { Prompt Laser } \\
\text { N = 293 }\end{array}$ & $\begin{array}{l}\text { Ranibizumab + } \\
\text { Prompt Laser N = } \\
187\end{array}$ & $\begin{array}{l}\text { Ranibizumab + } \\
\text { Deferred Laser N = } \\
188\end{array}$ & $\begin{array}{l}\text { Triamcinolone + } \\
\text { Prompt Laser N = } \\
186\end{array}$ \\
\hline \multicolumn{5}{|l|}{ Prior to the 1 year visit } \\
\hline $\begin{array}{l}\text { Eyes with alternative treatments (number of } \\
\text { treatments applied) }\end{array}$ & $14(25)$ & $1(1)$ & 0 & $1(1)$ \\
\hline Per protocol, no. ${ }^{*}$ & 5 & 1 & 0 & 1 \\
\hline Deviations from protocol, no. & 9 & 0 & 0 & 0 \\
\hline \multicolumn{5}{|l|}{ Alternative treatments, no. ${ }^{\dagger}$} \\
\hline Intravitreal Bevacizumab & 3 & 0 & 0 & 1 \\
\hline Intravitreal Triamcinolone Acetonide & 5 & 1 & 0 & 0 \\
\hline Vitrectomy & 2 & 0 & 0 & 0 \\
\hline $\begin{array}{l}\text { Intravitreal Bevacizumab + Intravitreal } \\
\text { Triamcinolone Acetonide }\end{array}$ & 4 & 0 & 0 & 0 \\
\hline \multicolumn{5}{|l|}{1 year through prior to the 2 year visit } \\
\hline $\begin{array}{l}\text { Eyes with alternative treatments (number of } \\
\text { treatments) }\end{array}$ & $29(55)$ & $1(1)$ & 0 & $3(4)$ \\
\hline Per protocol, no. ${ }^{*}$ & 20 & 1 & 0 & 2 \\
\hline Deviations from protocol, no. & 9 & 0 & 0 & 1 \\
\hline \multicolumn{5}{|l|}{ Alternative Treatments, no. ${ }^{\dagger}$} \\
\hline Intravitreal Bevacizumab & 9 & 0 & 0 & 0 \\
\hline Intravitreal Ranibizumab & 2 & 0 & 0 & 0 \\
\hline Intravitreal Triamcinolone Acetonide & 12 & 1 & 0 & $2 \neq$ \\
\hline Vitrectomy & 2 & 0 & 0 & 0 \\
\hline $\begin{array}{l}\text { Vitrectomy + Intravitreal Triamcinolone } \\
\text { Acetonide }\end{array}$ & 0 & 0 & 0 & 1 \\
\hline $\begin{array}{l}\text { Intravitreal Bevacizumab + Intravitreal } \\
\text { Ranibizumab }\end{array}$ & 1 & 0 & 0 & 0 \\
\hline $\begin{array}{l}\text { Intravitreal Bevacizumab + Intravitreal } \\
\text { Triamcinolone Acetonide }\end{array}$ & 2 & 0 & 0 & 0 \\
\hline $\begin{array}{l}\text { Intravitreal Bevacizumab + Intravitreal } \\
\text { Ranibizumab + Intravitreal Triamcinolone } \\
\text { Acetonide }\end{array}$ & 1 & 0 & 0 & 0 \\
\hline
\end{tabular}

* Per protocol if met failure. Failure is defined as: Visual acuity 10 or more letters worse than baseline, optical coherence tomography central subfield thickness $\geq 250$ microns, diabetic macular edema present on clinical exam that is the cause of the visual loss, complete laser given AND $\geq 13$ weeks since last laser treatment with no improvement since the last laser treatment

${ }^{\dagger}$ Number of eyes, each combination of treatment only counted once

Non-study drug was given (intravitreal Kenalog) 
Table 5

Change in Visual Acuity (Last Observation Carried Forward) from Baseline to 1 Year (Primary Outcome)*

\begin{tabular}{|c|c|c|c|c|}
\hline & $\begin{array}{c}\text { Sham + } \\
\text { Prompt Laser } \\
N=293\end{array}$ & $\begin{array}{l}\text { Ranibizumab + } \\
\text { Prompt Laser } \\
\quad N=187\end{array}$ & $\begin{array}{l}\text { Ranibizumab + } \\
\text { Deferred Laser } \\
\quad N=188\end{array}$ & $\begin{array}{c}\text { Triamcinolone }+ \\
\text { Prompt Laser } N=186\end{array}$ \\
\hline \multicolumn{5}{|l|}{ Change in visual acuity (letters) } \\
\hline Mean \pm SD & $+3 \pm 13$ & $+9 \pm 11$ & $+9 \pm 12$ & $+4 \pm 13$ \\
\hline Median (25th, 75 th percentile) & $+5(-2,+10)$ & $+10(+3,+16)$ & $+9(+5,+15)$ & $+5(-3,+12)$ \\
\hline $\begin{array}{l}\text { Difference in mean change from sham }+ \text { prompt } \\
\text { laser }(95 \% \mathrm{CI})[P \text { value }]^{\dagger}\end{array}$ & & $\begin{array}{l}+5.8(+3.2 \text { to }+8.5) \\
\quad[P<0.001]\end{array}$ & $\begin{array}{c}+6.0(+3.4 \text { to }+8.6) \\
{[P<0.001]}\end{array}$ & $\begin{array}{c}+1.1(-1.5 \text { to }+3.7) \\
{[P=0.31]}\end{array}$ \\
\hline \multicolumn{5}{|l|}{ Distribution of change, No. (\%) } \\
\hline$\geq 15$ letter improvement & $43(15 \%)$ & $57(30 \%)$ & $52(28 \%)$ & $39(21 \%)$ \\
\hline 14-10 letter improvement & $38(13 \%)$ & $38(20 \%)$ & $36(19 \%)$ & $22(12 \%)$ \\
\hline 9-5 letter improvement & $67(23 \%)$ & $34(18 \%)$ & $54(29 \%)$ & $32(17 \%)$ \\
\hline Same \pm 4 letters & $86(29 \%)$ & $38(20 \%)$ & $35(19 \%)$ & $54(29 \%)$ \\
\hline 5-9 letters worse & $20(7 \%)$ & $14(7 \%)$ & $5(3 \%)$ & $12(6 \%)$ \\
\hline 10-14 letters worse & $16(5 \%)$ & $3(2 \%)$ & $2(1 \%)$ & $12(6 \%)$ \\
\hline$\geq 15$ letters worse & $23(8 \%)$ & $3(2 \%)$ & $4(2 \%)$ & $15(8 \%)$ \\
\hline $\begin{array}{l}\text { Difference in proportion with } \geq 10 \text { letter } \\
\text { improvement from sham }+ \text { prompt laser }(95 \% \mathrm{CI})\end{array}$ & & $\begin{array}{l}+23 \%(+13 \% \text { to } \\
+34 \%)\end{array}$ & $+19 \%(+9 \%$ to $+29 \%)$ & $+6 \%(-4 \%$ to $+16 \%)$ \\
\hline $\begin{array}{l}\text { Relative risk }(95 \% \mathrm{CI})[P \text { value }]^{\S} \text { for } \\
\text { comparison with sham + prompt laser }\end{array}$ & 1.0 & $\begin{array}{c}1.84(1.40 \text { to } 2.42) \\
{[P<0.001]}\end{array}$ & $\begin{array}{c}1.68(1.27 \text { to } 2.21) \\
{[P<0.001]}\end{array}$ & $\begin{array}{c}1.21(0.88 \text { to } 1.66) \\
{[P=0.16]}\end{array}$ \\
\hline $\begin{array}{l}\text { Difference in proportion with } \geq 10 \text { letter worsening } \\
\text { from sham + prompt laser }(95 \% \mathrm{CI})^{\ddagger}\end{array}$ & & $-10 \%(-16 \%$ to $-5 \%)$ & $-10 \%(-16 \%$ to $-4 \%)$ & $+1 \%(-7 \%$ to $+9 \%)$ \\
\hline $\begin{array}{l}\text { Relative risk }(95 \% \mathrm{CI})[P \text { value }]^{+} \text {for } \\
\text { comparison with sham + prompt laser }\end{array}$ & 1.0 & $\begin{array}{l}0.24(0.09 \text { to } 0.65) \\
{[P<0.001]}\end{array}$ & $\begin{array}{l}0.24(0.08 \text { to } 0.68) \\
\quad[P=0.001]\end{array}$ & $\begin{array}{c}1.08(0.62 \text { to } 1.87) \\
\quad[P=0.75]\end{array}$ \\
\hline $\begin{array}{l}\text { Difference in proportion with } \geq 15 \text { letter } \\
\text { improvement from sham }+ \text { prompt laser }(95 \% \text { CI) }\end{array}$ & & $+16 \%(+6 \%$ to $+26 \%)$ & $+13 \%(+4 \%$ to $+22 \%)$ & $+6 \%(-2 \%$ to $+15 \%)$ \\
\hline $\begin{array}{l}\text { Relative risk }(95 \% \mathrm{CI})[P \text { value }]^{\S} \text { for } \\
\text { comparison with sham + prompt laser }\end{array}$ & 1.0 & $\begin{array}{c}2.09(1.35 \text { to } 3.22) \\
{[P<0.001]}\end{array}$ & $\begin{array}{c}1.89(1.25 \text { to } 2.87) \\
{[P<0.001]}\end{array}$ & $\begin{array}{c}1.43(0.90 \text { to } 2.29) \\
\quad[P=0.07]\end{array}$ \\
\hline $\begin{array}{l}\text { Difference in proportion with } \geq 15 \text { letter worsening } \\
\text { from sham }+ \text { prompt laser }(95 \% \mathrm{CI})^{\ddagger}\end{array}$ & & $-6 \%(-11 \%$ to $-2 \%)$ & $-6 \%(-10 \%$ to $-1 \%)$ & $0(-6 \%$ to $+6 \%)$ \\
\hline $\begin{array}{l}\text { Relative risk }(95 \% \mathrm{CI})[P \text { value }]^{\S} \text { for } \\
\text { comparison with sham + prompt laser }\end{array}$ & 1.0 & $\begin{array}{c}0.21(0.05 \text { to } 0.87) \\
\quad[P=0.009]\end{array}$ & $\begin{array}{l}0.28(0.08 \text { to } 0.97) \\
\quad[P=0.01]\end{array}$ & $\begin{array}{c}1.02(0.47 \text { to } 2.20) \\
\quad[P=0.95]\end{array}$ \\
\hline
\end{tabular}

$\mathrm{CI}=$ confidence interval; $\mathrm{SD}=$ standard deviation.

*Visits occurring between 308 and 420 days (between 44 and $60 \mathrm{wks}$ ) from randomization were included as 1-yr visits. When >1 visit occurred in this window, data from the visit closest to the 1-yr target date were used. For other eyes without any 1-yr data (19 eyes in the sham + prompt laser group, 16 eyes in the ranibizumab + prompt laser group, 10 eyes in the ranibizumab + deferred laser group, and 10 eyes in the triamcinolone + prompt laser group), the last observation carried forward method was used to impute data for the primary analysis.

${ }^{\dagger}$ Analysis of covariance adjusted for baseline visual acuity and correlation between 2 study eyes. Confidence intervals are adjusted for multiple comparisons.

FAdjusted for correlation between 2 study eyes. Confidence intervals are adjusted for multiple comparisons.

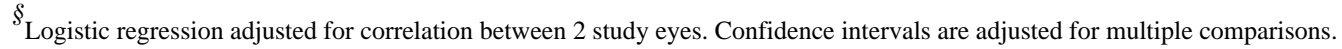


Table 6

Change in Visual Acuity from Baseline to 2 Years*

\begin{tabular}{|c|c|c|c|c|}
\hline Change in visual acuity (letters) ${ }^{\dagger}$ & $\begin{array}{l}\text { Sham + } \\
\text { Prompt Laser } \\
\text { N = 163 }\end{array}$ & $\begin{array}{l}\text { Ranibizumab + Prompt } \\
\text { Laser N = } 106\end{array}$ & $\begin{array}{c}\text { Ranibizumab + } \\
\text { Deferred Laser N = } 112\end{array}$ & $\begin{array}{c}\text { Triamcinolone }+ \\
\text { Prompt Laser } N=103\end{array}$ \\
\hline \multicolumn{5}{|l|}{ Overall change } \\
\hline Mean \pm SD & $+2 \pm 16$ & $+7 \pm 13$ & $+10 \pm 15$ & $0 \pm 21$ \\
\hline Median $\left(25^{\text {th }}, 75^{\text {th }}\right.$ percentile $)$ & $+5(-2,+11)$ & $+8(+2,+15)$ & $+10(+4,+17)$ & $+6(-5,+13)$ \\
\hline $\begin{array}{l}\text { Difference in mean change from sham } \\
+ \text { tprompt laser }(95 \% \mathrm{CI})[P \text { Value }]^{\frac{F}{*}}\end{array}$ & & $\begin{array}{c}+5.0(0.1,+9.9)[P= \\
0.01]\end{array}$ & $\begin{array}{c}+7.2(+2.4,+12.0)[P< \\
0.001]\end{array}$ & $\begin{array}{c}-1.6(-6.6,+3.3)[P< \\
0.001]\end{array}$ \\
\hline \multicolumn{5}{|l|}{ Distribution of change, no. (\%) } \\
\hline$\geq 15$ letter improvement & $28(17 \%)$ & $28(26 \%)$ & $33(29 \%)$ & $20(19 \%)$ \\
\hline 14-10 letter improvement & $22(13 \%)$ & $18(17 \%)$ & $24(21 \%)$ & $21(20 \%)$ \\
\hline 9-5 letter improvement & $32(20 \%)$ & $25(24 \%)$ & $23(21 \%)$ & $13(13 \%)$ \\
\hline Same \pm 4 letters & $46(28 \%)$ & $25(24 \%)$ & $25(22 \%)$ & $22(21 \%)$ \\
\hline 5-9 letters worse & $13(8 \%)$ & $3(3 \%)$ & $3(3 \%)$ & $5(5 \%)$ \\
\hline 10-14 letters worse & $3(2 \%)$ & $4(4 \%)$ & $1(1 \%)$ & $6(6 \%)$ \\
\hline$\geq 15$ letters worse & $19(12 \%)$ & $3(3 \%)$ & $3(3 \%)$ & $16(16 \%)$ \\
\hline $\begin{array}{l}\text { Difference in proportion with } \geq 10 \text { letter } \\
\text { improvement from sham }+ \text { prompt laser } \\
(95 \% \mathrm{CI})^{\S}\end{array}$ & & $+13 \%(-2 \%,+27 \%)$ & $+20 \%(+6 \%,+34 \%)$ & $+9 \%(-5 \%,+23 \%)$ \\
\hline $\begin{array}{l}\text { Relative risk }(95 \% \mathrm{CI})[P \text { Value }]]^{/ /} \text {for } \\
\text { comparison with sham+laser }\end{array}$ & 1.0 & $\begin{array}{c}1.41(0.96,2.07)[P= \\
0.03]\end{array}$ & $\begin{array}{l}1.65(1.16,2.36) \\
\quad[P<0.001]\end{array}$ & $\begin{array}{c}1.30(0.88,1.92)[P= \\
0.11]\end{array}$ \\
\hline $\begin{array}{l}\text { Difference in proportion with } \geq 10 \text { letter } \\
\text { worsening from sham +prompt laser }(95 \% \\
\mathrm{CI})^{\S}\end{array}$ & & $-7 \%(-16 \%,+2 \%)$ & $-10 \%(-18 \%,-2 \%)$ & $+8 \%(-4 \%,+19 \%)$ \\
\hline $\begin{array}{l}\text { Relative risk }(95 \% \mathrm{CI})[P \text { Value }]^{/ /} \text {for } \\
\text { comparison with sham+prompt laser }\end{array}$ & 1.0 & $\begin{array}{c}0.49(0.18,1.33)[P= \\
0.09]\end{array}$ & $\begin{array}{c}0.26(0.07,0.95)[P= \\
0.01]\end{array}$ & $\begin{array}{c}1.58(0.83,3.02)[P= \\
0.09]\end{array}$ \\
\hline
\end{tabular}

$\mathrm{CI}=$ confidence interval; $\mathrm{SD}=$ standard deviation .

* Visits occurring between 616 and 840 days (between 88 and 120 weeks) from randomization were included as 2-year visits. When more than 1 visit occurred in this window, data from the visit closest to the 2-year target date were used.

${ }^{\dagger}$ Among the 432 eyes with 2 year follow up, the 2-year results were similar to the 1-year results of the entire cohort of 854 eyes (data not shown)

*Analysis of covariance adjusted for baseline visual acuity and correlation between 2 study eyes. Confidence intervals are adjusted for multiple comparisons.

$\S$ Adjusted for correlation between 2 study eyes. Confidence intervals are adjusted for multiple comparisons.

"Logistic regression adjusted for correlation between 2 study eyes. Confidence intervals are adjusted for multiple comparisons. 
Table 7

Distribution of Visual Acuity at 1 and 2 Years

\begin{tabular}{|c|c|c|c|c|}
\hline $\begin{array}{l}\text { Change in visual acuity letter score } \\
\text { (approximate Snellen equivalent) }\end{array}$ & $\begin{array}{c}\text { Sham + Prompt } \\
\text { Laser N = 293 }\end{array}$ & $\begin{array}{c}\text { Ranibizumab }+ \\
\text { Prompt Laser } N=187\end{array}$ & $\begin{array}{c}\text { Ranibizumab + } \\
\text { Deferred Laser N }= \\
188\end{array}$ & $\begin{array}{c}\text { Triamcinolone }+ \\
\text { Prompt Laser } N=186\end{array}$ \\
\hline \multicolumn{5}{|l|}{ Baseline visual acuity letter score } \\
\hline Median (25th, 75th percentile) & $65(56,73)$ & $66(55,72)$ & $66(58,72)$ & $66(57,72)$ \\
\hline \multicolumn{5}{|l|}{$\begin{array}{l}\text { Visual acuity (LOCF) letter score } \\
\text { (approximate Snellen equivalent) at the } \\
1 \text { year visit }{ }^{*}\end{array}$} \\
\hline Median (25th and 75 th percentile) & $69(59,77)$ & $75(66,81)$ & $75(66,81)$ & $70(58,77)$ \\
\hline$\geq 79(\geq 20 / 25)$ & $59(20 \%)$ & $64(34 \%)$ & $65(35 \%)$ & $40(22 \%)$ \\
\hline $78-69(20 / 32$ to $20 / 40)$ & $89(30 \%)$ & $70(37 \%)$ & $66(35 \%)$ & $55(30 \%)$ \\
\hline $68-59(20 / 50$ to $20 / 63)$ & $73(25 \%)$ & $27(14 \%)$ & $34(18 \%)$ & $43(23 \%)$ \\
\hline $58-49(20 / 80$ to $20 / 100)$ & $31(11 \%)$ & $11(6 \%)$ & $16(9 \%)$ & $28(15 \%)$ \\
\hline $48-39(20 / 125$ to $20 / 160)$ & $24(8 \%)$ & $8(4 \%)$ & $4(2 \%)$ & $14(8 \%)$ \\
\hline$\leq 38(\leq 20 / 200)$ & $17(6 \%)$ & $7(4 \%)$ & $3(2 \%)$ & $6(3 \%)$ \\
\hline $\begin{array}{l}\text { Visual acuity letter score (approximate } \\
\text { Snellen equivalent) at the } 2 \text { year visit }{ }^{\dagger}\end{array}$ & $N=163$ & $N=106$ & $N=112$ & $\mathrm{~N}=103$ \\
\hline Median (25th and 75 th percentile) & $71(59,77)$ & $75(62,81)$ & $75(65,80)$ & $71(54,79)$ \\
\hline$\geq 79(\geq 20 / 25)$ & $34(21 \%)$ & $39(37 \%)$ & $36(32 \%)$ & $30(29 \%)$ \\
\hline $78-69(20 / 32$ to $20 / 40)$ & $59(36 \%)$ & $33(31 \%)$ & $42(38 \%)$ & $26(25 \%)$ \\
\hline $68-59(20 / 50$ to $20 / 63)$ & $30(18 \%)$ & $12(11 \%)$ & $22(20 \%)$ & $13(13 \%)$ \\
\hline $58-49(20 / 80$ to $20 / 100)$ & $17(10 \%)$ & $8(8 \%)$ & $7(6 \%)$ & $19(18 \%)$ \\
\hline $48-39(20 / 125$ to $20 / 160)$ & $7(4 \%)$ & $11(10 \%)$ & $1(1 \%)$ & $5(5 \%)$ \\
\hline$\leq 38(\leq 20 / 200)$ & $16(10 \%)$ & $3(3 \%)$ & $4(4 \%)$ & $10(10 \%)$ \\
\hline
\end{tabular}

LOCF $=$ last observation carried forward.

*Visits occurring between 308 and 420 days (between 44 and 60 weeks) from randomization were included as 1-year visits. When more than 1 visit occurred in this window, data from the visit closest to the 1-year target date were used. For other eyes without any 1-year data (19 eyes in the sham +prompt laser group, 16 eyes in the ranibizumab+prompt laser group, 10 eyes in the ranibizumab+deferred laser group, and 10 eyes in the triamcinolone +prompt laser group) the last observation carried forward method was used to impute data for the primary analysis.

${ }^{\dagger}$ Visits occurring between 616 and 840 days (between 88 and 120 weeks) from randomization were included as 2-year visits. When more than 1 visit occurred in this window, data from the visit closest to the 2-year target date were used. 


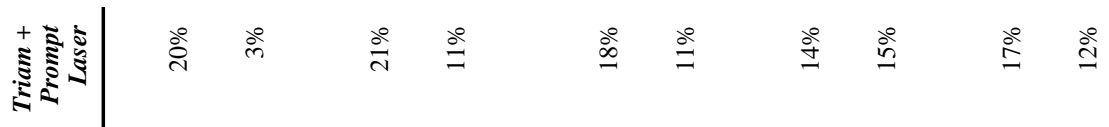

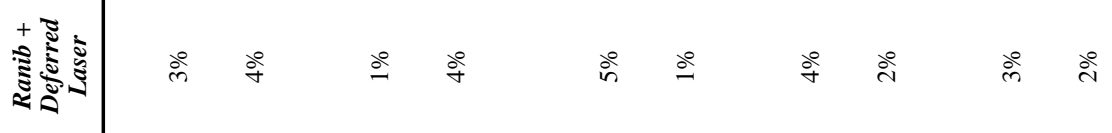

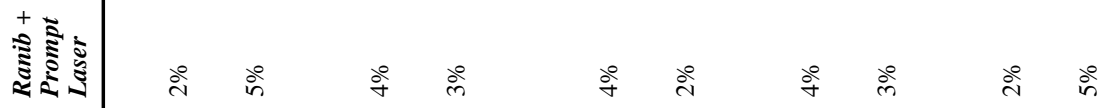

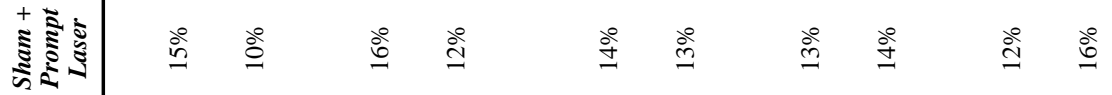

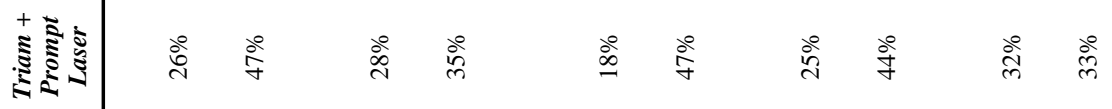

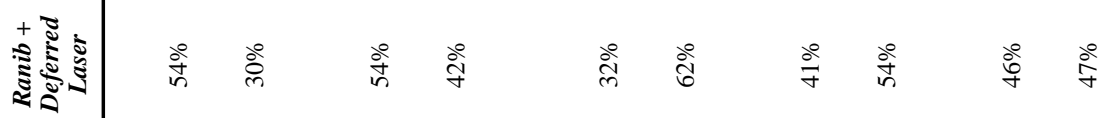

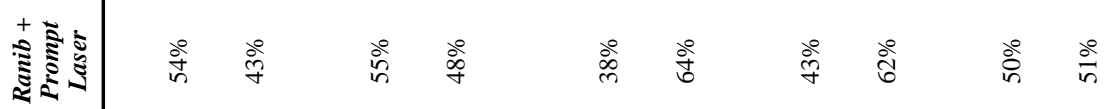

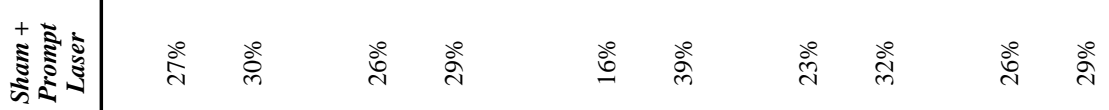

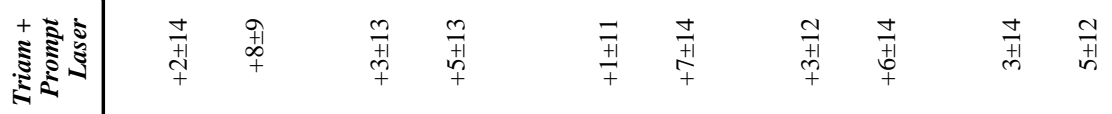

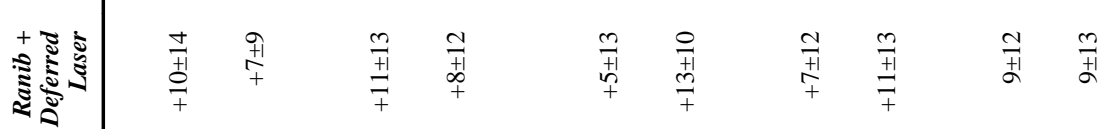

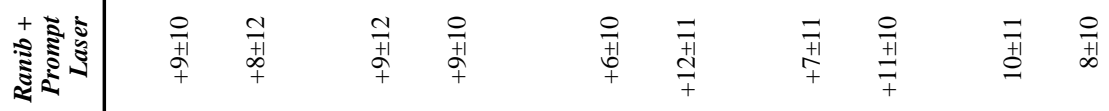

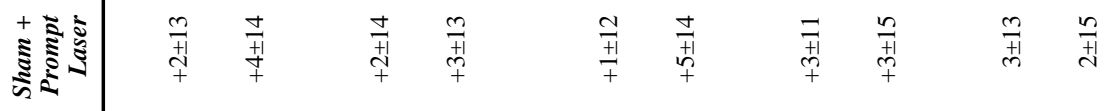

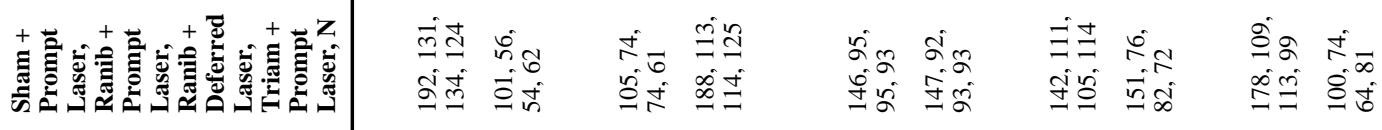

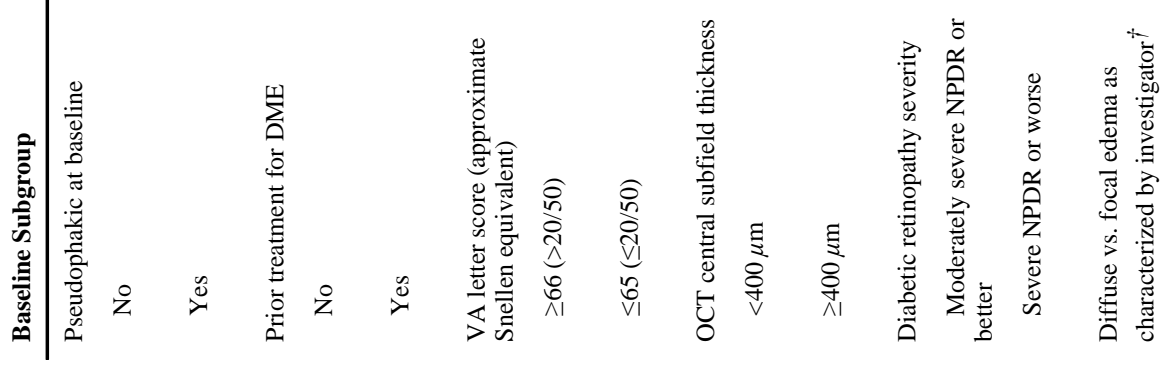


et al.

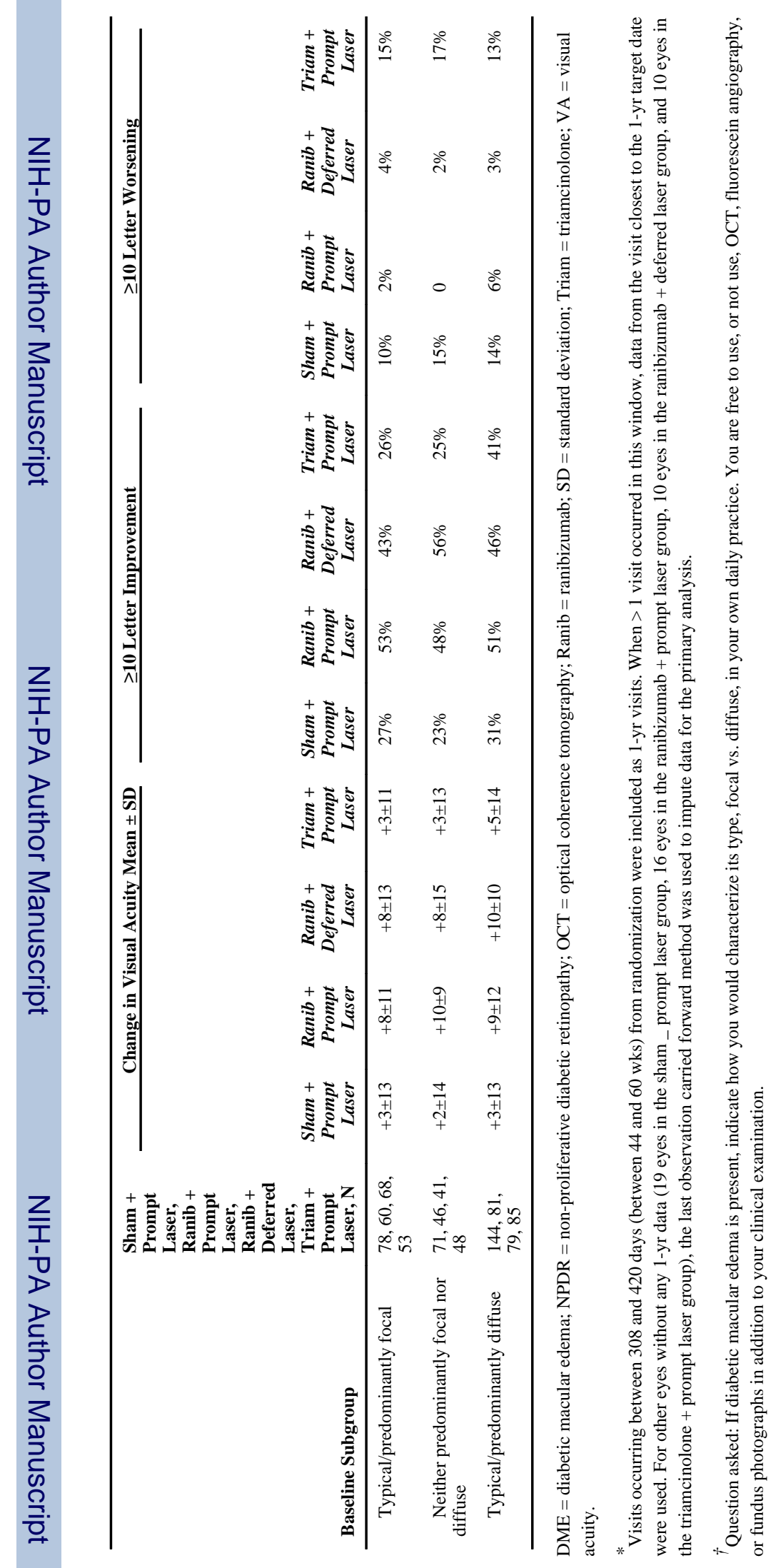

Ophthalmology. Author manuscript; available in PMC 2011 June 1. 
Table 9

Change in Visual Acuity (Last Observation Carried Forward) from Baseline to 1 Year* among Study Participants with 2 Study Eyes

\begin{tabular}{|c|c|c|c|c|}
\hline Change in visual acuity (letters) & $\begin{array}{c}\text { Sham + Prompt } \\
\text { Laser } N=163\end{array}$ & $\begin{array}{c}\text { Ranibizumab + } \\
\text { Prompt Laser } N=56\end{array}$ & $\begin{array}{c}\text { Ranibizumab + } \\
\text { Deferred Laser } N=56\end{array}$ & $\begin{array}{c}\text { Triamcinolone }+ \\
\text { Prompt Laser } N=51\end{array}$ \\
\hline \multicolumn{5}{|l|}{ Change from baseline } \\
\hline Mean \pm SD & $+2 \pm 13$ & $+11 \pm 8$ & $+7 \pm 17$ & $+4 \pm 14$ \\
\hline $\begin{array}{l}\text { Difference in mean change from sham } \\
\text { +prompt laser }(95 \% \mathrm{CI})^{\dagger}\end{array}$ & & $+7.1(+3.4,+10.8)$ & $+4.7(-1.0,+10.3)$ & $+2.8(-1.9,+7.5)$ \\
\hline Median (25th, 75th percentile) & $+4(-3,+9)$ & $+11(+5,+16)$ & $+7(+3,+15)$ & $+4(-4,+12)$ \\
\hline \multicolumn{5}{|l|}{ Distribution of change, no. (\%) } \\
\hline$\geq 15$ letter improvement & $21(13 \%)$ & $17(30 \%)$ & $14(25 \%)$ & $12(24 \%)$ \\
\hline 14-10 letter improvement & $19(12 \%)$ & $16(29 \%)$ & $7(13 \%)$ & $3(6 \%)$ \\
\hline 9-5 letter improvement & $38(23 \%)$ & $11(20 \%)$ & $18(32 \%)$ & $9(18 \%)$ \\
\hline Same \pm 4 letters & $47(29 \%)$ & $9(16 \%)$ & $14(25 \%)$ & $15(29 \%)$ \\
\hline 5-9 letters worse & $12(7 \%)$ & $2(4 \%)$ & 0 & $6(12 \%)$ \\
\hline 10-14 letters worse & $9(6 \%)$ & $1(2 \%)$ & $1(2 \%)$ & $1(2 \%)$ \\
\hline$\geq 15$ letters worse & $17(10 \%)$ & 0 & $2(4 \%)$ & $5(10 \%)$ \\
\hline
\end{tabular}

$\mathrm{CI}=$ confidence interval $\mathrm{SD}=$ standard deviation

* Visits occurring between 308 and 420 days (between 44 and 60 weeks) from randomization were included as 1-year visits. When more than 1 visit occurred in this window, data from the visit closest to the 1-year target date were used. For other eyes without any 1-year data (11 eyes in the sham +prompt laser group, 4 eyes in the ranibizumab+prompt laser group, 2 eyes in the ranibizumab+deferred laser group, and 5 eyes in the triamcinolne +prompt laser group) the last observation carried forward method was used to impute data for the primary analysis.

${ }^{\dagger}$ Analysis of covariance adjusted for baseline visual acuity and correlation between 2 study eyes. Confidence intervals are adjusted for multiple comparisons. 


\section{Table 10}

Change in Visual Acuity (Last Observation Carried Forward) from Baseline to 1 Year ${ }^{*}$ Excluding Eyes with Baseline Optical Coherence Tomography Central Subfield Thickness $<250$ microns

\begin{tabular}{|c|c|c|c|c|}
\hline & $\begin{array}{l}\text { Sham + } \\
\text { Prompt } \\
\text { Laser N = } \\
275\end{array}$ & $\begin{array}{l}\text { Ranibizumab + Prompt } \\
\text { Laser } N=175\end{array}$ & $\begin{array}{c}\text { Ranibizumab }+ \\
\text { Deferred Laser } \mathbf{N}= \\
172\end{array}$ & $\begin{array}{c}\text { Triamcinolone }+ \\
\text { Prompt Laser } N=171\end{array}$ \\
\hline \multicolumn{5}{|l|}{ Change in visual acuity (letters) } \\
\hline Mean \pm SD & $+3 \pm 13$ & $+9 \pm 11$ & $+9 \pm 11$ & $+4 \pm 13$ \\
\hline Median (25th, 75th percentile) & $+4(-2,+10)$ & $+10(+4,+16)$ & $+9(+5,+15)$ & $+4(-3,+12)$ \\
\hline $\begin{array}{l}\text { Difference in mean change from sham } \\
\text { +prompt laser }(95 \% \mathrm{CI})[P \text { Value }]^{\dagger}\end{array}$ & & $\begin{array}{l}+6.3(+3.6,+8.9) \\
\quad[P<0.001]\end{array}$ & $\begin{array}{l}+6.8(+4.1,+9.4) \\
\quad[P<0.001]\end{array}$ & $\begin{array}{c}+1.1(-1.6,+3.8)[P= \\
0.33]\end{array}$ \\
\hline \multicolumn{5}{|l|}{ Distribution of change, no. (\%) } \\
\hline$\geq 15$ letter improvement & $39(14 \%)$ & $54(31 \%)$ & $48(28 \%)$ & $34(20 \%)$ \\
\hline 14-10 letter improvement & $36(13 \%)$ & $37(21 \%)$ & $33(19 \%)$ & $19(11 \%)$ \\
\hline 9-5 letter improvement & $62(23 \%)$ & $32(18 \%)$ & $50(29 \%)$ & $31(18 \%)$ \\
\hline Same \pm 4 letters & $81(29 \%)$ & $34(19 \%)$ & $32(19 \%)$ & $51(30 \%)$ \\
\hline 5-9 letters worse & $19(7 \%)$ & $13(7 \%)$ & $5(3 \%)$ & $10(6 \%)$ \\
\hline $10-14$ letters worse & $15(5 \%)$ & $3(2 \%)$ & $2(1 \%)$ & $12(7 \%)$ \\
\hline$\geq 15$ letters worse & $23(8 \%)$ & $2(1 \%)$ & $2(1 \%)$ & $14(8 \%)$ \\
\hline $\begin{array}{l}\text { Difference in proportion with } \geq 10 \text { letter } \\
\text { improvement from sham }+ \text { prompt laser } \\
(95 \% \mathrm{CI})^{*}\end{array}$ & & $+25 \%(+14 \%,+36 \%)$ & $+20 \%(+9 \%,+30 \%)$ & $+5 \%(-6 \%,+15 \%)$ \\
\hline $\begin{array}{l}\text { Relative risk }(95 \% \mathrm{CI})[P \text { Value }]^{\S} \text { for } \\
\text { comparison with sham+prompt laser }\end{array}$ & 1.0 & $\begin{array}{l}1.91(1.44,2.53) \\
\quad[P<0.001]\end{array}$ & $\begin{array}{l}1.73(1.29,2.30) \\
{[P<0.001]}\end{array}$ & $\begin{array}{c}1.16(0.83,1.64)[P= \\
0.29]\end{array}$ \\
\hline $\begin{array}{l}\text { Difference in proportion with } \geq 10 \text { letter } \\
\text { worsening from sham }+ \text { prompt laser }(95 \% \\
\mathrm{CI})^{*}\end{array}$ & & $-11 \%(-17 \%,-5 \%)$ & $-11 \%(-17 \%,-6 \%)$ & $+1 \%(-7 \%,+9 \%)$ \\
\hline $\begin{array}{l}\text { Relative risk }(95 \% \mathrm{CI})[P \text { Value }]^{\S} \text { for } \\
\text { comparison with sham+prompt laser }\end{array}$ & 1.0 & $\begin{array}{l}0.20(0.07,0.61) \\
\quad[P<0.001]\end{array}$ & $\begin{array}{c}0.17(0.05 .0 .59) \\
{[P<0.001]}\end{array}$ & $\begin{array}{c}1.08(0.62,1.91)[P= \\
0.74]\end{array}$ \\
\hline $\begin{array}{l}\text { Difference in proportion with } \geq 15 \text { letter } \\
\text { improvement from sham }+ \text { prompt laser } \\
(95 \% \mathrm{CI})^{\ddagger}\end{array}$ & & $+17 \%(+7 \%,+27 \%)$ & $+14 \%(+5 \%,+23 \%)$ & $+6 \%(-3 \%,+15 \%)$ \\
\hline $\begin{array}{l}\text { Relative risk }(95 \% \mathrm{CI})[P \text { Value }]^{\S} \text { for } \\
\text { comparison with sham+prompt laser }\end{array}$ & 1.0 & $\begin{array}{l}2.18(1.39,3.41) \\
\quad[P<0.001]\end{array}$ & $\begin{array}{c}1.97(1.27,3.07) \\
\quad[P<0.001]\end{array}$ & $\begin{array}{c}1.40(0.85,2.32)[P= \\
0.10]\end{array}$ \\
\hline $\begin{array}{l}\text { Difference in proportion with } \geq 15 \text { letter } \\
\text { worsening from sham }+ \text { prompt laser }(95 \% \\
\text { CI })^{+}\end{array}$ & & $-7 \%(-12 \%,-3 \%)$ & $-7 \%(-12 \%,-3 \%)$ & $-0.2 \%(-7 \%,+6 \%)$ \\
\hline $\begin{array}{l}\text { Relative risk }(95 \% \mathrm{CI})[P \text { Value }]^{\S} \text { for } \\
\text { comparison with sham+prompt laser }\end{array}$ & 1.0 & $\begin{array}{c}0.14(0.03,0.77)[P= \\
0.006]\end{array}$ & $\begin{array}{c}0.14(0.03,0.78)[P= \\
0.006]\end{array}$ & $\begin{array}{c}0.97(0.44,2.13)[P= \\
0.93]\end{array}$ \\
\hline \multicolumn{5}{|l|}{$\mathrm{CI}=$ confidence interval; $\mathrm{SD}=$ standard deviation. } \\
\hline \multicolumn{5}{|c|}{$\begin{array}{l}\text { Adjusted for correlation between } 2 \text { study eyes. Confidence intervals are adjusted for multiple comparisons. } \\
\text { * Visits occurring between } 308 \text { and } 420 \text { days (between } 44 \text { and } 60 \text { weeks) from randomization were included as } 1 \text {-year visits. When more than } 1 \text { visit } \\
\text { occurred in this window, data from the visit closest to the } 1 \text {-year target date were used. For other eyes without any } 1 \text {-year data (15 eyes in the sham } \\
+ \text { prompt laser group, } 14 \text { eyes in the ranibizumab+prompt laser group, } 8 \text { eyes in the ranibizumab+deferred laser group, and } 8 \text { eyes in the triamcinolone } \\
+ \text { prompt laser group) the last observation carried forward method was used to impute data for the primary analysis. }\end{array}$} \\
\hline
\end{tabular}

Ophthalmology. Author manuscript; available in PMC 2011 June 1. 


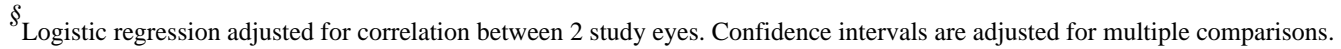




\section{Table 11}

Change in Retinal Thickness from Baseline to 1 Year*

\begin{tabular}{|c|c|c|c|c|}
\hline $\begin{array}{l}\text { Change in OCT Central Subfield } \\
\text { Thickness }\end{array}$ & $\begin{array}{l}\text { Sham + Prompt } \\
\text { Laser } N=271\end{array}$ & $\begin{array}{c}\text { Ranibizumab }+ \\
\text { Prompt Laser } N=171\end{array}$ & $\begin{array}{c}\text { Ranibizumab + } \\
\text { Deferred Laser } \\
\quad N=175\end{array}$ & $\begin{array}{c}\text { Triamcinolone }+ \\
\text { Prompt Laser } N=173\end{array}$ \\
\hline \multicolumn{5}{|l|}{ Overall Change $^{\dagger}$} \\
\hline $\begin{array}{l}\text { Thickness }(\mu \mathrm{m}) \text { Median (25th, 75th } \\
\text { percentile) }\end{array}$ & $307(234,393)$ & $241(209,291)$ & $256(206,311)$ & $247(206,305)$ \\
\hline Change from baseline $(\mu \mathrm{m})$ Mean $\pm \mathrm{SD}$ & $-102 \pm 151$ & $-131 \pm 129$ & $-137 \pm 136$ & $-127 \pm 140$ \\
\hline $\begin{array}{l}\text { Change from baseline }(\mu \mathrm{m}) \text { Median } \\
\text { (25th, 75th percentile) }\end{array}$ & $-79(-191,-7)$ & $-112(-210,-44)$ & $-111(-203,-35)$ & $-90(-219,-36)$ \\
\hline $\begin{aligned} & \text { Difference in mean change from sham } \\
+ & \text { prompt laser }(95 \% \mathrm{CI})[P \text { value }]^{+}\end{aligned}$ & & $\begin{array}{c}-55-78 \text { to }-32) \\
{[P<0.001]}\end{array}$ & $\begin{array}{c}-49(-72 \text { to }-26) \\
{[P<0.001]}\end{array}$ & $\begin{array}{c}-52(-75 \text { to }-29) \\
{[P<0.001]}\end{array}$ \\
\hline $\begin{array}{l}\text { Thickness }<250 \text { with at least a } 25 \mu \mathrm{m} \\
\text { decrease from baseline, No. (\%) }\end{array}$ & $72(27 \%)$ & $91(53 \%)$ & $74(42 \%)$ & $82(47 \%)$ \\
\hline $\begin{array}{l}\text { Relative risk }(95 \% \mathrm{CI})[P \text { value }]^{\S} \text { for } \\
\text { comparison with sham }+ \text { prompt laser }\end{array}$ & 1.0 & $\begin{array}{c}2.00(1.52 \text { to } 2.64) \\
{[P<0.001]}\end{array}$ & $\begin{array}{c}1.55(1.13 \text { to } 2.13) \\
\quad[P=0.001]\end{array}$ & $\begin{array}{c}1.76(1.31 \text { to } 2.36) \\
{[\mathrm{P}<0.001]}\end{array}$ \\
\hline \multicolumn{5}{|l|}{ LogOCT, No. $(\%)^{/ l}$} \\
\hline$\geq 2$ step improvement & $81(30 \%)$ & $72(42 \%)$ & $71(41 \%)$ & $65(38 \%)$ \\
\hline$\geq 2$ step worsening & $6(2 \%)$ & $1(1 \%)$ & 0 & $4(2 \%)$ \\
\hline Baseline thickness $<400 \mu \mathrm{m}$ & $\mathrm{N}=\mathbf{1 2 7}$ & $\mathrm{N}=\mathbf{1 0 0}$ & $\mathrm{N}=97$ & $\mathrm{~N}=104$ \\
\hline $\begin{array}{l}\text { Thickness }(\mu \mathrm{m}) \text { Median (25th, 75th } \\
\text { percentile) }\end{array}$ & $286(222,353)$ & $235(203,266)$ & $241(197,285)$ & $246(211,287)$ \\
\hline Change from baseline $(\mu \mathrm{m})$ Mean \pm SD & $-21 \pm 88$ & $-65 \pm 78$ & $-64 \pm 73$ & $-53 \pm 85$ \\
\hline $\begin{array}{l}\text { Change from baseline }(\mu \mathrm{m}) \text { Median } \\
\text { (25th, 75th percentile) }\end{array}$ & $-27(-79,+25)$ & $-75(-120,-8)$ & $-54(-112,-18)$ & $-52(-93,-9)$ \\
\hline $\begin{array}{l}\text { Thickness }<250 \text { with at least a } 25 \mu \mathrm{m} \\
\text { decrease from baseline }\end{array}$ & $36(28 \%)$ & $55(55 \%)$ & $45(47 \%)$ & $48(46 \%)$ \\
\hline \multicolumn{5}{|l|}{ LogOCT, No. $(\%) / /$} \\
\hline$\geq 2$ step improvement & $16(13 \%)$ & $22(22 \%)$ & $21(22 \%)$ & $15(14 \%)$ \\
\hline$\geq 2$ step worsening & $5(4 \%)$ & $1(1 \%)$ & 0 & $4(4 \%)$ \\
\hline Baseline thickness $\geq 400 \mu \mathrm{m}$ & $N=144$ & $\mathrm{~N}=71$ & $N=78$ & $N=69$ \\
\hline $\begin{array}{l}\text { Thickness }(\mu \mathrm{m}) \text { Median (25th, } 75 \text { th } \\
\text { percentile) }\end{array}$ & $333(246,423)$ & $249(221,320)$ & $279(219,356)$ & $253(193,337)$ \\
\hline Change from baseline $(\mu \mathrm{m})$ Mean \pm SD & $-174 \pm 158$ & $-225 \pm 128$ & $-226 \pm 142$ & $-239 \pm 134$ \\
\hline $\begin{array}{l}\text { Change from baseline ( } \mu \mathrm{m}) \text { Median } \\
\text { (25th, 75th percentile) }\end{array}$ & $-175(-263,-71)$ & $-238(-299,-158)$ & $-208(-306,-143)$ & $-254(-317,-172)$ \\
\hline $\begin{array}{l}\text { Thickness }<250 \text { with at least a } 25 \mu \mathrm{m} \\
\text { decrease from baseline }\end{array}$ & $36(25 \%)$ & $36(51 \%)$ & $29(37 \%)$ & $34(49 \%)$ \\
\hline \multicolumn{5}{|l|}{ LogOCT, No. $(\%) / /$} \\
\hline$\geq 2$ step improvement & $65(45 \%)$ & $50(70 \%)$ & $50(64 \%)$ & $50(72 \%)$ \\
\hline$\geq 2$ step worsening & $1(1 \%)$ & 0 & 0 & 0 \\
\hline
\end{tabular}

$\mathrm{CI}=$ confidence interval; $\log \mathrm{OCT}=\log$ arithmic transformation of optical coherence tomography $\mathrm{OCT}=$ optical coherence tomography; $\mathrm{SD}=$ standard deviation. 
* Visits occurring between 308 and 420 days (between 44 and 60 wks) from randomization were included as 1 -yr visits. When $>1$ visit occurred in this window, data from the visit closest to the 1-yr target date were used.

${ }^{\dagger}$ Missing (or ungradeable) data as follows for the sham + prompt laser, ranibizumab + prompt laser, ranibizumab + deferred laser, and triamcinolone + prompt laser groups, respectively: 22, 16, 13, 13 .

* Analysis of covariance adjusted for baseline OCT retinal thickness and visual acuity and correlation between 2 study eyes. Confidence intervals are adjusted for multiple comparisons.

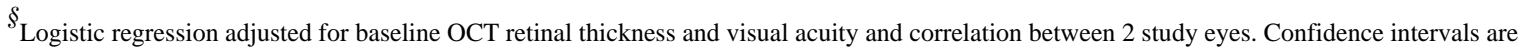
adjusted for multiple comparisons.

"Logarithmic transformation of OCT central subfield thickness is calculated by taking the log base 10 of the ratio of the central subfield thickness divided by 200 and rounding to the nearest hundredth. The change is the change in the log values. (Ferris FL III, Miller KM, Glassman AR, Beck RW. A proposed method of logarithmic transformation of optical coherence tomography data for use in clinical research. Ophthalmology. In Press.) 
Table 12

Change in Retinal Thickening from Baseline to 2 Years*

\begin{tabular}{|c|c|c|c|c|}
\hline $\begin{array}{l}\text { Change in OCT Central Subfield } \\
\text { Thickness }^{\dagger}\end{array}$ & $\begin{array}{l}\text { Sham + Prompt } \\
\text { Laser N = 152 }\end{array}$ & $\begin{array}{c}\text { Ranibizumab + } \\
\text { Prompt Laser N = } 99\end{array}$ & $\begin{array}{c}\text { Ranibizumab + } \\
\text { Deferred Laser } N=100\end{array}$ & $\begin{array}{c}\text { Triamcinolone }+ \\
\text { Prompt Laser } N=93\end{array}$ \\
\hline \multicolumn{5}{|l|}{ Overall Change } \\
\hline $\begin{array}{l}\text { Thickness (microns) Median (25th, } \\
\text { 75th percentile) }\end{array}$ & $267(204,350)$ & $240(197,289)$ & $231(206,288)$ & $258(207,330)$ \\
\hline $\begin{array}{l}\text { Change from baseline (microns) } \\
\text { Mean } \pm \text { SD }\end{array}$ & $-133 \pm 145$ & $-144 \pm 165$ & $-170 \pm 143$ & $-95 \pm 158$ \\
\hline $\begin{array}{l}\text { Change from baseline (microns) } \\
\text { Median ( } 25 \text { th, } 75 \text { th percentile) }\end{array}$ & $-104(-231,-25)$ & $-107(-255,-37)$ & $-146(-229,-81)$ & $-78(-176,-12)$ \\
\hline $\begin{array}{l}\text { Difference in mean change from } \\
\text { sham+prompt laser (95\% CI) [P value }] \\
\neq\end{array}$ & & $\begin{array}{c}-31(-60,-0.9)[P= \\
0.01]\end{array}$ & $\begin{array}{c}-36(-66,-7)[P= \\
0.004]\end{array}$ & $\begin{array}{c}-3(-34,+28)[P= \\
0.81]\end{array}$ \\
\hline $\begin{array}{l}\text { Thickness }<250 \text { with at least a } 25 \\
\text { micron decrease from baseline, no. (\%) }\end{array}$ & $57(38 \%)$ & $53(54 \%)$ & $55(55 \%)$ & $41(44 \%)$ \\
\hline $\begin{array}{l}\text { Relative risk (95\% CI) }[P \text { Value }]^{\S} \text { for } \\
\text { comparison with sham+prompt laser }\end{array}$ & & $\begin{array}{c}1.36(1.01,1.84)[P= \\
0.01]\end{array}$ & $\begin{array}{c}1.39(1.01,1.90)[P= \\
0.01]\end{array}$ & $\begin{array}{c}1.18(0.85,1.63)[P= \\
0.22]\end{array}$ \\
\hline \multicolumn{5}{|l|}{ LogOCT, no. $(\%)^{/ l}$} \\
\hline Two or more step improvement & $65(43 \%)$ & $44(44 \%)$ & $56(56 \%)$ & $33(35 \%)$ \\
\hline Two or more step worsening & $2(1 \%)$ & $1(1 \%)$ & 0 & $4(4 \%)$ \\
\hline
\end{tabular}

$\mathrm{CI}=$ confidence interval; $\mathrm{OCT}=$ optical coherence tomography; $\mathrm{SD}=$ standard deviation.

* Visits occurring between 616 and 840 days (between 88 and 120 weeks) from randomization were included as 2-year visits. When more than 1 visit occurred in this window, data from the visit closest to the 2-year target date were used.

${ }^{\dagger}$ Missing (or ungradeable) data as follows for the sham+prompt laser, ranibizumab+prompt laser, ranibizumab+deferred laser, and triamcinolone +prompt laser groups, respectively: 11, 7, 12, 10 .

\#Analysis of covariance adjusted for baseline OCT retinal thickness and visual acuity and correlation between 2 study eyes. Confidence intervals are adjusted for multiple comparisons.

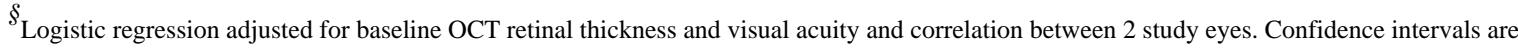
adjusted for multiple comparisons.

"Logarithmic transformation of OCT central subfield thickness (LogOCT) is calculated by taking the log base 10 of the ratio of the central subfield thickness divided by 200 and rounding to the nearest hundredth. The change is the change in the log values. (Ferris FL III, Miller KM, Glassman AR, Beck RW. A proposed method of logarithmic transformation of optical coherence tomography data for use in clinical research. Ophthalmology. In Press.) 


\section{Table 13}

Change in Optical Coherence Tomography Retinal Volume from Baseline to 1 Year*

\begin{tabular}{|c|c|c|c|c|}
\hline Change in OCT Retinal Volume ${ }^{\dagger}$ & $\begin{array}{c}\text { Sham + Prompt } \\
\text { Laser } N=189\end{array}$ & $\begin{array}{c}\text { Ranibizumab + } \\
\text { Prompt Laser N = } 117\end{array}$ & $\begin{array}{c}\text { Ranibizumab + } \\
\text { Deferred Laser } N= \\
132\end{array}$ & $\begin{array}{c}\text { Triamcinolone }+ \\
\text { Prompt Laser } N=121\end{array}$ \\
\hline \multicolumn{5}{|l|}{ Total volume $\left(\mathrm{mm}^{3}\right)$ at 1 year } \\
\hline Mean \pm SD & $8.1 \pm 1.4$ & $7.3 \pm 1.0$ & $7.4 \pm 1.2$ & $7.5 \pm 1.3$ \\
\hline Median (25th, 75 th percentile) & $7.9(7.2,8.7)$ & $7.0(6.6,7.8)$ & $7.1(6.6,7.8)$ & $7.2(6.7,7.9)$ \\
\hline \multicolumn{5}{|l|}{$\begin{array}{l}\text { Change in volume }\left(\mathrm{mm}^{3}\right) \text { from } \\
\text { baseline }\end{array}$} \\
\hline Mean \pm SD & $-1.0 \pm 1.4$ & $-1.4 \pm 1.4$ & $-1.5 \pm 1.5$ & $-1.4 \pm 1.6$ \\
\hline Median (25th, 75th percentile) & $-0.6(-1.7,-0.1)$ & $-1.1(-2.1,-0.6)$ & $-1.1(-2.1,-0.4)$ & $-1.2(-2.2,-0.6)$ \\
\hline $\begin{array}{l}\text { Difference in mean change from sham } \\
\text { +prompt laser }(95 \% \mathrm{CI})[P \text { Value }]^{\dagger}\end{array}$ & & $\begin{array}{c}-0.73(-1.01,-0.44) \\
{[P<0.001]}\end{array}$ & $\begin{array}{c}-0.68(-0.96,-0.41) \\
{[P<0.001]}\end{array}$ & $\begin{array}{c}-0.62(-0.91,-0.34) \\
{[P<0.001]}\end{array}$ \\
\hline
\end{tabular}

OCT = optical coherence tomography $\mathrm{SD}=$ standard deviation $; \mathrm{CI}=$ confidence interval.

* Visits occurring between 308 and 420 days (between 44 and 60 weeks) from randomization were included as 1 year visits. When more than 1 visit occurred in this window, data from the visit closest to the 1-year target date were used.

${ }^{\dagger}$ Missing (or ungradeable) data as follows for the sham+prompt laser, ranibizumab+prompt laser, ranibizumab+deferred laser, and triamcinolone +prompt laser groups, respectively: $85,54,46,55$.

*Analysis of covariance adjusted for baseline OCT retinal volume, OCT retinal thickness and visual acuity and correlation between 2 study eyes. Confidence intervals are adjusted for multiple comparisons. 
Table 14

Diabetic Retinopathy Progression from Baseline to 1 Year by Baseline Retinopathy Severity Group

\begin{tabular}{|c|c|c|c|}
\hline Change from Baseline to 1-Year Visit ${ }^{*}$ & Sham $\mathbf{N}=233$ & Ranibizumab $\mathbf{N}=303$ & Triamcinolone $\mathbf{N}=150$ \\
\hline Baseline severity: Moderately severe NPDR or better, No. $(\%)$ & $\mathbf{N}=150$ & $\mathbf{N}=182$ & $\mathbf{N}=\mathbf{8 0}$ \\
\hline Improved by 2 or more levels & $6(4 \%)$ & $46(25 \%)$ & $20(25 \%)$ \\
\hline Worsened by 2 or more levels & $11(7 \%)$ & $5(3 \%)$ & $2(3 \%)$ \\
\hline$P$ value for comparison with Sham & & $P=0.08$ & $P=0.17$ \\
\hline Baseline severity: Severe NPDR or worse, No. (\%) & $\mathbf{N}=\mathbf{8 3}$ & $\mathbf{N}=121$ & $\mathbf{N}=\mathbf{7 0}$ \\
\hline Improved by 2 or more levels ${ }^{\dagger}$ & $10(19 \%)$ & $18(28 \%)$ & $6(13 \%)$ \\
\hline Worsened by 2 or more levels & $7(8 \%)$ & $1(1 \%)$ & $2(3 \%)$ \\
\hline$P$ value for comparison with Sham & & $P=0.03$ & $P=0.17$ \\
\hline
\end{tabular}

NPDR $=$ non-proliferative diabetic retinopathy

${ }^{*} \mathrm{~N}=685 ; 113$ eyes had missing or ungradeable photos at 1 year

${ }^{\dagger}$ Excludes 127 eyes with baseline Level 60 (scars of full or partial PRP present; abnormalities of PDR absent) 
Table 15

Major Ocular Adverse Events during First Year of Follow-Up

\begin{tabular}{|c|c|c|c|c|}
\hline & $\begin{array}{c}\text { Sham + } \\
\text { Prompt Laser } \\
\text { N=293 }\end{array}$ & $\begin{array}{c}\text { Ranibizumab + } \\
\text { Prompt Laser } \\
\text { N=187 No. of } \\
\text { Injections }=1497\end{array}$ & $\begin{array}{c}\text { Ranibizumab + } \\
\text { Deferred Laser } \\
\mathbf{N}=188 \text { No. of } \\
\text { Injections = 1613 }\end{array}$ & $\begin{array}{c}\text { Triamcinolone + } \\
\text { Prompt Laser N=186 } \\
\text { No. of Injections = } \\
541\end{array}$ \\
\hline Endophthalmitis, No. $(\%)^{*}$ & $1(<1 \%)$ & $1(1 \%)$ & $1(1 \%)$ & 0 \\
\hline Pseudoendophthalmitis, No. $(\%)^{\dagger}$ & $1(<1 \%)$ & 0 & 0 & $1(1 \%)$ \\
\hline Ocular vascular event, No. $(\%)^{*}$ & $1(<1 \%)$ & $1(1 \%)$ & 0 & $2(1 \%)$ \\
\hline Retinal detachment, No. (\%) & 0 & 0 & $1(1 \%)^{\S}$ & 0 \\
\hline Vitrectomy, No. $(\%)$ & $7(2 \%)$ & 0 & $3(2 \%)$ & 0 \\
\hline Vitreous hemorrhage, No. (\%) & $15(5 \%)$ & $3(2 \%)$ & $4(2 \%)$ & $2(1 \%)$ \\
\hline \multicolumn{5}{|l|}{ Elevated intraocular pressure/glaucoma, No. (\%) } \\
\hline Increase $\geq 10 \mathrm{mmHg}$ from baseline & $16(5 \%)$ & $10(5 \%)$ & $5(3 \%)$ & $70(38 \%)$ \\
\hline $\mathrm{IOP} \geq 30 \mathrm{mmHg}$ & $3(1 \%)$ & $2(1 \%)$ & $4(2 \%)$ & $46(25 \%)$ \\
\hline $\begin{array}{l}\text { Initiation of IOP-lowering medication at any } \\
\text { visit } / /\end{array}$ & $9(3 \%)$ & $5(3 \%)$ & $4(2 \%)$ & $41(22 \%)$ \\
\hline No. of eyes meeting $\geq 1$ of the above & $23(8 \%)$ & $12(6 \%)$ & $7(4 \%)$ & $79(42 \%)$ \\
\hline Glaucoma surgery & 0 & 0 & 0 & 0 \\
\hline \multicolumn{5}{|l|}{ Cataract surgery } \\
\hline Phakic at baseline & $\mathrm{N}=192$ & $\mathrm{~N}=131$ & $\mathrm{~N}=134$ & $\mathrm{~N}=124$ \\
\hline No. $(\%)$ with cataract surgery & $11(6 \%)$ & $6(5 \%)$ & $8(6 \%)$ & $19(15 \%)$ \\
\hline
\end{tabular}

$\mathrm{IOP}=$ intraocular pressure

* One case unrelated to study drug injection (after cataract extraction) in the sham + prompt laser group; 2 cases related to study drug injection in the ranibizumab groups ( $0.06 \%$ of ranibizumab injections given). One case occurred at baseline and 1 at the 4 -wk visit. Endophthalmitis was defined as any patient having an intravitreal or anterior chamber tap for presumed endophthalmitits or treated for infectious endophthalmitis regardless of whether a tap was performed or whether a culture is positive.

${ }^{\dagger}$ One case was unrelated to the study drug injection (vitreous opacity with hypopyon), and 1 case was related to study drug injection in the triamcinolone group. Pseudoendophthalmitis was defined on the basis of investigator diagnosis and patient not tapped or treated for infectious endophthalmitis.

*Includes 2 central retinal vein occlusions and 2 branch retinal vein occlusions.

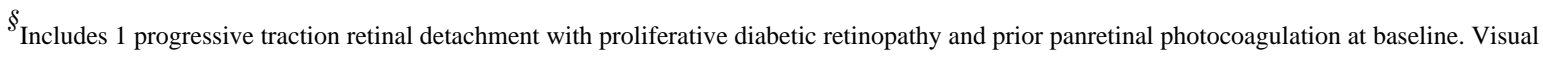
acuity remained stable, within 5 letters of the baseline visual acuity letter score of $66(20 / 50)$, while ranibizumab was given every 4 wks through the 24-wk visit when focal/grid laser also was applied. Ranibizumab was given again at the 28 -wk visit and 5 wks later, sudden vision loss was reported, and a table-top detachment involving the central macula was noted at an unscheduled visit with a visual acuity letter score of 48 (20/125). Vitrectomy surgery was delayed for several weeks because of other medical problems; after surgery, the visual acuity letter score remained $0(<20 / 800)$.

"Excludes eyes with IOP-lowering medications at baseline. 
Table 16

Major Ocular Adverse Events During 2 Years of Follow Up

\begin{tabular}{|c|c|c|c|c|}
\hline & $\begin{array}{c}\text { Sham + } \\
\text { Prompt Laser } \\
\text { N= 293 }\end{array}$ & $\begin{array}{c}\text { Ranibizumab + } \\
\text { Prompt Laser N = } \\
187 \text { \# injections = } \\
1833\end{array}$ & $\begin{array}{c}\text { Ranibizumab + } \\
\text { Deferred Laser } N= \\
188 \text { \# injections = } \\
2140\end{array}$ & $\begin{array}{c}\text { Triamcinolone + } \\
\text { Prompt Laser } N= \\
186 \# \text { injections = 685 }\end{array}$ \\
\hline Endophthalmitis, no. $(\%)^{*}$ & $1(<1 \%)$ & $2(1 \%)$ & $2(1 \%)$ & 0 \\
\hline Pseudoendophthalmitis, no. $(\%)^{\dagger}$ & $1(<1 \%)$ & 0 & 0 & $1(1 \%)$ \\
\hline Ocular vascular event, no. $(\%)^{\frac{\hbar}{*}}$ & $1(<1 \%)$ & $1(1 \%)$ & $1(1 \%)$ & $3(2 \%)$ \\
\hline Retinal detachment, no. (\%) & 0 & 0 & $1(1 \%)^{\S}$ & 0 \\
\hline Vitrectomy, no. (\%) & $15(5 \%)$ & $4(2 \%)$ & $7(4 \%)$ & $2(1 \%)$ \\
\hline Vitreous hemorrhage, no. (\%) & $27(9 \%)$ & $6(3 \%)$ & $8(4 \%)$ & $7(4 \%)$ \\
\hline \multicolumn{5}{|l|}{ Elevated intraocular pressure/glaucoma, no. (\%) } \\
\hline Increase $\geq 10 \mathrm{mmHg}$ from baseline & $22(8 \%)$ & $16(9 \%)$ & $11(6 \%)$ & $78(42 \%)$ \\
\hline $\mathrm{IOP} \geq 30 \mathrm{mmHg}$ & $8(3 \%)$ & $3(2 \%)$ & $6(3 \%)$ & $51(27 \%)$ \\
\hline $\begin{array}{l}\text { Initiation of IOP-lowering medication at any } \\
\text { visit } / /\end{array}$ & $16(5 \%)$ & $9(5 \%)$ & $6(3 \%)$ & $53(28 \%)$ \\
\hline Number of eyes meeting one or more of the above & $32(11 \%)$ & $20(11 \%)$ & $14(7 \%)$ & $93(50 \%)$ \\
\hline Glaucoma surgery $^{a}$ & $1(<1 \%)$ & $1(1 \%)$ & 0 & $2(1 \%)$ \\
\hline \multicolumn{5}{|l|}{ Cataract surgery } \\
\hline Phakic at baseline & $N=192$ & $N=131$ & $N=134$ & $N=124$ \\
\hline No. $(\%)$ with cataract surgery & $23(12 \%)$ & $16(12 \%)$ & $17(13 \%)$ & $68(55 \%)$ \\
\hline
\end{tabular}

$\mathrm{IOP}=$ intraocular pressure

* One case unrelated to study drug injection (following cataract extraction) in the sham+prompt laser group; 1 case related to study drug injection and 1 case unrelated to injection (following cataract surgery) in the ranibizumab+prompt laser group; 2 cases related to study drug injection in the ranibizumab+deferred laser group. The 3 cases related to study drug injection in the ranibizumab groups are $0.08 \%$ of ranibizumab study drug injections given. Endophthalmitis was defined as any patient having an intravitreal or anterior chamber tap for presumed endophthalmitis or treated for infectious endophthalmitis regardless of whether a tap was performed or whether a culture is positive.

$\dagger$ group. Pseudoendophthalmitis was defined based on investigator diagnosis and patient not tapped or treated for infectious endophthalmitis.

tIncludes 2 central retinal vein occlusions and 4 branch retinal vein occlusions.

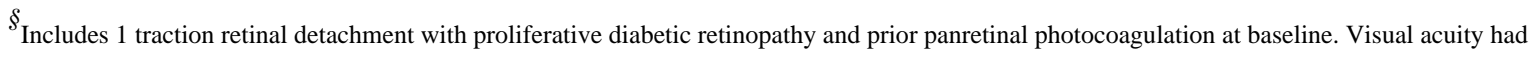
remained stable (within 5 letters) of the baseline visual acuity letter score of 66 (20/50) while ranibizumab was given every 4 weeks through the 24week visit when focal/grid laser also was applied. Ranibizumab again was given at the 28 -week visit and five weeks later, sudden vision loss was reported and a table top detachment involving the central macula was noted at an unscheduled visit with a visual acuity letter score of 48 (20/125). Vitrectomy surgery was delayed for several weeks because of other medical problems; following surgery, the visual acuity letter score remained 0 $(<20 / 800)$.

"Excludes eyes with IOP lowering medications at baseline.

$a_{\text {Includes }} 2$ filter and 2 cilliary body destruction. 


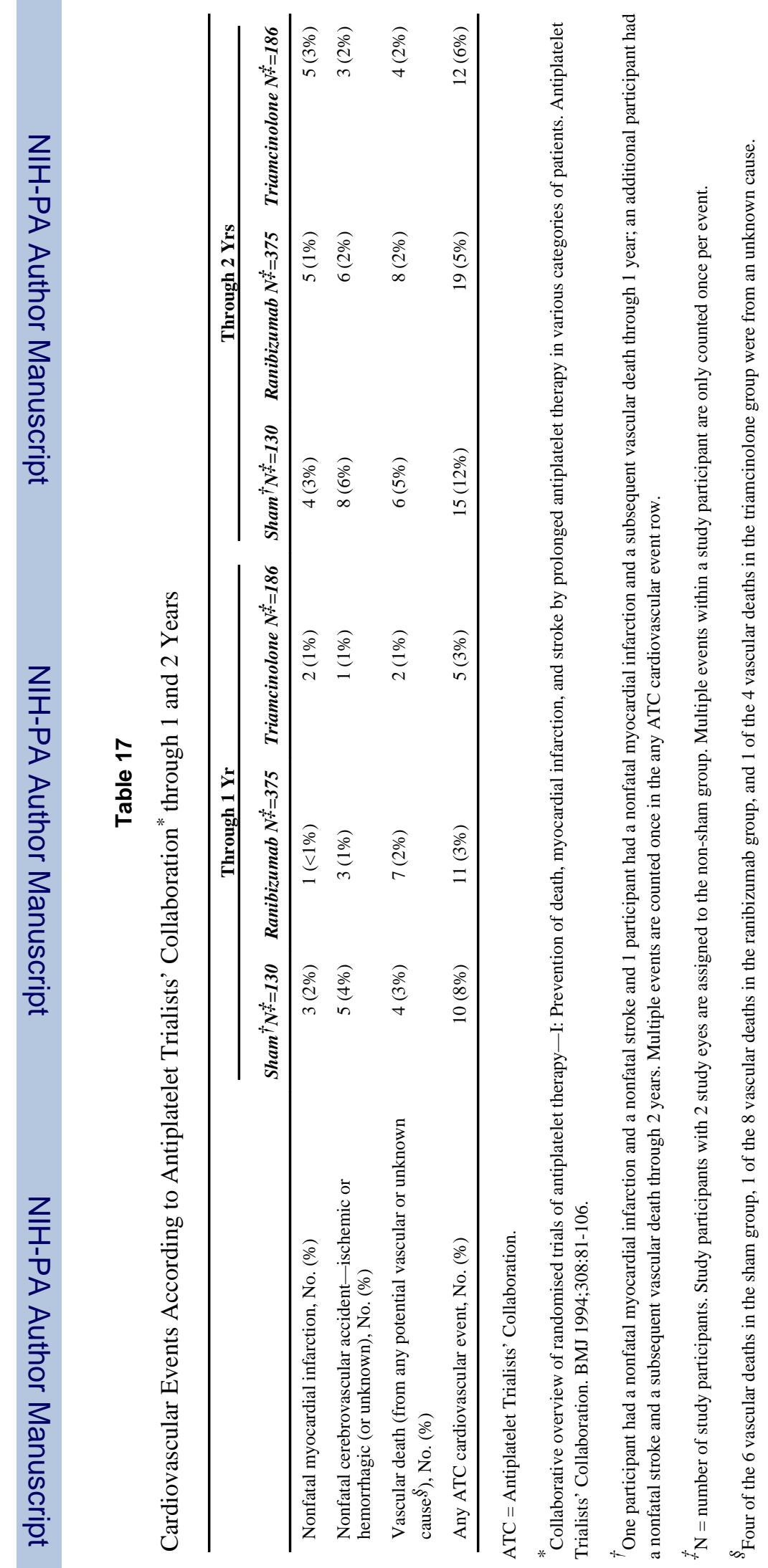

Ophthalmology. Author manuscript; available in PMC 2011 June 1. 


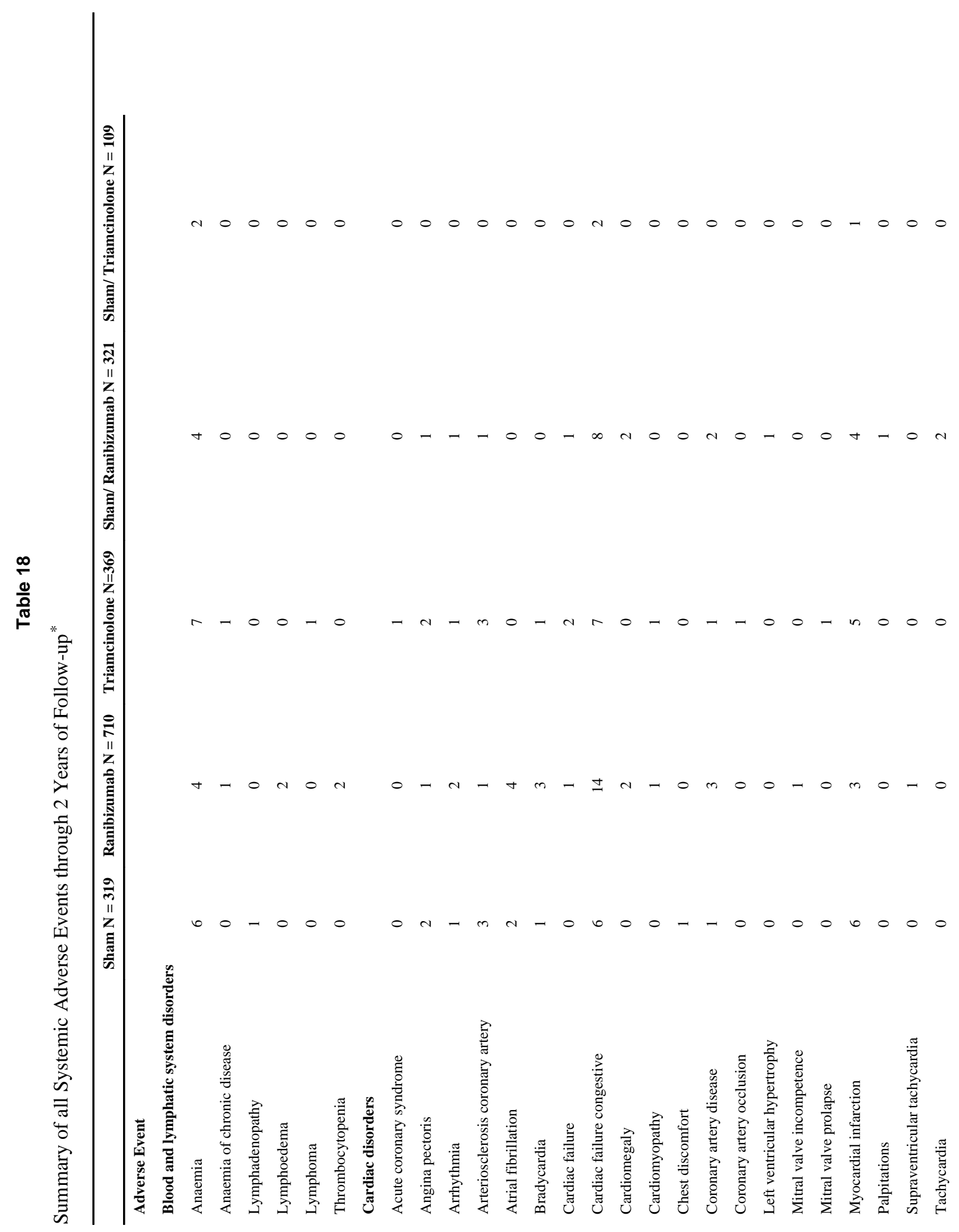

Ophthalmology. Author manuscript; available in PMC 2011 June 1. 


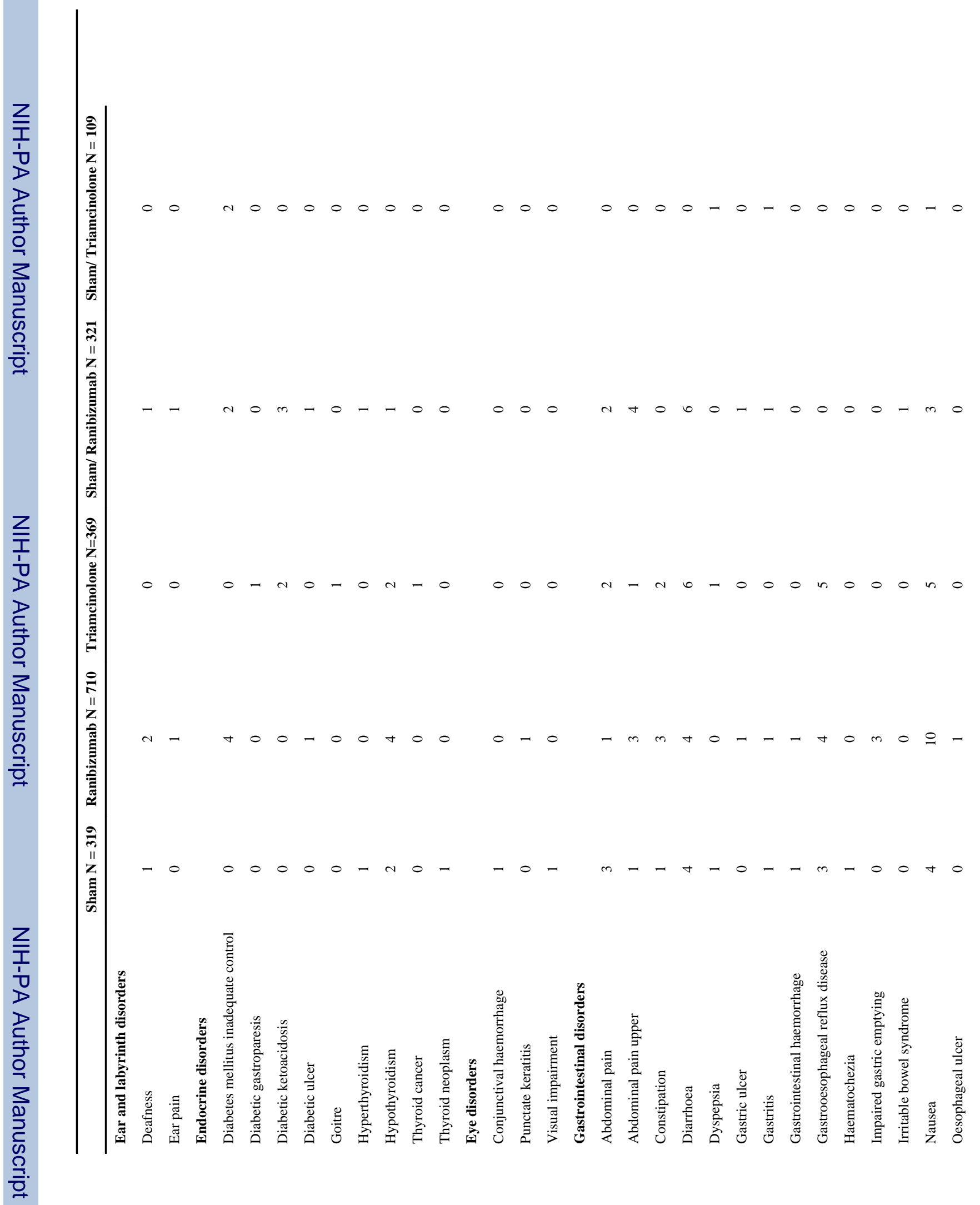

Ophthalmology. Author manuscript; available in PMC 2011 June 1. 


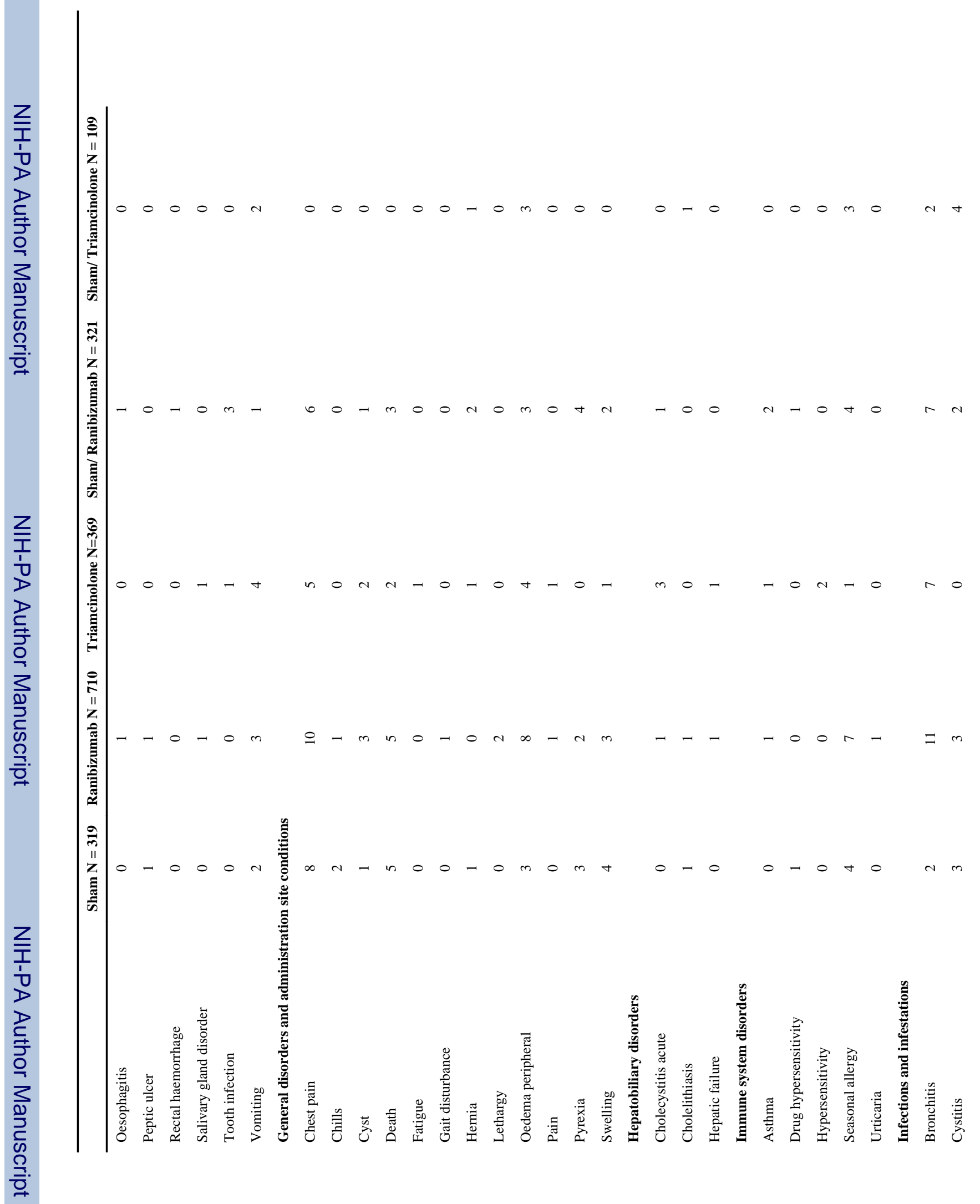

Ophthalmology. Author manuscript; available in PMC 2011 June 1. 


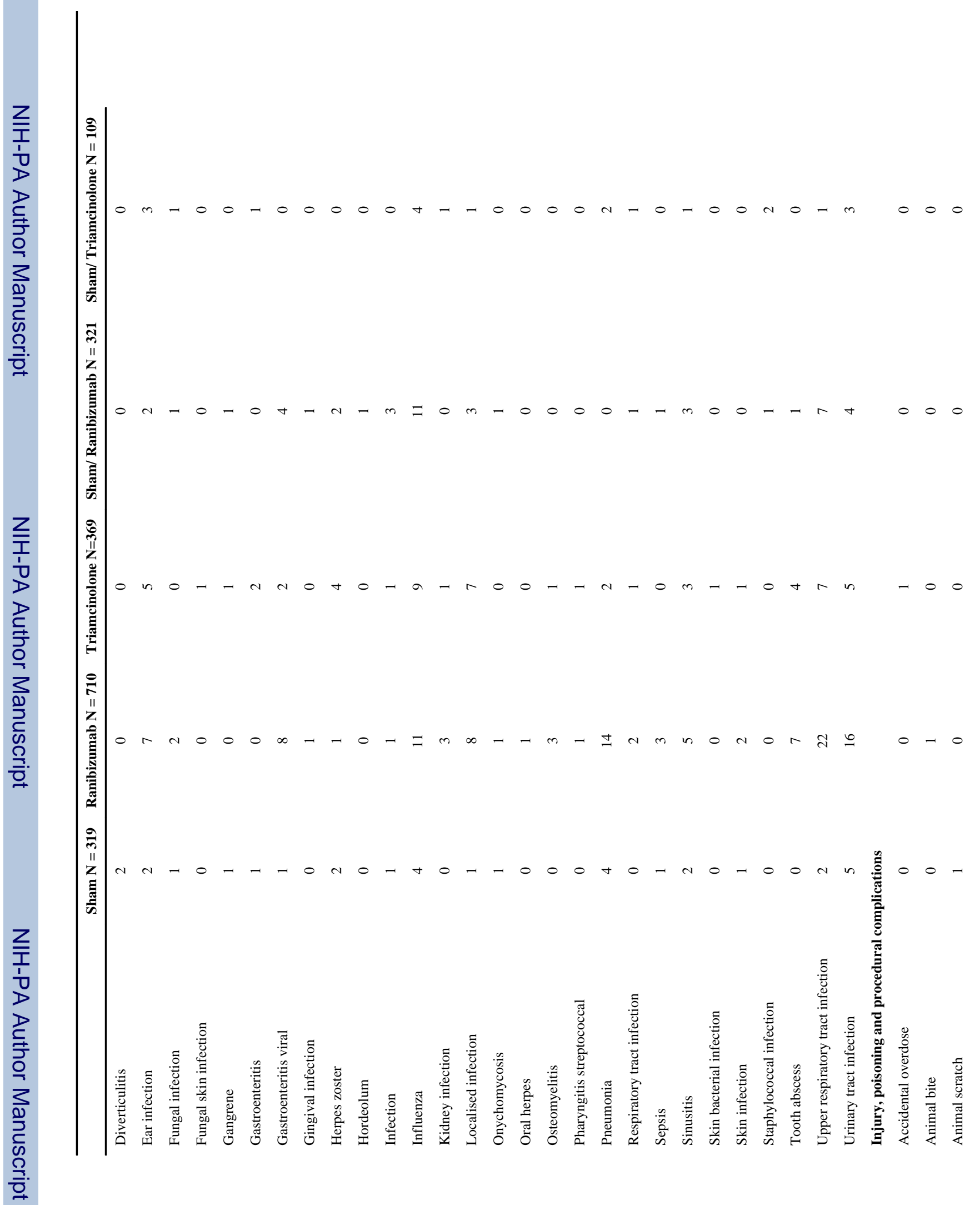

Ophthalmology. Author manuscript; available in PMC 2011 June 1. 


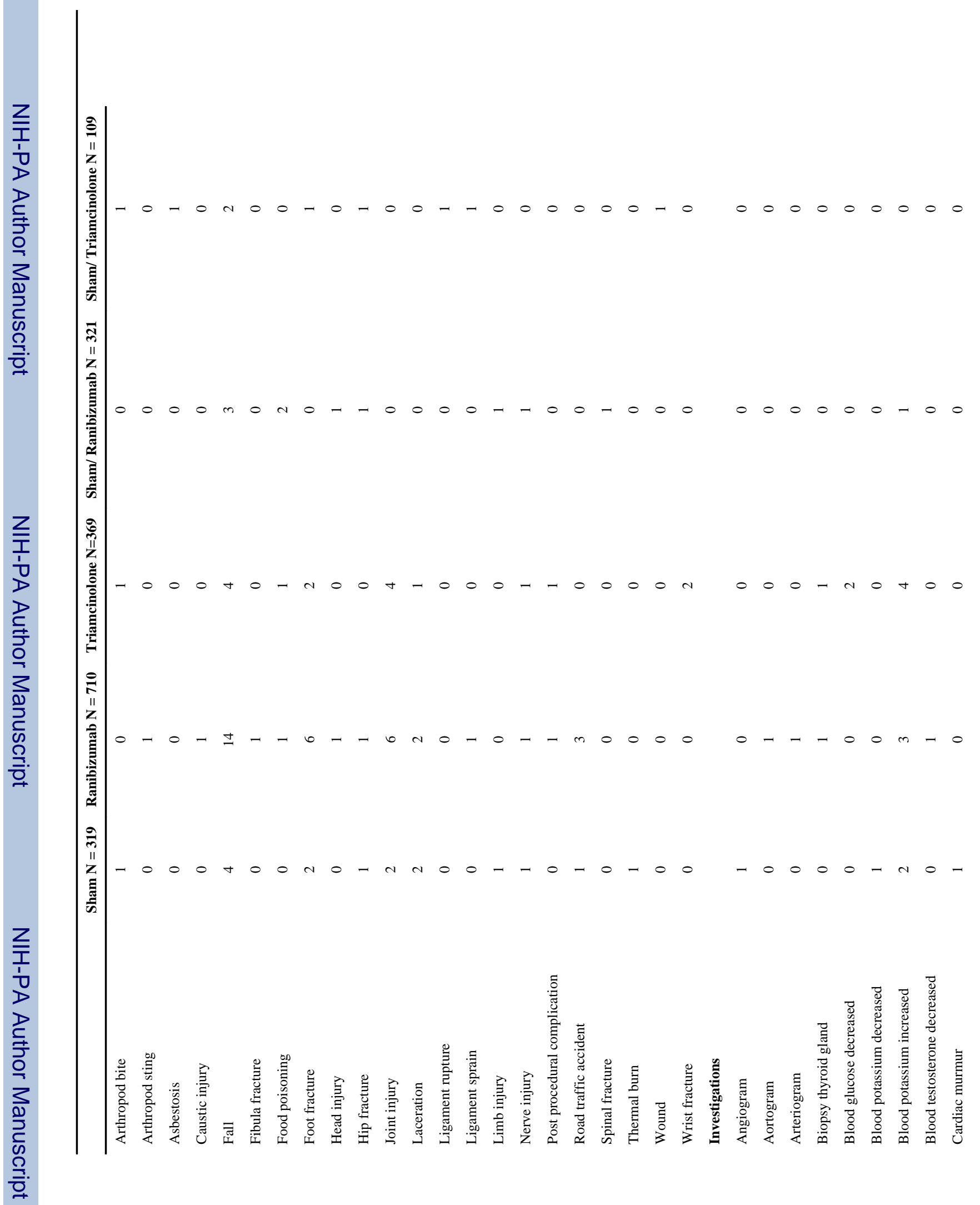

Ophthalmology. Author manuscript; available in PMC 2011 June 1. 


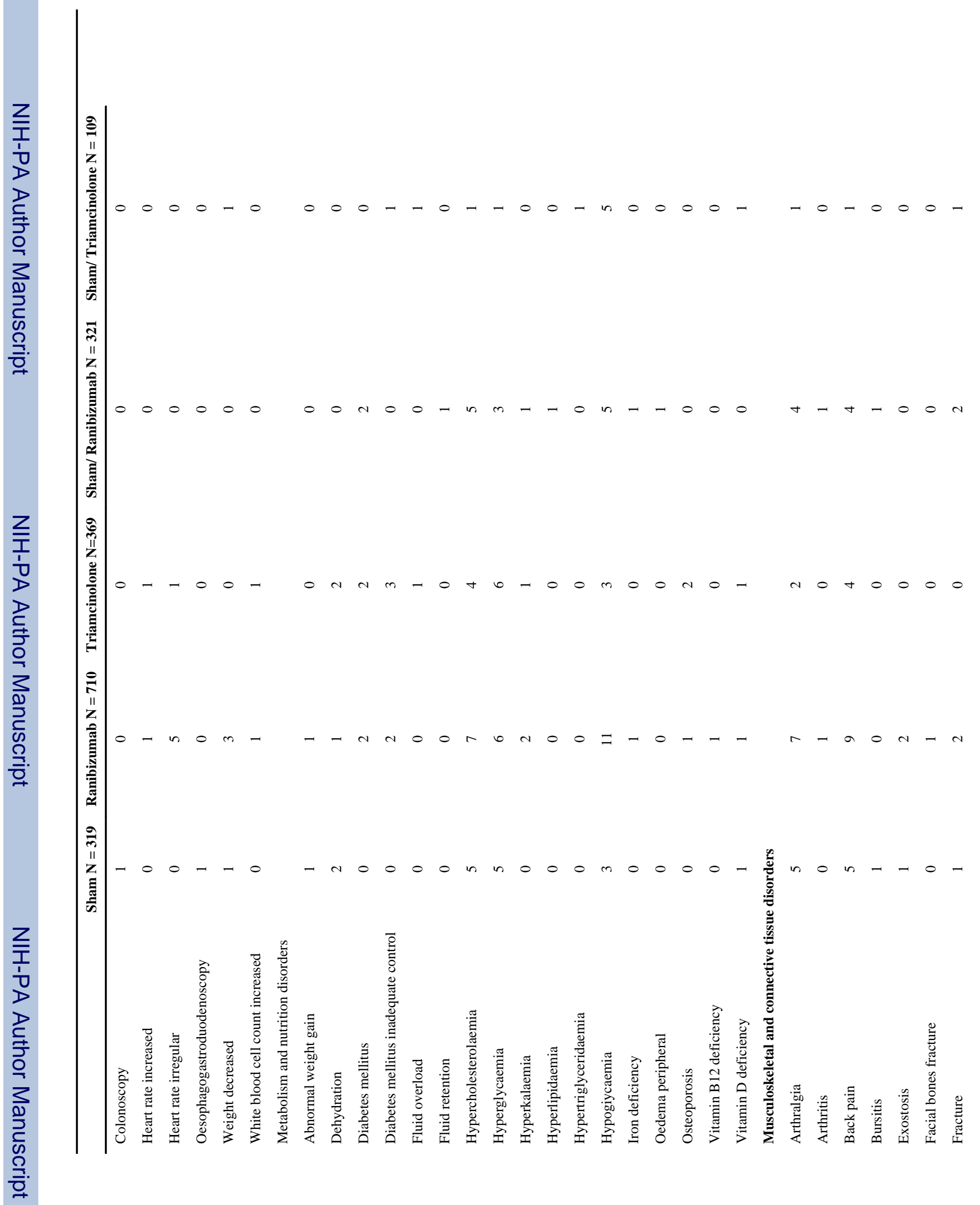

Ophthalmology. Author manuscript; available in PMC 2011 June 1. 


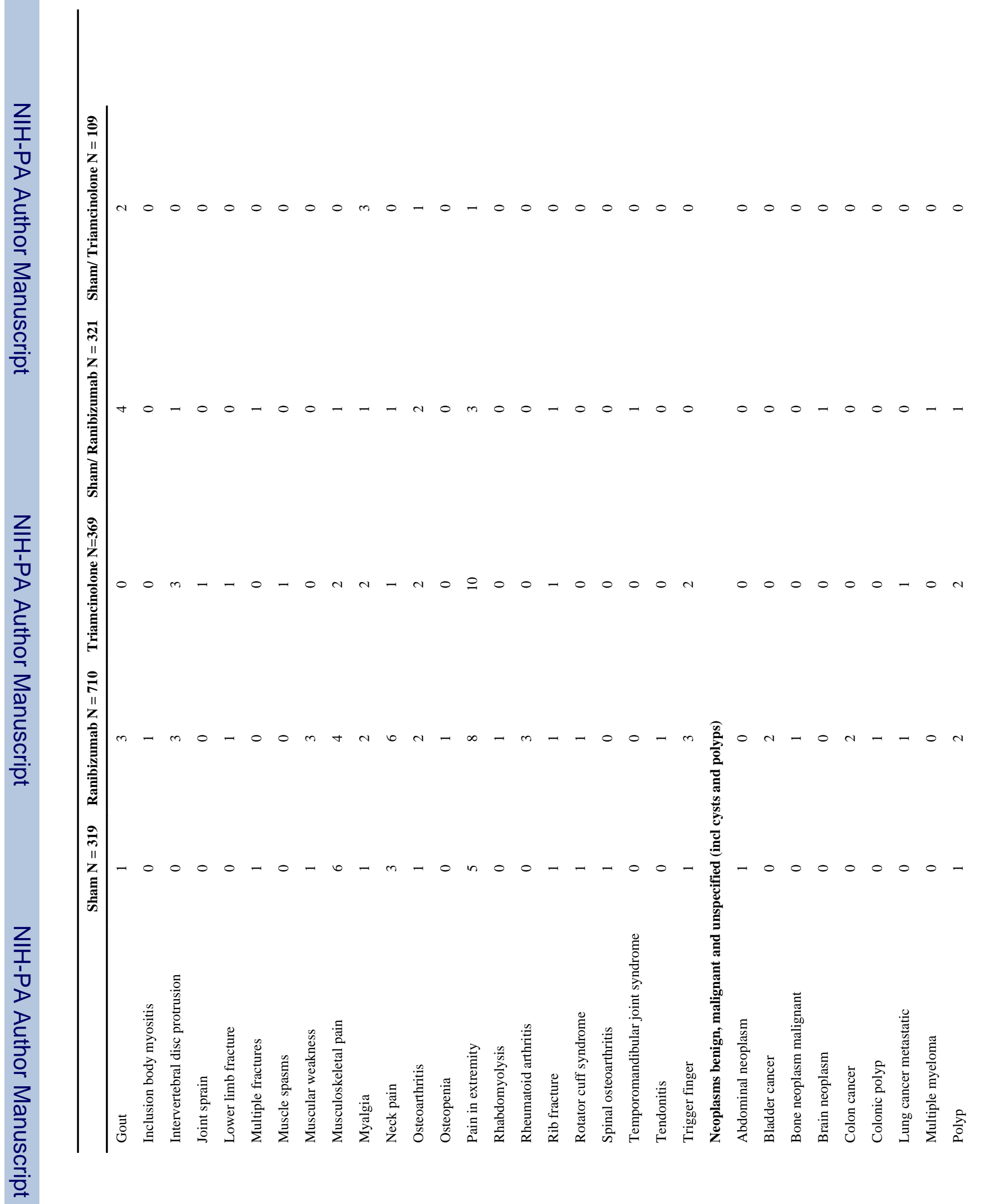

Ophthalmology. Author manuscript; available in PMC 2011 June 1. 


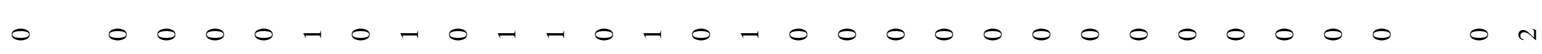




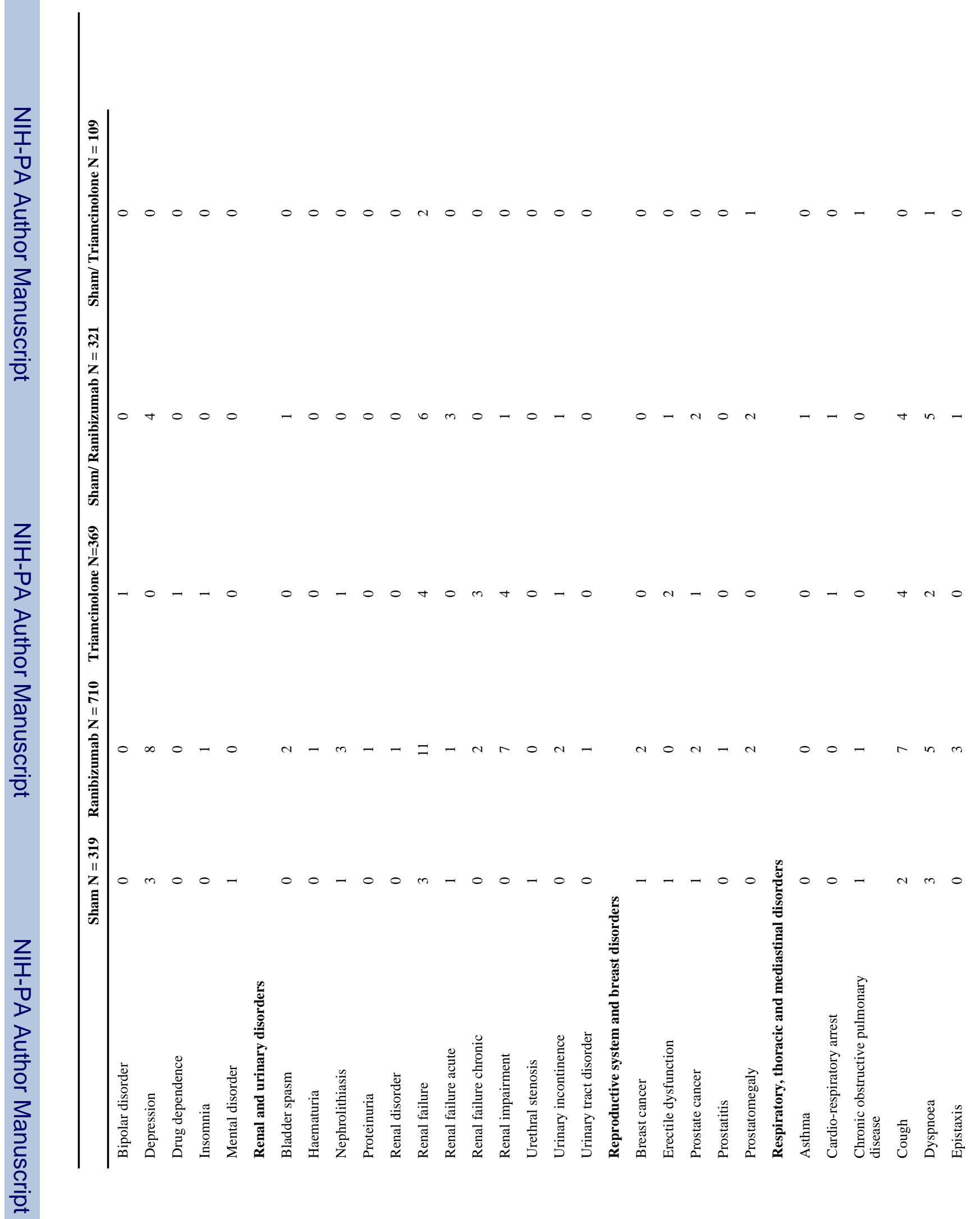

Ophthalmology. Author manuscript; available in PMC 2011 June 1. 


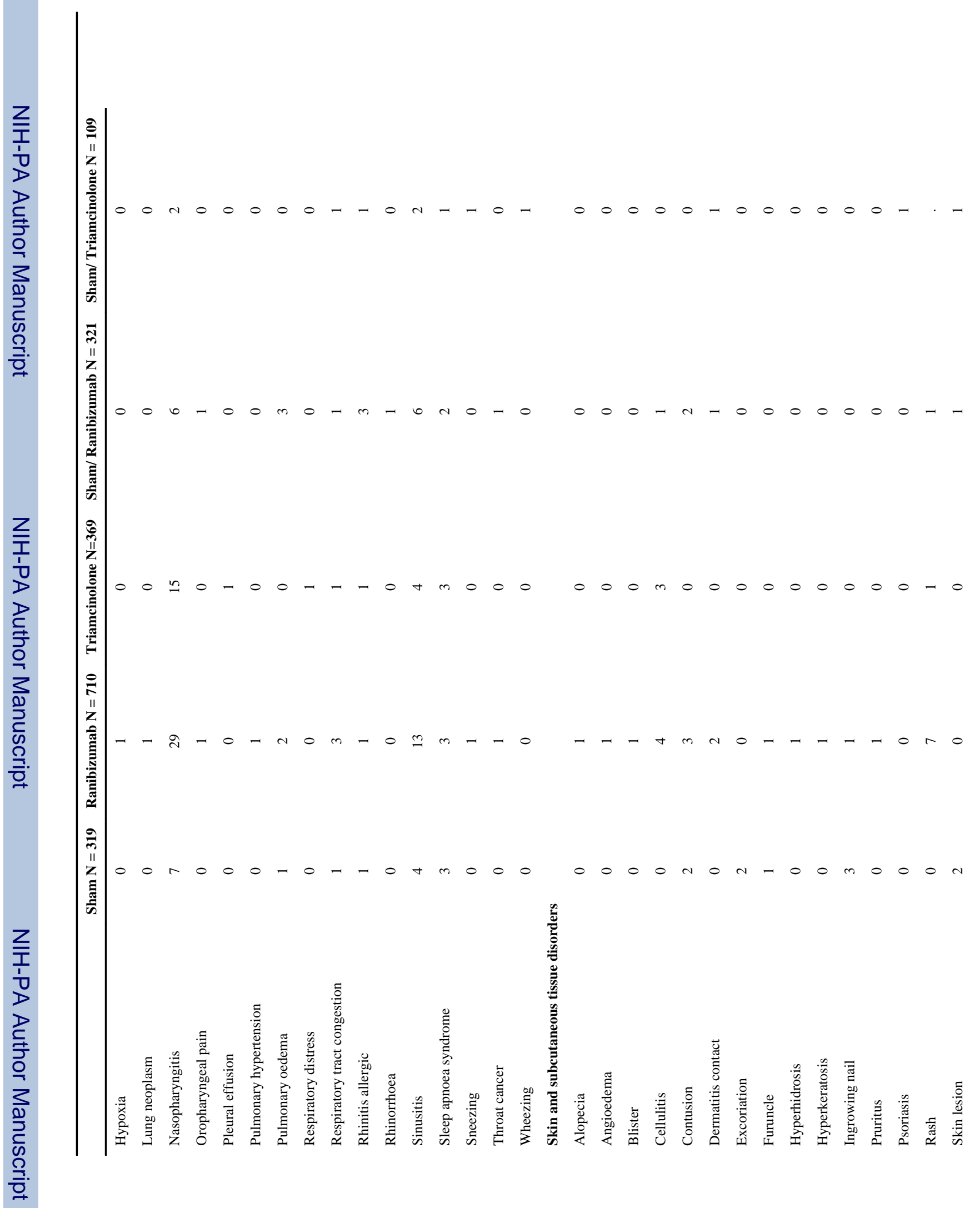

Ophthalmology. Author manuscript; available in PMC 2011 June 1. 


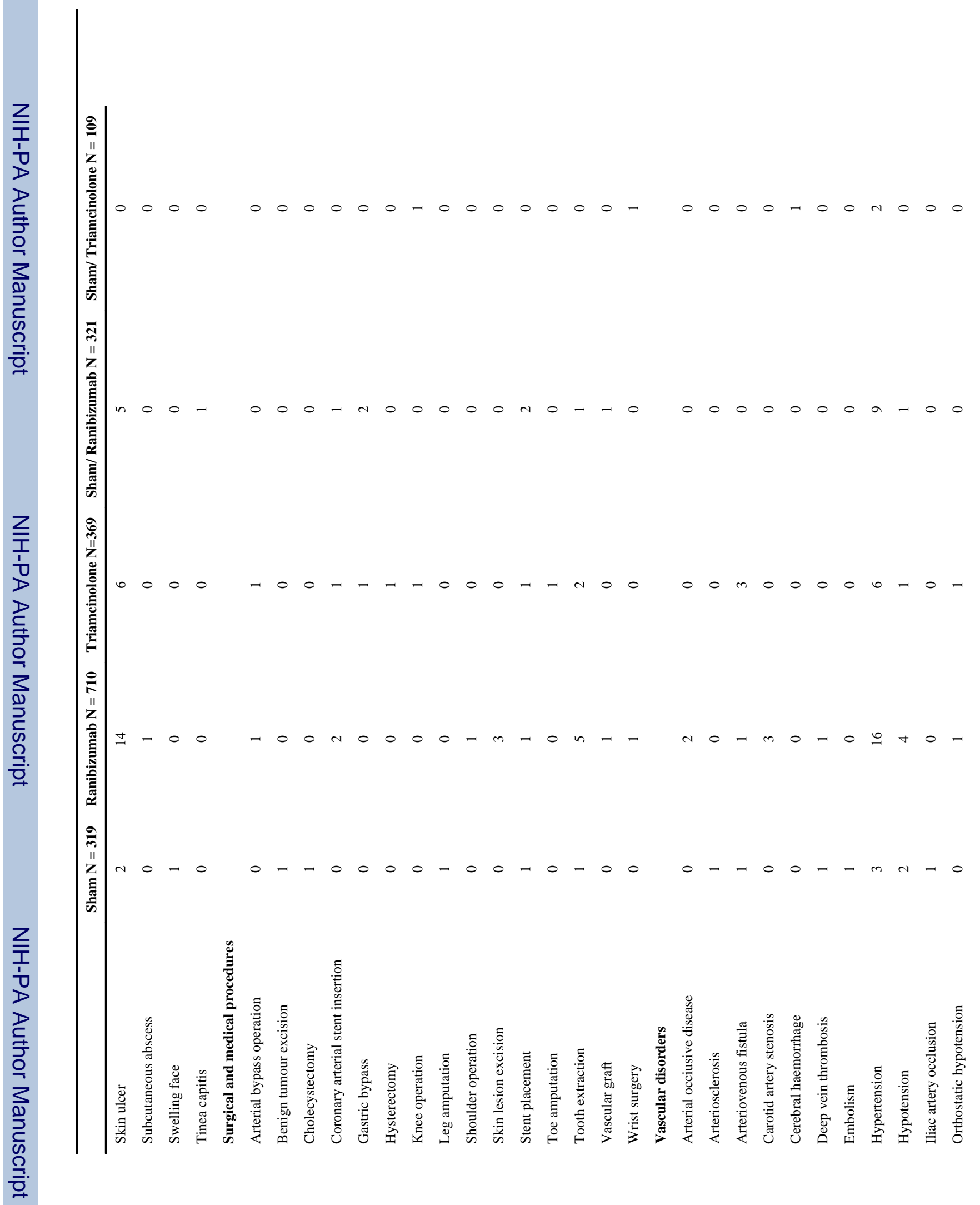

Ophthalmology. Author manuscript; available in PMC 2011 June 1. 


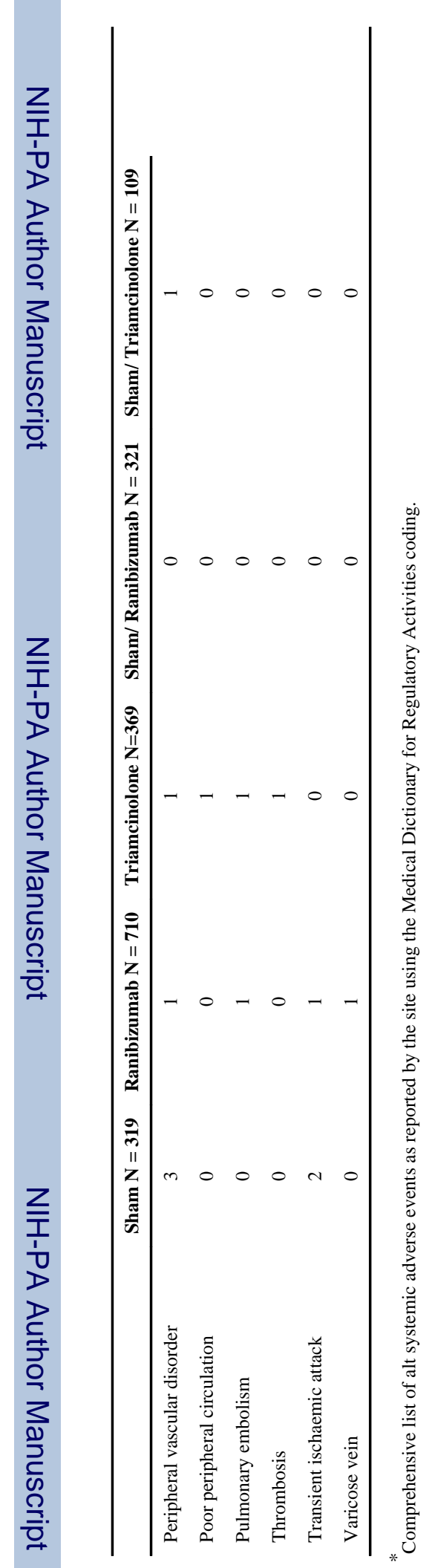

Ophthalmology. Author manuscript; available in PMC 2011 June 1. 
Table 19

Summary of Study Eye Ocular Adverse Events

\begin{tabular}{|c|c|c|c|c|}
\hline & $\begin{array}{c}\text { Sham +Prompt } \\
\text { Laser } N=488\end{array}$ & $\begin{array}{c}\text { Ranibizumab+Prompt } \\
\text { Laser } \mathbf{N}=338\end{array}$ & $\begin{array}{c}\text { Ranibizumab } \\
\text { +Deferred Laser } \mathrm{N}= \\
\mathbf{3 8 4}\end{array}$ & $\begin{array}{c}\text { Triamcinolone +Prompt } \\
\text { Laser } \mathbf{N}=\mathbf{5 3 8}\end{array}$ \\
\hline \multicolumn{5}{|l|}{ Anterior chamber } \\
\hline Anterior chamber cell & 0 & 0 & 1 & 0 \\
\hline Flat anterior chamber of eye & 1 & 0 & 1 & 0 \\
\hline Hyphaema & 1 & 1 & 0 & 0 \\
\hline Iris neovascularisation & 3 & 0 & 0 & 1 \\
\hline Pigment dispersion syndrome & 0 & 0 & 1 & 0 \\
\hline \multicolumn{5}{|l|}{ Cataract } \\
\hline Cataract nuclear & 2 & 2 & 6 & 5 \\
\hline \multicolumn{5}{|l|}{ Choroid } \\
\hline Choroidal detachment & 1 & 0 & 0 & 1 \\
\hline Choroidal neovascularisation & 4 & 1 & 0 & 0 \\
\hline \multicolumn{5}{|l|}{ Conjunctiva } \\
\hline Conjunctival haemorrhage & 7 & 31 & 42 & 25 \\
\hline Conjunctival hyperaemia & 0 & 1 & 0 & 1 \\
\hline Conjunctivitis & 3 & 5 & 1 & 4 \\
\hline Conjunctivitis allergic & 3 & 3 & 2 & 1 \\
\hline Conjunctivitis viral & 0 & 0 & 0 & 1 \\
\hline Dry eye & 11 & 4 & 1 & 6 \\
\hline Eye discharge & 6 & 3 & 1 & 1 \\
\hline Eye inflammation & 0 & 0 & 0 & 1 \\
\hline Keratoconjunctivitis sicca & 6 & 2 & 6 & 2 \\
\hline Ocular hyperaemia & 4 & 6 & 3 & 1 \\
\hline Pterygium & 1 & 0 & 0 & 0 \\
\hline \multicolumn{5}{|l|}{ Cornea } \\
\hline Arcus lipoides & 1 & 0 & 0 & 0 \\
\hline Corneal abrasion & 5 & 2 & 6 & 4 \\
\hline Comeal disorder & 0 & 3 & 0 & 0 \\
\hline Corneal dystrophy & 0 & 0 & 1 & 0 \\
\hline Corneal erosion & 1 & 0 & 0 & 0 \\
\hline Corneal oedema & 0 & 1 & 0 & 1 \\
\hline Corneal opacity & 0 & 1 & 0 & 0 \\
\hline Comeal pigmentation & 0 & 1 & 0 & 0 \\
\hline Corneal scar & 1 & 0 & 0 & 0 \\
\hline Keratitis & 0 & 0 & 1 & 0 \\
\hline Keratopathy & 1 & 1 & 0 & 0 \\
\hline Punctate keratitis & 5 & 5 & 1 & 5 \\
\hline \multicolumn{5}{|l|}{ Endocrine } \\
\hline Retinal aneurysm & 0 & 0 & 1 & 0 \\
\hline
\end{tabular}

Ophthalmology. Author manuscript; available in PMC 2011 June 1. 


\begin{tabular}{|c|c|c|c|c|}
\hline & $\begin{array}{c}\text { Sham +Prompt } \\
\text { Laser } N=488\end{array}$ & $\begin{array}{c}\text { Ranibizumab+Prompt } \\
\text { Laser } \mathbf{N}=338\end{array}$ & $\begin{array}{c}\text { Ranibizumab } \\
\text { +Deferred Laser N }= \\
\mathbf{3 8 4}\end{array}$ & $\begin{array}{c}\text { Triamcinolone +Prompt } \\
\text { Laser } \mathbf{N}=\mathbf{5 3 8}\end{array}$ \\
\hline Eye irritation & 13 & 10 & 14 & 11 \\
\hline Eye swelling & 2 & 0 & 3 & 1 \\
\hline Foreign body in eye & 1 & 0 & 2 & 4 \\
\hline Hypersensitivity & 0 & 0 & 1 & 0 \\
\hline Lacrimation increased & 12 & 8 & 23 & 5 \\
\hline Seasonal allergy & 1 & 0 & 0 & 0 \\
\hline \multicolumn{5}{|l|}{ Glaucoma-IOP } \\
\hline Angle closure glaucoma & 0 & 1 & 0 & 0 \\
\hline Borderline glaucoma & 2 & 2 & 0 & 4 \\
\hline Glaucoma & 2 & 2 & 2 & 1 \\
\hline Intraocular pressure decreased & 0 & 0 & 0 & 2 \\
\hline Intraocular pressure increased & 16 & 8 & 11 & 79 \\
\hline Ocular hypertension & 1 & 1 & 0 & 4 \\
\hline \multicolumn{5}{|l|}{ Inflammation } \\
\hline Iritis & 1 & 4 & 1 & 2 \\
\hline \multicolumn{5}{|l|}{ Injection related } \\
\hline Injection site extravasation & 0 & 0 & 0 & 1 \\
\hline \multicolumn{5}{|l|}{ Lens } \\
\hline Cataract & 23 & 19 & 20 & 50 \\
\hline Cataract cortical & 8 & 4 & 4 & 1 \\
\hline Cataract operation & 6 & 2 & 3 & 17 \\
\hline Cataract operation complication & 1 & 0 & 0 & 0 \\
\hline Cataract subcapsular & 8 & 6 & 7 & 28 \\
\hline Posterior capsule opacification & 5 & 4 & 3 & 2 \\
\hline Pseudoexfoliation of lens capsule & 0 & 1 & 0 & 0 \\
\hline \multicolumn{5}{|l|}{ Lids } \\
\hline Blepharitis & 4 & 2 & 6 & 2 \\
\hline Chalazion & 1 & 0 & 1 & 0 \\
\hline Entropion & 1 & 0 & 0 & 1 \\
\hline Erythema of eyelid & 0 & 0 & 1 & 0 \\
\hline Eyelid disorder & 0 & 0 & 0 & 1 \\
\hline Eyelid oedema & 3 & 0 & 1 & 2 \\
\hline Eyelid ptosis & 2 & 2 & 2 & 10 \\
\hline Hordeolum & 1 & 0 & 1 & 0 \\
\hline Periorbital haematoma & 0 & 1 & 0 & 0 \\
\hline Pseudo-blepharoptosis & 0 & 0 & 0 & 1 \\
\hline \multicolumn{5}{|l|}{ Miscellaneous } \\
\hline Chemical eye injury & 0 & 1 & 0 & 0 \\
\hline Eye discharge & 2 & 1 & 0 & 0 \\
\hline Eye pain & 3 & 3 & 6 & 2 \\
\hline Glaucoma & 2 & 1 & 0 & 3 \\
\hline
\end{tabular}

Ophthalmology. Author manuscript; available in PMC 2011 June 1. 


\begin{tabular}{|c|c|c|c|c|}
\hline & $\begin{array}{c}\text { Sham +Prompt } \\
\text { Laser N = 488 }\end{array}$ & $\begin{array}{c}\text { Ranibizumab+Prompt } \\
\text { Laser } \mathbf{N}=\mathbf{3 3 8}\end{array}$ & $\begin{array}{c}\text { Ranibizumab } \\
\text { +Deferred Laser } N= \\
384\end{array}$ & $\begin{array}{c}\text { Triamcinolone +Prompt } \\
\text { Laser N = 538 }\end{array}$ \\
\hline Ocular hyperaemia & 3 & 6 & 2 & 3 \\
\hline Photopsia & 0 & 1 & 2 & 0 \\
\hline Vision blurred & 1 & 2 & 1 & 1 \\
\hline Visual impairment & 5 & 4 & 3 & 3 \\
\hline \multicolumn{5}{|l|}{ Neurological } \\
\hline Gliosis & 0 & 0 & 0 & 1 \\
\hline \multicolumn{5}{|l|}{ Optic nerve } \\
\hline Optic disc disorder & 1 & 0 & 0 & 0 \\
\hline \multicolumn{5}{|l|}{ Retina } \\
\hline Diabetic retinal oedema & 0 & 0 & 3 & 0 \\
\hline Macular cyst & 1 & 1 & 0 & 0 \\
\hline Macular degeneration & 0 & 1 & 0 & 2 \\
\hline Macular hole & 0 & 1 & 2 & 0 \\
\hline Macular ischaemia & 0 & 0 & 1 & 0 \\
\hline Macular oedema & 1 & 1 & 1 & 0 \\
\hline Maculopathy & 39 & 17 & 19 & 14 \\
\hline Neovascularisation & 2 & 0 & 0 & 0 \\
\hline Retinal aneurysm & 0 & 1 & 0 & 0 \\
\hline Retinal degeneration & 0 & 1 & 0 & 1 \\
\hline Retinal detachment & 0 & 1 & 1 & 0 \\
\hline Retinal exudates & 2 & 3 & 1 & 1 \\
\hline Retinal haemorrhage & 2 & 0 & 3 & 1 \\
\hline Retinal neovascularisation & 6 & 2 & 1 & 0 \\
\hline Retinal vein occlusion & 1 & 1 & 1 & 4 \\
\hline \multicolumn{5}{|l|}{ Sensation-pain } \\
\hline Abnormal sensation in eye & 0 & 0 & 1 & 1 \\
\hline Asthenopia & 1 & 0 & 0 & 0 \\
\hline Eye pain & 32 & 33 & 24 & 13 \\
\hline Eye pruritus & 7 & 9 & 5 & 6 \\
\hline Eyelid pain & 1 & 0 & 0 & 2 \\
\hline Foreign body sensation in eyes & 8 & 3 & 6 & 12 \\
\hline \multicolumn{5}{|l|}{ Skin } \\
\hline Ecchymosis & 1 & 0 & 0 & 0 \\
\hline Pruritus & 1 & 0 & 0 & 0 \\
\hline \multicolumn{5}{|l|}{ Strabismus } \\
\hline Extraocular muscle paresis & 0 & 1 & 0 & 0 \\
\hline \multicolumn{5}{|l|}{ Visual field } \\
\hline Visual field defect & 0 & 0 & 0 & 1 \\
\hline \multicolumn{5}{|l|}{ Visual symptoms/abnormality } \\
\hline Altered visual depth perception & 1 & 0 & 0 & 1 \\
\hline Diplopia & 3 & 4 & 7 & 3 \\
\hline
\end{tabular}

Ophthalmology. Author manuscript; available in PMC 2011 June 1. 


\begin{tabular}{|c|c|c|c|c|}
\hline & $\begin{array}{c}\text { Sham +Prompt } \\
\text { Laser N = 488 }\end{array}$ & $\begin{array}{c}\text { Ranibizumab+Prompt } \\
\text { Laser } N=338\end{array}$ & $\begin{array}{c}\text { Ranibizumab } \\
+ \text { +Deferred Laser } \mathrm{N}= \\
\mathbf{3 8 4}\end{array}$ & $\begin{array}{c}\text { Triamcinolone +Prompt } \\
\text { Laser N = 538 }\end{array}$ \\
\hline Photophobia & 3 & 1 & 3 & 5 \\
\hline Photopsia & 5 & 4 & 4 & 4 \\
\hline Vision blurred & 55 & 23 & 29 & 42 \\
\hline Visual acuity reduced & 19 & 9 & 15 & 21 \\
\hline Visual disturbance & 16 & 7 & 6 & 14 \\
\hline Visual field defect & 0 & 0 & 0 & 1 \\
\hline Visual impairment & 4 & 2 & 6 & 1 \\
\hline \multicolumn{5}{|l|}{ Vitreous } \\
\hline Endophthalmitis & 2 & 2 & 2 & 0 \\
\hline Hyalosis asteroid & 0 & 1 & 0 & 1 \\
\hline Myodesopsia & 20 & 13 & 14 & 34 \\
\hline Vitrectomy & 1 & 0 & 0 & 0 \\
\hline Vitreous degeneration & 0 & 1 & 3 & 0 \\
\hline Vitreous detachment & 9 & 5 & 7 & 8 \\
\hline Vitreous disorder & 1 & 0 & 0 & 0 \\
\hline Vitreous floaters & 9 & 14 & 14 & 28 \\
\hline Vitreous haemorrhage & 30 & 6 & 9 & 9 \\
\hline Vitreous opacities & 1 & 0 & 0 & 2 \\
\hline
\end{tabular}

$\mathrm{IOP}=$ intraocular pressure 